ESRI

SURVEY AND

STATISTICAL

REPORT SERIES

NUMBER 94

JULY 2020
THE IMPLICATIONS OF THE COVID-19 PANDEMIC

FOR POLICY IN RELATION TO CHILDREN AND

YOUNG PEOPLE

ARESEARCH REVIEW

MERIKE DARMODY, EMER SMYTH AND HELEN RUSSELL

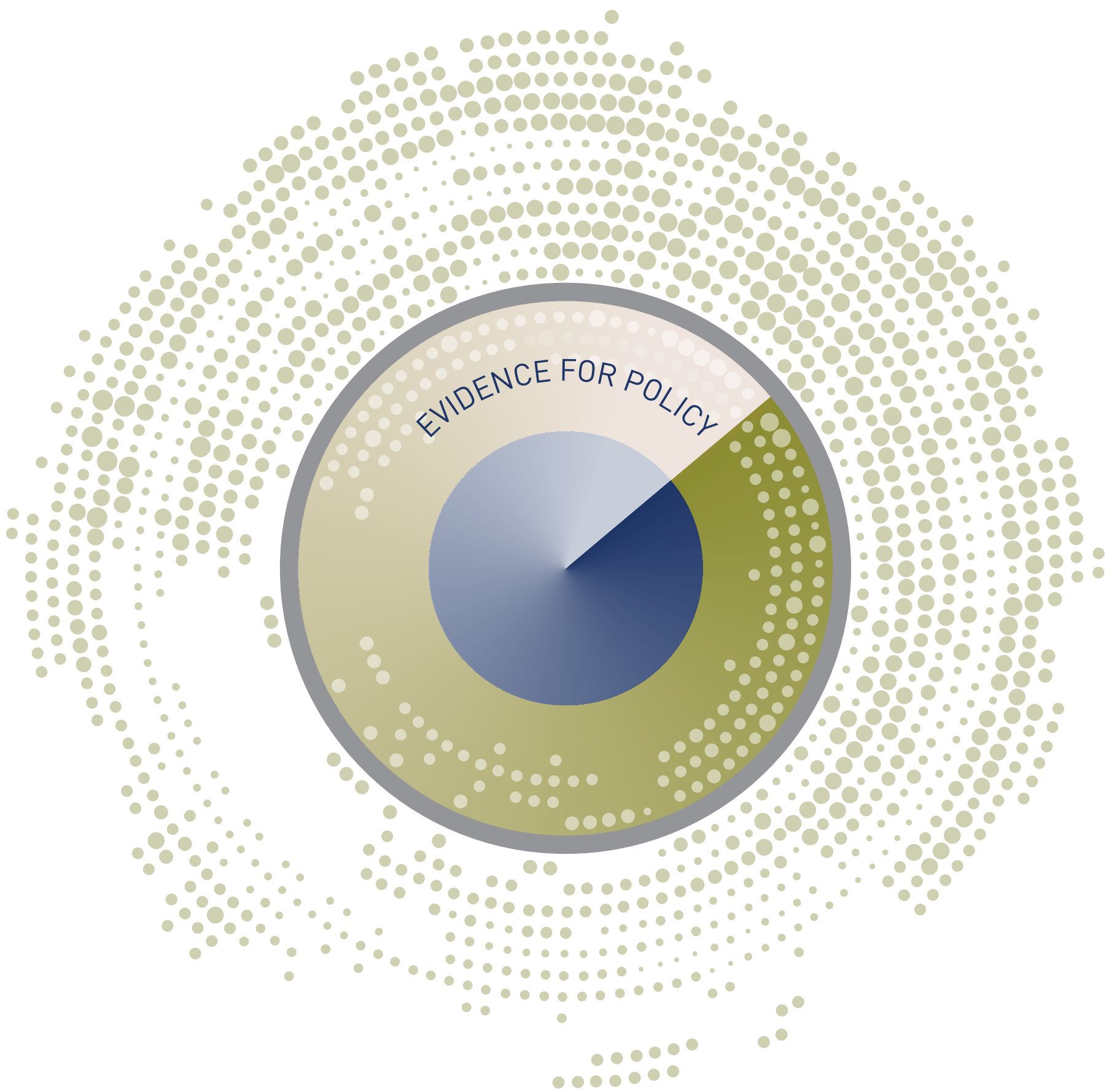

○

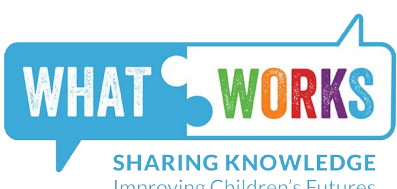

SHARING KNOWLEDGE Improving Children's Futures
An Roinn Leanaí agus Gnóthaí Óige Department of Children and Youth Affairs

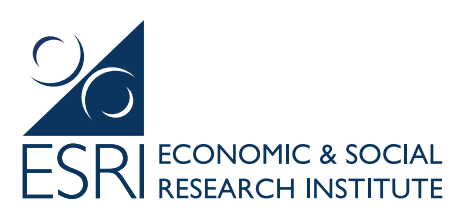




\section{IMPLICATIONS OF THE COVID-19 PANDEMIC FOR POLICY IN RELATION TO CHILDREN AND YOUNG PEOPLE: A RESEARCH REVIEW}

Merike Darmody

Emer Smyth

Helen Russell

July 2020

\section{ESRI SURVEY AND STATISTICAL REPORT SERIES}

\section{NUMBER 94}

Available to download from www.esri.ie

The Economic and Social Research Institute Whitaker Square, Sir John Rogerson's Quay, Dublin 2

ISBN: 978-0-7070-0532-4

DOI: https://doi.org/10.26504/sustat94

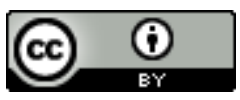

This Open Access work is licensed under a Creative Commons Attribution 4.0 International License (https://creativecommons.org/licenses/by/4.0/), which permits unrestricted use, distribution, and reproduction in any medium, provided the original work is properly credited. 


\section{ABOUT THE ESRI}

The mission of the Economic and Social Research Institute is to advance evidencebased policymaking that supports economic sustainability and social progress in Ireland. ESRI researchers apply the highest standards of academic excellence to challenges facing policymakers, focusing on 12 areas of critical importance to 21st Century Ireland.

The Institute was founded in 1960 by a group of senior civil servants led by $\mathrm{Dr}$ T. K. Whitaker, who identified the need for independent and in-depth research analysis to provide a robust evidence base for policymaking in Ireland.

Since then, the Institute has remained committed to independent research and its work is free of any expressed ideology or political position. The Institute publishes all research reaching the appropriate academic standard, irrespective of its findings or who funds the research.

The quality of its research output is guaranteed by a rigorous peer review process. ESRI researchers are experts in their fields and are committed to producing work that meets the highest academic standards and practices.

The work of the Institute is disseminated widely in books, journal articles and reports. ESRI publications are available to download, free of charge, from its website. Additionally, ESRI staff communicate research findings at regular conferences and seminars.

The ESRI is a company limited by guarantee, answerable to its members and governed by a Council, comprising 14 members who represent a cross-section of ESRI members from academia, civil services, state agencies, businesses and civil society. The Institute receives an annual grant-in-aid from the Department of Public Expenditure and Reform to support the scientific and public interest elements of the Institute's activities; the grant accounted for an average of 30 per cent of the Institute's income over the lifetime of the last Research Strategy. The remaining funding comes from research programmes supported by government departments and agencies, public bodies and competitive research programmes.

Further information is available at www.esri.ie 


\section{THE AUTHORS}

Merike Darmody is a Research Officer at the Economic and Social Research Institute (ESRI) and an Adjunct Professor at Trinity College Dublin (TCD). Emer Smyth is a Research Professor at the ESRI and an Adjunct Professor at TCD. Helen Russell is a Research Professor at the ESRI and an Adjunct Professor at TCD.

\section{ACKNOWLEDGEMENTS}

This publication was funded by the Department of Children and Youth Affairs through a joint Research Partnership with the ESRI. The views, opinions, findings, conclusions and/or recommendations expressed here are strictly those of the authors. They do not necessarily reflect the views of the Department of Children and Youth Affairs, which takes no responsibility for any errors or omissions in, or for the accuracy of, the information contained in this publication. It is presented to inform and stimulate wider debate among the policy community and among academics and practitioners in the field.

The authors are grateful to members of the programme steering group and ESRI colleagues for comments on an earlier draft of the paper. The discussion of the potential use of the Growing Up in Ireland study to provide insights into the effects of the pandemic owes a good deal to the input of Dorothy Watson, Aisling Murray and Amanda Quail.

This research programme has received funding through WHAT WORKS. This is an initiative led by the Department of Children and Youth Affairs, with funding from Dormant Accounts, to support a move towards evidence informed prevention and early intervention services for children, young people and their families. 



\section{TABLE OF CONTENTS}

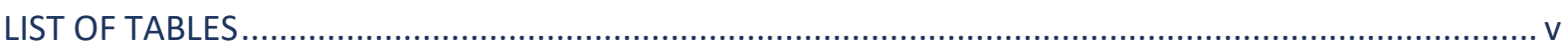

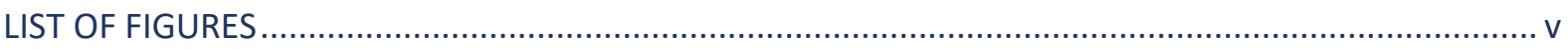

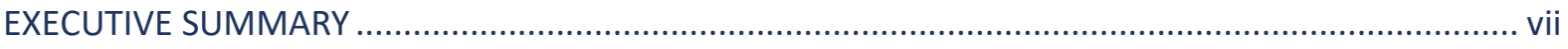

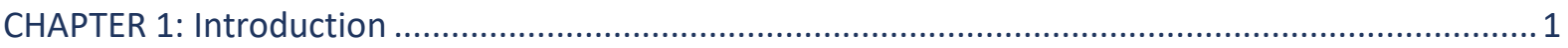

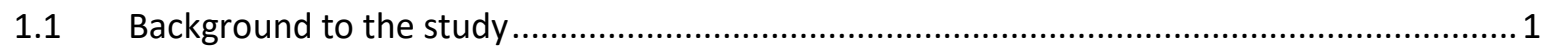

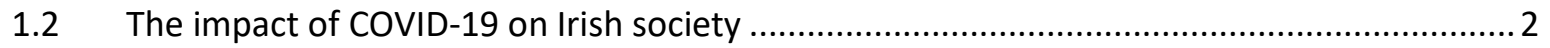

1.3 Approaches to studying the impact of COVID-19 ..................................................

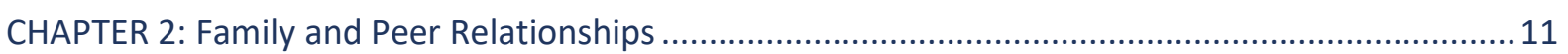

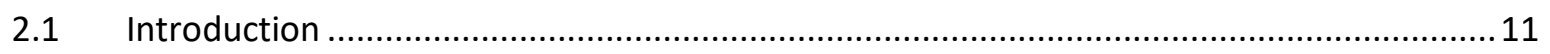

2.2 The quality of family relationships and child outcomes ............................................... 11

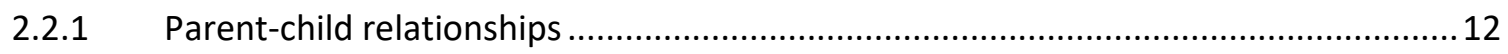

2.2.2 The child's relationship with other family members and peers ................................13

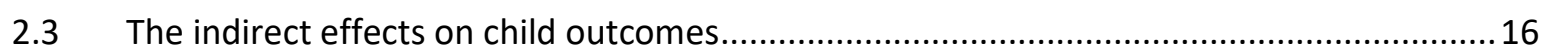

2.3.1 Economic and work-related challenges ........................................................... 16

2.3.2 Time and division-of-labour challenges ....................................................... 17

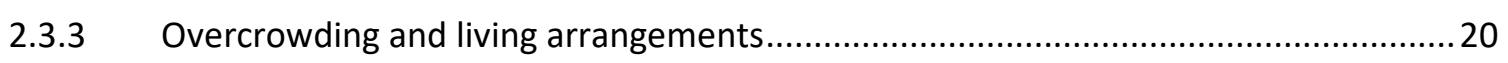

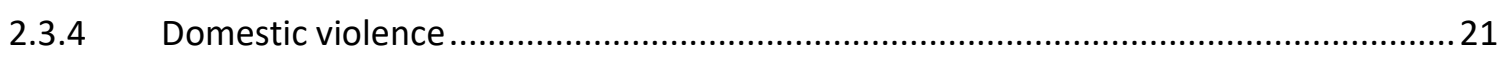

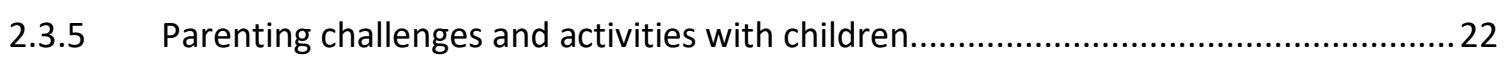

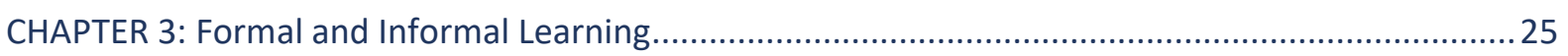

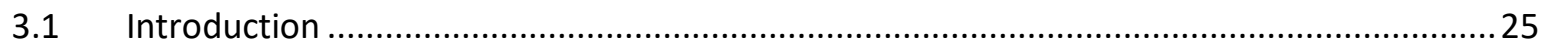

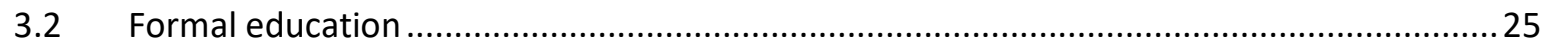

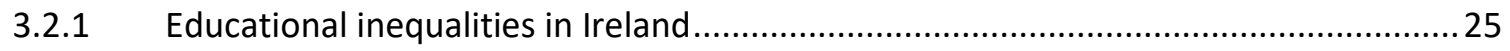

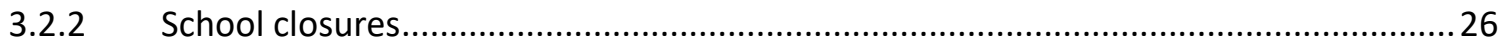

3.2.3 Participation in early-years education and care .............................................28

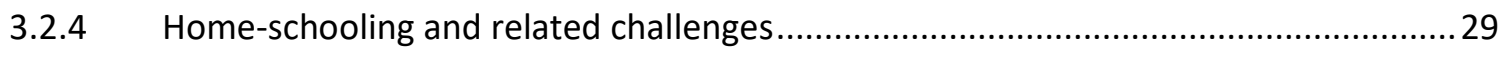

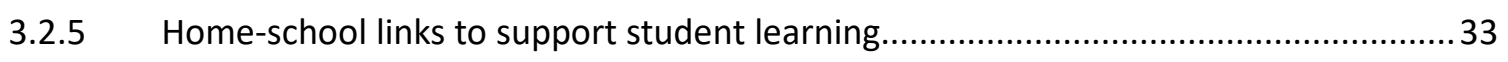

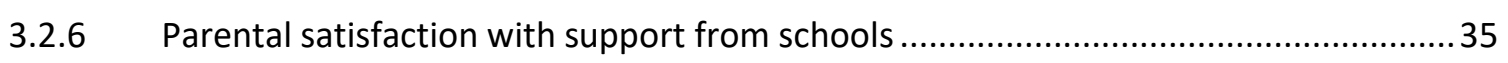

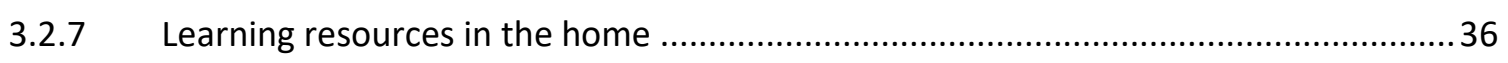

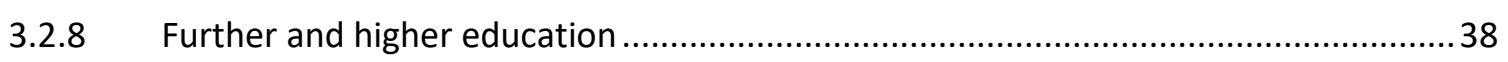

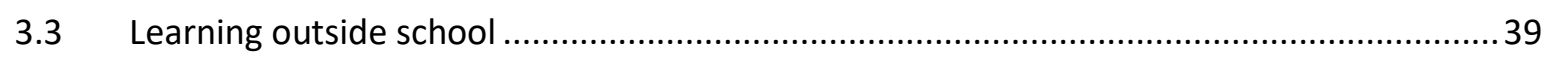

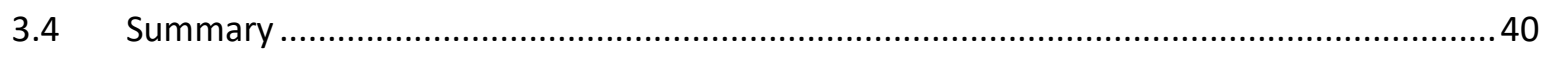

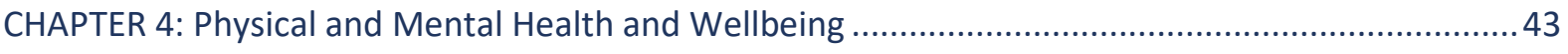

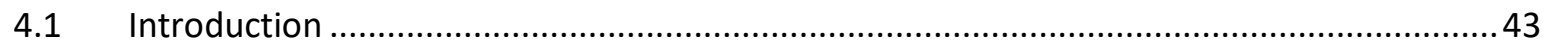

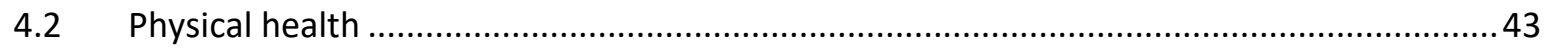

4.2.1 General health and long-standing conditions .................................................43 


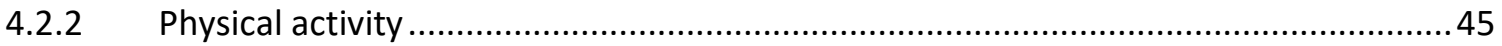

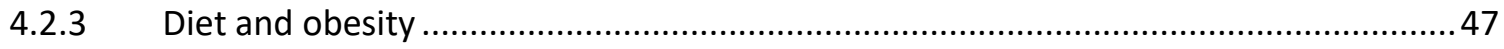

4.3 Mental health and socio-emotional wellbeing ............................................................. 49

4.3.1 Psychological wellbeing among the adult population ................................................. 49

4.3.2 Psychological wellbeing among children and young people ......................................52

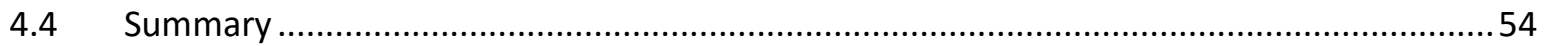

CHAPTER 5: The Transition to Further/Higher Education, Training and the Labour Market ...............57

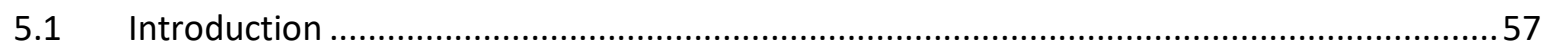

5.2 The labour-market position of young people pre-COVID-19 ............................................57

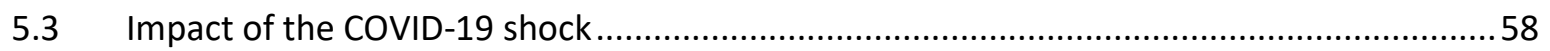

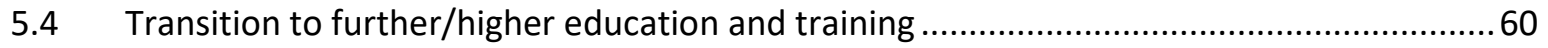

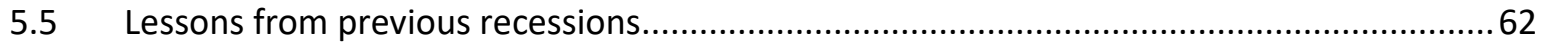

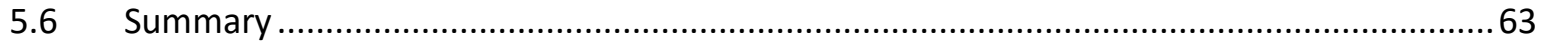

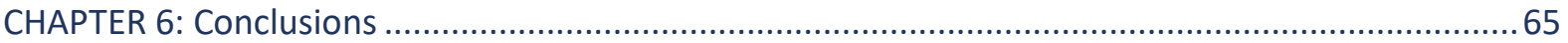

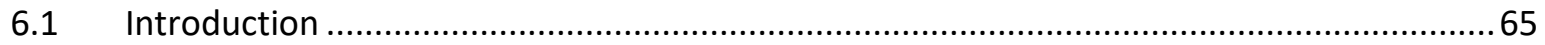

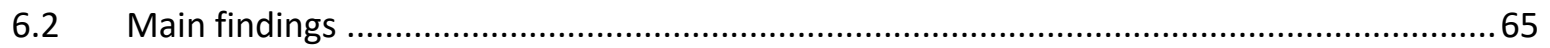

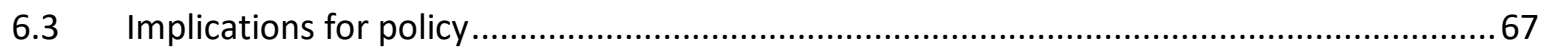

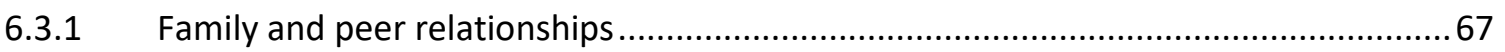

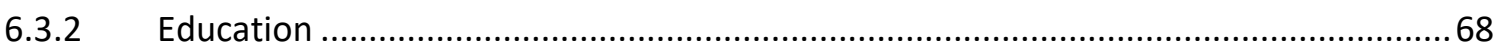

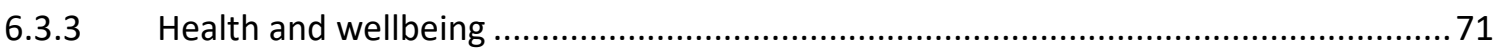

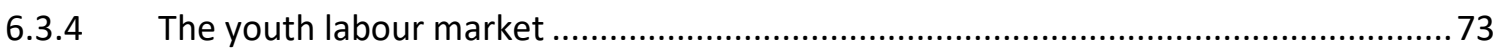

6.4 Assessing the medium- and longer-term impact of the pandemic on children and young

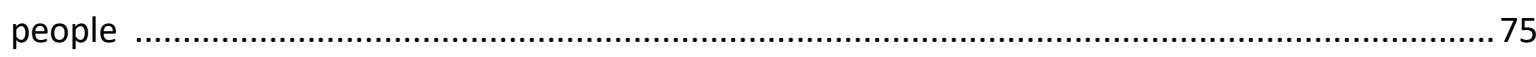

APPENDIX

REFERENCES 


\section{LIST OF TABLES}

Table 1.1 Examples of international and Irish studies based on convenience samples ..................7

Table 1.2 Examples of international and Irish studies based on representative samples...............8

Table A1 List of COVID-19 research (empirical evidence, related reviews and data) included in

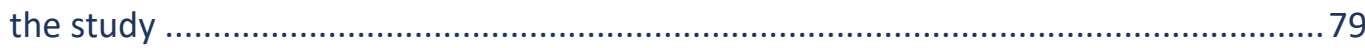

\section{LIST OF FIGURES}

Figure 1.1 Closure of educational institutions in 26 EU countries .................................................2

Figure 1.2 Closure of workplaces in 26 EU countries.................................................................

Figure 5.1 Pandemic Unemployment Payment claims as \% of employment level in 2019 Q4 .......59

Figure 5.2 Proportion of 20-year-olds who had ever taken part in post-school education/training (GUI Cohort '98, wave 4) 



\section{BACKGROUND TO THE STUDY}

COVID-19 has led to a global public health crisis. Measures to reduce transmission have resulted in the closure of educational institutions and workplaces, and reduced social interaction. Rates of serious illness from COVID-19 have been very low among children and young people. However, the impact on their lives has been substantial, both directly because of the closure of schools and lack of face-to-face interaction with peers and wider family, and indirectly because of increased financial stress for many families. This report presents a critical analysis of Irish and international research involving children and young people before and during the pandemic period as a basis for discussing the implications for policy development. The study focuses on four main domains: family and peer relationships; formal and informal learning; physical and mental health and wellbeing; and transitions to further/higher education, training and the youth labour market. As restrictions ease, it is timely to look at policies to address the impact of the pandemic and what compensatory measures might be needed to ameliorate the effects of restrictions.

\section{RESEARCH ON THE IMPACT OF COVID-19}

Since the start of the pandemic, many studies have been conducted internationally on the impact of restrictions on individuals and families. At the time of writing, much of this research is ongoing, with findings from many studies yet to be published. Much of the research has been based on online or convenience samples. Such surveys have the advantage of being quick to administer and thus flexible in responding to emerging issues. However, the self-selective nature of responses means that the findings cannot be generalised to the population as a whole. Other studies have been based on rapid reviews of existing studies on relevant issues (such as the effects of quarantine) or have used qualitative methods to investigate the experiences of particular groups. Studies based on representative samples of the population have been less common and largely focus on adults, with a lack of systematic research on the experiences of children and young people in Ireland during the period of pandemic restrictions. This review places greater weight on studies based on representative samples, though studies based on convenience samples are mentioned where their findings are suggestive of emerging issues.

\section{COVID-19 AND INEQUALITY}

The Growing Up in Ireland study and other research studies have documented the inequalities evident in the lives of children and young people in Ireland in the preCOVID-19 period: those from more disadvantaged backgrounds have poorer 
health, lower levels of physical activity, poorer-quality diet, greater disengagement from school, lower academic performance and more socio-emotional difficulties. Having a special educational need or being from a minority group, such as Travellers or asylum-seekers, serve as additional sources of inequality. Available evidence in Ireland and internationally suggests that these inequalities have grown in the wake of the pandemic. The negative effects on wellbeing and mental health have been more apparent among those from disadvantaged backgrounds, as well as among younger adults. The impact is gendered; women are more likely to report feelings of depression, anxiety or sadness during the period of restrictions. While there is less systematic evidence on the effects on children, findings suggest increased inequality for them too. Children's wellbeing is highly influenced by parental stress and depression, so a reduction in their parents' wellbeing is likely to affect them. Given that emotional difficulties increased more for younger adults during the period of restrictions, they are likely to have done so for children and young people.

Increased inequality is also related to the differential economic impact of pandemic-related restrictions. Job losses have been concentrated among younger and lower-income groups, and unemployment is predicted to remain at relatively high levels in the short to medium term. Previous research has pointed to the negative effects of recessions on children's socio-emotional and educational outcomes. Therefore, greater financial strain in many families, particularly after the phasing-out of the Pandemic Unemployment Payment and the Temporary Wage Subsidy Scheme, will negatively affect the wellbeing of children and young people. Young people making the transition to the labour market are likely to face particular difficulties in obtaining employment, especially as emigration is no longer an option for those who face difficulties in accessing jobs in Ireland.

\section{IMPLICATIONS FOR POLICY DEVELOPMENT}

The review highlights the importance of policy intervention to address the growing inequality evident over the period of restrictions. Available evidence indicates that school closures have resulted in marked inequalities, as children and young people vary in their access to books and digital resources and parents themselves have differential educational, cultural, and time resources to support their children's learning. Evidence points, too, to a digital divide between schools, with some schools making a smoother transition to distance education where they had the infrastructure in place and/or greater prior experience of digital teaching and learning. Children and young people from more disadvantaged backgrounds will return to school having suffered greater levels of 'learning loss' on average. Indeed, there is a risk that some of those who were not highly engaged in school before the closure may not re-engage in full-time education. Children with special educational needs will likely face particular challenges in readjusting to the routine of school and in making up learning loss. If schools do not resume on a full-cohort or full-time basis in the coming school year, the learning loss is likely to continue 
to grow, especially for socio-economically disadvantaged students and those with special educational needs. Additional learning supports will be crucial when schools resume to make up for the (differential) learning loss experienced by students, with individual and small group tuition emerging as the most effective supports from previous research. For younger children, play-based learning will be an important component of re-engaging them in education and addressing the learning gap. In addition to the summer programme, supports will be required to assist children and young people with special educational needs to reintegrate into school. The provision of such supports, especially one-to-one and small-group tuition, will require the allocation of substantial resources in the coming academic year, but this increased expenditure should be set against the societal costs of early school-leaving and academic underperformance.

In reopening schools, learning supports should be placed in the context of the broad spectrum of activities and supports offered in schools. Social, Personal and Health Education (SPHE) and the broader wellbeing programme at junior cycle are likely to be a very important resource in young people's adjustment to a postCOVID-19 world; additional supports in the form of SPHE and life skills could be usefully incorporated into senior cycle. Ongoing professional development (through Education Centres and other organisations such as Jigsaw) and other resources for teachers are crucial in this respect. Some children and young people will experience greater psychological difficulties than others. Given the level of unmet need in child and adolescent mental health services, there is a case for enhancing access to specialist psychological and therapeutic supports through schools, building on existing provision such as the National Educational Psychological Service (NEPS) and the School Completion Programme.

Summer camps or programmes, and subsequently after-school provision, provide an important opportunity for young people to re-engage in sports and cultural activities. However, the paid-for nature of much provision will serve as a constraint for low-income families, highlighting the importance of community-based provision, such as the School Completion Programme and local youth clubs, in catering for more socio-economically disadvantaged groups.

The transition to life after school will be very different for cohort 2020 than for earlier cohorts. Higher education institutions appear likely to use blended learning for at least part of the coming academic year, highlighting the importance of addressing the digital divide in access to resources and adopting innovative approaches to providing academic and social support to students to enhance their wellbeing and prevent dropout. The resumption of face-to-face provision is particularly important for further education courses (such as Youthreach) which cater for more disadvantaged groups of young people where relationships of trust between participants and staff are key in re-engaging disaffected youth. Young people entering the labour market face particular challenges and need additional 
supports to avoid long-term damage to their prospects. Such supports include early intervention to provide career guidance and promote retention as well as targeted (re)training to respond to potential new areas of employment growth. Employers that provide apprenticeships may need particular supports to maintain training, and incentives may be required for employers to take on apprentices in the coming year.

The pandemic experience has highlighted broader policy challenges, including the reliance on a largely market-based model of early-years service provision and inequalities in access to health services, including psychological and therapeutic supports, providing further impetus for the roll-out of Sláintecare, the National Oral Health Policy and the Sharing the Vision policy for mental health services.

\section{THE NEED FOR FURTHER RESEARCH}

Research on earlier disasters (such as Hurricane Katrina) and recessions have pointed to longer-term effects on the developmental outcomes of children and young people. It is crucial, therefore, that systematic evidence on the impact on children and young people of the pandemic restrictions and related economic shock is collected to inform policy development. A dedicated survey of the Growing Up in Ireland cohorts would provide such an evidence base. It would be crucial that such a survey capture the perceived effects of the pandemic restrictions on direct aspects of young people's lives as well as objective changes in outcomes before and after the pandemic. This study could collect information on variation in the direct experience of the pandemic (for example, the illness of a family member) and in experiences of the restrictions (for example, the level of contact from their school) and the effects of such variation. 


\section{CHAPTER 1}

\section{Introduction}

\section{$1.1 \quad$ BACKGROUND TO THE STUDY}

The spread of COVID-19 has resulted in a global public health crisis. Measures to mitigate transmission have had an unprecedented impact on economic activity and social interaction. Ireland has been among the countries adopting the most stringent measures to contain transmission and, at the time of writing, is engaged in a phased exit from restrictions. Although children and young people have been less likely than adults to become very ill from COVID-19, it is widely acknowledged that the impact on their lives of measures such as school closures has been substantial (Reimers and Sleicher, 2020). It is therefore important to look at the potential implications of COVID-19 restrictions for policy development regarding children and young people.

This study draws on Growing Up in Ireland (GUI) survey findings, along with the results of cross-sectional studies such as My World and the Health Behaviour of School-Aged Children (HBSC), to briefly document the lives of children and young people in pre-COVID-19 Ireland, as a basis for understanding the policy issues and inequalities that were already apparent. The report then draws on emerging studies internationally and in Ireland on the impact of COVID-19 on children and young people. Both overall findings and variation across groups of children, young people and families are discussed. The terms 'advantaged' and 'disadvantaged' are used in the report to document inequality in terms of social class, education and/or household income, though where studies refer to particular dimensions of inequality, that study's original terminology is used. Research findings from before and during the COVID-19 pandemic are then used to identify the main issues for policy as restrictions are removed, with a particular emphasis on what compensatory measures may be needed to address these issues. The report is structured around four main domains: relationships with family and peers; education (covering formal and informal learning); physical and mental health and wellbeing; and transitions to post-school education, training and the labour market.

The remainder of this chapter provides an overview of high-level findings on the impact of COVID-19 on Irish society and the economy. The third section looks at the methodological approaches used in emerging research on COVID-19 and the implications of these differing approaches for our understanding of its impact. 


\subsection{THE IMPACT OF COVID-19 ON IRISH SOCIETY}

The first case of COVID-19 was reported in Wuhan, China, in December 2019, and the first case in Ireland on 29 February 2020. By 6 July, there had been 11.3 million confirmed cases and 531,806 deaths globally. ${ }^{1}$ Between 29 February and 5 July, Ireland recorded 25,527 confirmed cases and 1,741 deaths. ${ }^{2}$

Most countries responded to the pandemic by closing non-essential workplaces, including educational institutions, and placing restrictions on social interactions. However, as Figures 1.1 and 1.2 show, countries have differed in the nature and timing of such restrictions.

\section{FIGURE 1.1 CLOSURE OF EDUCATIONAL INSTITUTIONS IN 26 EU COUNTRIES}

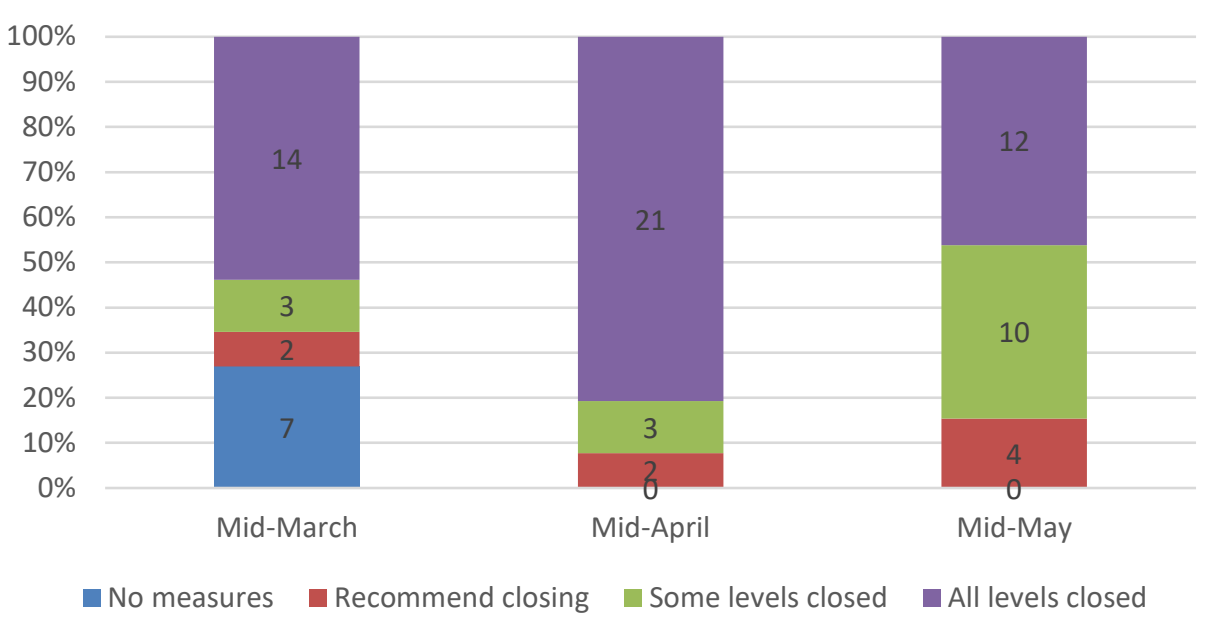

Source: $\quad$ Oxford COVID-19 Government Response Tracker (OxCGRT).

Note: Data are not provided on Latvia and Malta. The UK is included as one entity but the introduction and easing of restrictions has differed across countries within the UK.

Figure 1.1 shows that, in mid-March, several European countries had yet to introduce measures to close educational institutions but, by mid-April, all had at least recommended closing them. During April, most countries closed all levels of their educational systems (from primary to tertiary), with some reopening of some levels of the system by mid-May. The situation in Sweden contrasted with that in many other European countries, with no mandated closing of schools. Ireland was among the countries where all educational levels remained closed at the three timepoints. Early-years provision has reopened since 29 June, though it not clear that all providers have reopened. At the time of writing, it is intended that primary and second-level schools reopen in late August. The impact of social distancing requirements on the nature of schools reopening is still under discussion (see Chapter 3). Third-level institutions seem likely to use blended learning in the coming academic year, combining online learning with some campus-based

\footnotetext{
${ }^{1}$ https://covid19.who.int/

${ }^{2}$ www.gov.ie/en/news/7e0924-latest-updates-on-covid-19-coronavirus/\#the-latest-news-as-of-530pm-onsunday-5-july
} 
activity such as tutorials or practical sessions (see Chapter 5).

In many countries, only workplaces seen as essential for economic and social activity remained open, though the definition of essential workplaces differed across countries. In other countries, most workplaces remained open (Figure 1.2). The general pattern is one of increasing restrictions between mid-March and midApril, to the point where only essential businesses (such as food shops) remained open in around half of the countries. By mid-May, at least some workplaces began to reopen in many countries. Ireland moved from recommending workplace closures in mid-March to all but essential businesses being closed in April and May. The timing of reopening for different businesses and services is set out in a government roadmap, ${ }^{3}$ with some measures originally scheduled for the final phase brought forward to 29 June and the final phase of reopening due to happen on 20 July.

\section{FIGURE 1.2 CLOSURE OF WORKPLACES IN 26 EU COUNTRIES}

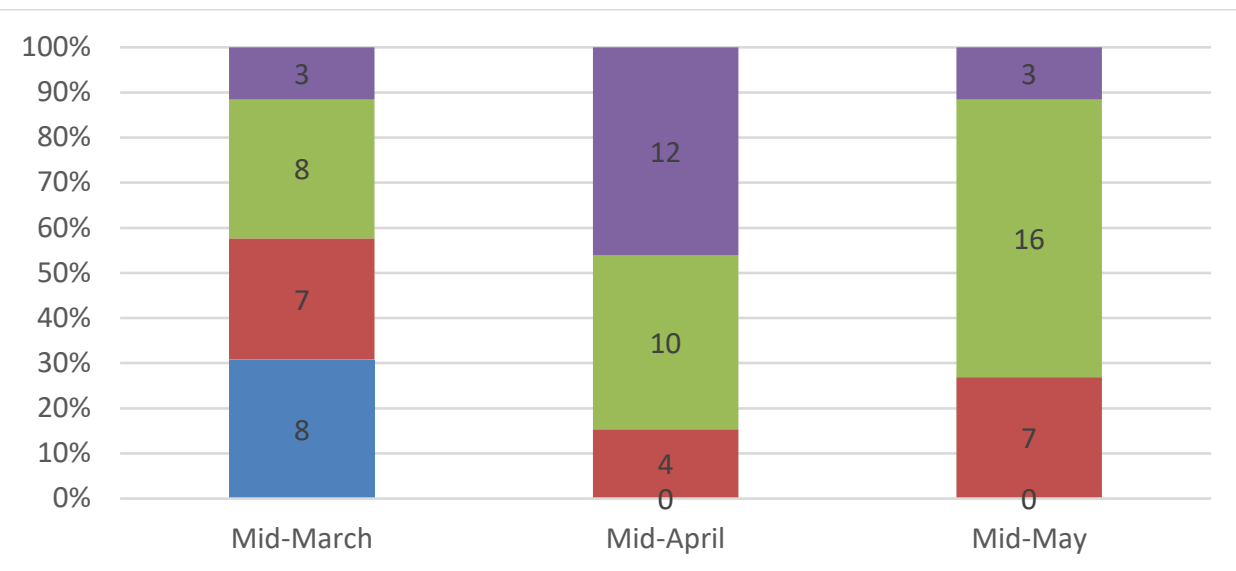

$\square$ No measures $\square$ Recommend closing $\square$ Some sectors closed $\square$ All but essential closed

Source: Oxford COVID-19 Government Response Tracker (OxCGRT).

Note: Data are not provided on Latvia and Malta. The UK is included as one entity but the introduction and easing of restrictions has differed across countries within the UK.

These restrictions have resulted in a sharp shock to the economy, with a dramatic rise in unemployment in many countries, including Ireland. In response to the crisis, the Irish Government introduced the Pandemic Unemployment Payment (PUP), paid at a higher rate (€350) ${ }^{4}$ than Jobseeker's Benefit and with a fast-track application process, and a COVID-19 Enhanced IIIness Benefit (for those diagnosed or told to self-isolate) at the same rate as PUP. The Government also introduced a Temporary Wage Subsidy Scheme (TWSS) to provide pay-related subsidies to employers to retain their staff over the period of restrictions. A simulation conducted by the ESRI (Beirne et al., 2020) indicates that the measures would significantly cushion income losses among households, particularly those in the

\footnotetext{
${ }^{3}$ www.gov.ie/en/news/58bc8b-taoiseach-announces-roadmap-for-reopening-society-and-business-andu/?referrer=http://www.gov.ie/roadmap/

${ }^{4}$ From 29 June, a lower rate of $€ 203$ applies to those earning less than $€ 200$ per week before the pandemic.
} 
lowest two-fifths of the income distribution.

In the week ending 28 June, 438,933 people were in receipt of PUP while over 287,500 were covered by TWSS. ${ }^{5}$ The Central Statistics Office's (CSO) COVID19 adjusted unemployment rate (which includes those on PUP but not TWSS) rose dramatically to 28.2 per cent in April, its highest level ever, before dropping slightly to 26.1 per cent in May and further to 22.5 per cent in June (CSO, 2020a). Unemployment rose particularly dramatically among young people: the level reached 52.8 per cent in April for those aged 15 to 24 years and remained high at 45.4 per cent in June (see Chapter 5 for further details). Just over a quarter of those in work at the start of the pandemic had lost their job and were in receipt of PUP by early May; 59 per cent of 18-19 year-olds and 47 per cent of 20-23 year-olds lost their jobs (McQuinn et al., 2020). The ESRI Quarterly Commentary (McQuinn et al., 2020) estimates that unemployment rates in quarter 4 of 2020 will range from 17 to 24 per cent, with the higher figure relating to a second wave of infection and related restrictions. The direct costs of the pandemic in terms of additional health and social protection expenditure, along with reduced direct and indirect tax income, mean that the budget deficit is set to increase to at least 9 per cent (McQuinn et al., 2020). As other countries, Ireland is thus facing a recession, the scale and duration of which are as yet unknown.

\subsection{APPROACHES TO STUDYING THE IMPACT OF COVID-19}

In undertaking a review of the literature, the usual approach is to specify exact search terms and identify the relevant literature at the outset. This is not feasible in a context where new research is being issued all the time and policy developments change, often day to day. The literature on the impact of COVID-19 on children, young people and families was thus identified at several timepoints over the (short) course of the study. Because of the length of the peer review process for journal articles, the vast majority of the literature accessed was 'grey' in nature, being published by research institutions or as preprint versions of articles. To date, studies can broadly be divided into two main groups: those using convenience or volunteer sampling and those using existing or new representative samples of the relevant population. Other studies have been based on rapid reviews of existing studies on relevant issues (such as the effects of quarantine) or have used qualitative methods to investigate the experiences of particular groups.

Most studies identified to date rely on 'volunteer' convenience samples, depending on the circulation of survey links through social media and organisational or informal networks to recruit participants (for examples, see Table 1.1). For example, the University of Oxford/University of Limerick Co-Space study

\footnotetext{
${ }^{5}$ www.cso.ie/en/statistics/labourmarket/liveregister/detailedcovid-19incomesupportandliveregistertables/; https://revenue.ie/en/corporate/documents/statistics/registrations/wage-subsidy-scheme-statistics-02-julyl2020.pdf. Note that these figures are subject to ongoing revision as more complete information emerges.
} 
circulated a link to a survey for parents (and through them, where applicable, their adolescent children). ${ }^{6}$ An interesting feature of research undertaken during the COVID-19 pandemic has been the number of cross-national studies of this type, including the mental health study led by University College London (UCL) and the International Security and Development Center (ISDC) Life with Corona study. Just a few of these studies appear to reweight the results to take account of population characteristics such as education, gender and age. Online volunteer surveys have the advantage of being both cost-effective and quick, allowing researchers to respond quickly to emerging issues (in this case, the pandemic) and identify areas for immediate action. Steinmetz et al. (2014) distinguish between probabilitybased web surveys, which use a systematic sampling frame, and non-probability web surveys, where the likelihood of particular individuals being invited to complete the survey is not known.

The approach used in the latter group of surveys, the most commonly used approach in COVID-19 research to date, means that the characteristics and answers of volunteers can differ markedly from those of non-volunteers in ways that we cannot quantify, and so the findings cannot be generalised to the population (Steinmetz et al., 2014). Individuals may be more likely to complete a survey on the negative effects of the pandemic if they themselves have experienced them, thus overestimating the negative effects. Alternatively, the networks used to circulate a survey link may be disproportionately made up of those with higher levels of education and income, thus underestimating the negative effect of COVID-19. Online surveys of families' experience of homeschooling will, by their nature, be limited to those with broadband access and are therefore likely to underestimate difficulties in accessing online learning, leading to difficulties in accurately assessing variation across social groups or between urban and rural areas. Some researchers (for example, the UCL mental health survey) reweight the data to reflect the population characteristics in terms of age, education, etc. While this removes some sources of bias, it is still not possible to control for differences between social groups in access to, and engagement in, the web link for the survey.

The second, and smaller, set of studies is based on representative samples of the population (for examples, see Table 1.2). Such studies include the CSO's Social Impact of COVID-19 Survey and the Labour Force Survey, which are based on representative samples of the adult population. In addition, the long-running UKbased cohort studies have administered a COVID-19 module to their samples, covering a wide age-span. Maynooth University and ESRI surveys of schools in Ireland have targeted all school principals in the relevant primary and second-level sectors (Burke and Dempsey, 2020; Mohan et al., 2020). These population- and school-based surveys mean that the distribution of non-response is known and that appropriate reweighting can be used to allow the researchers to generalise to

\footnotetext{
${ }^{6}$ https://unioflimerick.eu.qualtrics.com/jfe/form/SV_787W65JwwoR49HD
} 
the whole population. This approach therefore provides a much stronger evidence base for policy development.

Even studies based on large representative samples tend to have too few cases to capture the experiences of particular minority groups. These include those experiencing homelessness or living in emergency accommodation, those living in direct provision, and Travellers. Where possible, a consideration of the policy implications for these groups is made on the basis of pre-COVID-19 research and/or findings on particular features (such as overcrowded accommodation) that are likely to especially affect these groups.

In the discussion of COVID-19 findings in the remainder of the report, greater weight is given to results based on representative samples of the relevant population, but reference is also made to findings from convenience samples where they are suggestive of particular experiences during the pandemic. At the time of writing, data collection for many studies was ongoing, so the discussion is based on available (often preliminary) findings. The months and, indeed, years to come will see a much larger body of research on the effects of the pandemic.

Given the timing, research so far has focused on the immediate impact of the pandemic restrictions on experiences and outcomes. However, research on other crises or traumatic events has indicated that some of the effects can be longerterm in nature. Research on children's experience of traumatic events, such as natural disasters, indicates long-lasting effects on psychological wellbeing (Abramson et al., 2010; Banks and Weems, 2014; Hoven et al., 2005; Fujiwara et al., 2016) - effects that are greater for families with lower socio-economic status (Pfefferbaum et al., 2015). ${ }^{7}$ Previous recessions have also had longer-term impacts on the careers and earnings trajectories of young people (see Chapter 5). The report refers to such studies where they provide additional insights into potential effects after restrictions are eased.

How best and when best to assess the impact of the pandemic is discussed in Chapter 6, which looks at methodological issues in assessing the medium- and longer-term impact of COVID-19 on the lives of children and young people. This chapter points to the potential for the GUI study to provide rich insights into the effects of the pandemic, both directly through disruption of school and social activities and indirectly through its effects on household income and deprivation.

\footnotetext{
${ }^{7}$ Exposure to other sources of trauma (such as parental stress) has been found to have long-lasting effects on physical and mental health as well as labour-market outcomes (for an overview, see Almond et al., 2018).
} 


\begin{tabular}{|c|c|c|}
\hline Name & Focus & Status \\
\hline \multicolumn{3}{|l|}{ Irish studies } \\
\hline $\begin{array}{l}\text { University of Oxford/University of } \\
\text { Limerick Co-Space: Supporting } \\
\text { Parents, Children and Adolescents } \\
\text { during Epidemics }\end{array}$ & $\begin{array}{l}\text { Comparative online longitudinal } \\
\text { survey of parents and } \\
\text { children/young people on coping } \\
\text { and mental health; six countries } \\
\text { including Ireland }\end{array}$ & $\begin{array}{l}\text { Two sets of preliminary results for } \\
\text { Ireland published }\end{array}$ \\
\hline DCU Have Your Say & $\begin{array}{l}\text { Online survey for parents, } \\
\text { children and adolescents on } \\
\text { impact of restrictions on play } \\
\text { worlds and friendship groups }\end{array}$ & $\begin{array}{l}\text { Ongoing; preliminary findings } \\
\text { released }\end{array}$ \\
\hline $\begin{array}{l}\text { TCD Teaching and Learning } \\
\text { Practices during COVID }\end{array}$ & Online survey of teachers & Report released in early July \\
\hline $\begin{array}{l}\text { NUI Galway/DCU/Insight Corona } \\
\text { Citizens Science Project }\end{array}$ & $\begin{array}{l}\text { Online multi-wave survey on } \\
\text { perceptions and effects of COVID- } \\
19 \text { restrictions }\end{array}$ & $\begin{array}{l}\text { Ongoing; four sets of key findings } \\
\text { released }\end{array}$ \\
\hline $\begin{array}{l}\text { NWCI Women's Experiences of } \\
\text { Caring during COVID-19 }\end{array}$ & $\begin{array}{l}\text { Online survey on impact of the } \\
\text { pandemic on women's caring } \\
\text { responsibilities, health and } \\
\text { wellbeing }\end{array}$ & Headline figures published online \\
\hline $\begin{array}{l}\text { UCD Changes in Nation's Eating } \\
\text { Habits }\end{array}$ & $\begin{array}{l}\text { Online survey on lifestyle and } \\
\text { eating patterns during the } \\
\text { pandemic }\end{array}$ & Ongoing \\
\hline TU Dublin Feeding Young Children & $\begin{array}{l}\text { Online survey of caregivers' } \\
\text { experience of feeding children } \\
\text { under } 2 \text { during the pandemic }\end{array}$ & Ongoing \\
\hline \multicolumn{3}{|l|}{ International studies } \\
\hline $\begin{array}{l}\text { University College London (UCL) } \\
\text { Coping and Wellbeing in Families } \\
\text { during the COVID-19 Crisis }\end{array}$ & $\begin{array}{l}\text { Online survey on coping and } \\
\text { wellbeing in children aged 7-11 } \\
\text { and their families }\end{array}$ & Ongoing \\
\hline $\begin{array}{l}\text { UCL Families and Community } \\
\text { Transitions under COVID }\end{array}$ & $\begin{array}{l}\text { Mixed-methods comparative } \\
\text { study of families with children } \\
\text { under } 18 ; \text { focus on time-use } \\
\text { diaries to record activities and } \\
\text { coping }\end{array}$ & Ongoing \\
\hline $\begin{array}{l}\text { UCL Mental Health Research } \\
\text { Network }\end{array}$ & $\begin{array}{l}\text { Online panel survey of adults on } \\
\text { psychological and social } \\
\text { consequences of COVID-19 } \\
\text { restrictions; data reweighted to } \\
\text { population characteristics }\end{array}$ & Monthly key findings published \\
\hline $\begin{array}{l}\text { International Security and } \\
\text { Development Center (ISDC) Life } \\
\text { with Corona }\end{array}$ & $\begin{array}{l}\text { Online comparative survey on } \\
\text { effects of pandemic restrictions } \\
\text { on daily lives; data reweighted to } \\
\text { population characteristics }\end{array}$ & $\begin{array}{l}\text { Some key findings published as } \\
\text { infographics }\end{array}$ \\
\hline $\begin{array}{l}\text { Institute of Fiscal Studies/ } \\
\text { Institute of Education Learning } \\
\text { during the Lockdown }\end{array}$ & $\begin{array}{l}\text { Online survey of parents of } \\
\text { children in reception year and } \\
\text { years } 1,4,5,8 \text { and } 10 ; \text { data } \\
\text { reweighted to population } \\
\text { characteristics }\end{array}$ & Working paper published \\
\hline $\begin{array}{l}\text { Ecorys/University of Huddersfield } \\
\text { Young People's Experience of Life } \\
\text { During the COVID-19 Pandemic }\end{array}$ & $\begin{array}{l}\text { Mixed-methods web-based study } \\
\text { in } 7 \text { countries with young people } \\
\text { as co-researchers }\end{array}$ & Ongoing \\
\hline
\end{tabular}


TABLE 1.2 SAMPLES

\begin{tabular}{|c|c|c|c|}
\hline Name & Method & Focus & Status \\
\hline \multicolumn{4}{|l|}{ Irish studies } \\
\hline $\begin{array}{l}\text { CSO Social Impact of COVID- } \\
19 \text { Survey }\end{array}$ & $\begin{array}{l}\text { Surveys in April and June } 2020 \text { of } \\
\text { Labour Force Survey respondents } \\
\text { from Q1 } 2019 \text { who agreed to take } \\
\text { part in further research; } \\
\text { reweighted for non-response }\end{array}$ & $\begin{array}{l}\text { Life satisfaction and } \\
\text { personal concerns; } \\
\text { changes in working life, } \\
\text { wellbeing and lifestyle } \\
\text { during the restrictions }\end{array}$ & $\begin{array}{l}\text { Publication of } \\
\text { key findings } \\
\text { in May and } \\
\text { June } 2020\end{array}$ \\
\hline $\begin{array}{l}\text { CSO Employment and Life } \\
\text { Effects of COVID-19 }\end{array}$ & $\begin{array}{l}\text { Module to Labour Force Survey } \\
\text { respondents in Q2 } 2020 \text { who } \\
\text { were interviewed in April; } \\
\text { reweighted for non-response }\end{array}$ & $\begin{array}{l}\text { Changes in } \\
\text { employment situation; } \\
\text { remote working; caring } \\
\text { for those ill with } \\
\text { COVID-19; difficulties } \\
\text { in working from home; } \\
\text { fears re shopping, etc }\end{array}$ & $\begin{array}{l}\text { Publication of } \\
\text { key findings } \\
\text { in May and } \\
\text { June } 2020\end{array}$ \\
\hline $\begin{array}{l}\text { University of } \\
\text { Sheffield/Maynooth } \\
\text { University COVID-19 } \\
\text { Psychological Research } \\
\text { Consortium Study }\end{array}$ & $\begin{array}{l}\text { Online survey administered to a } \\
\text { quota sample in UK and Ireland; } \\
\text { plus follow-up survey }\end{array}$ & $\begin{array}{l}\text { Impact on mental } \\
\text { health and } \\
\text { psychological wellbeing }\end{array}$ & $\begin{array}{l}\text { One paper on } \\
\text { Irish findings; } \\
\text { one paper on } \\
\text { UK findings } \\
\text { published } \\
\text { (preprints) }\end{array}$ \\
\hline \multicolumn{4}{|l|}{ Surveys of schools } \\
\hline $\begin{array}{l}\text { MU Survey of Primary } \\
\text { School Principals }\end{array}$ & $\begin{array}{l}\text { Survey of all primary school } \\
\text { principals }\end{array}$ & $\begin{array}{l}\text { School experiences of } \\
\text { COVID-19 restrictions }\end{array}$ & $\begin{array}{l}\text { Publication of } \\
\text { two reports } \\
\text { (May and } \\
\text { June 2020) }\end{array}$ \\
\hline $\begin{array}{l}\text { ESRI/Comreg/Department } \\
\text { of Communications Survey } \\
\text { of Second-Level Principals }\end{array}$ & $\begin{array}{l}\text { Survey of all second-level school } \\
\text { principals }\end{array}$ & $\begin{array}{l}\text { School experiences of } \\
\text { COVID-19 restrictions }\end{array}$ & $\begin{array}{l}\text { Report } \\
\text { published in } \\
\text { June } 2020\end{array}$ \\
\hline \multicolumn{4}{|l|}{ International studies } \\
\hline $\begin{array}{l}\text { Understanding Society : the } \\
\text { UK Longitudinal Household } \\
\text { Survey COVID-19 Study }\end{array}$ & $\begin{array}{l}\text { Monthly survey of participants } \\
\text { from the main Understanding } \\
\text { Society study }\end{array}$ & $\begin{array}{l}\text { Wide variety of topics, } \\
\text { including wellbeing, } \\
\text { home-schooling, } \\
\text { employment, } \\
\text { loneliness }\end{array}$ & $\begin{array}{l}\text { Data released } \\
\text { to } \\
\text { researchers } \\
\text { in June 2020; } \\
\text { some } \\
\text { preprint } \\
\text { articles } \\
\text { already } \\
\text { available }\end{array}$ \\
\hline
\end{tabular}

Surveys of: Millennium Cohort

Study (born 2000-02); Next Steps (born 1989-90); 1970 British

Centre for Longitudinal Studies COVID-19 Survey of Cohort Study Respondents
Cohort Study; 1958 National Child

Development Study; MRC

National Survey of Health and

Development (1946 British birth cohort)

To be repeated over time
Wide range of topics, including physical and mental health, loneliness and social contact, employment, education, financial situation
On-going; initial results and data expected in July 2020
Born in Bradford COVID-19 study
Survey of BiB cohort (parents first, followed by children)
Wide range of topics, including physical and
On-going 


\begin{tabular}{|c|c|c|c|}
\hline & & $\begin{array}{l}\text { mental health, } \\
\text { loneliness and social } \\
\text { contact, employment, } \\
\text { education, financial } \\
\text { situation }\end{array}$ & \\
\hline $\begin{array}{l}\text { ONS Opinions and Lifestyles } \\
\text { Survey (UK) }\end{array}$ & $\begin{array}{l}\text { Monthly survey covering a range } \\
\text { of topics }\end{array}$ & $\begin{array}{l}\text { During pandemic, } \\
\text { questions were added } \\
\text { on perceptions and } \\
\text { fear of COVID-19, } \\
\text { home-schooling, } \\
\text { employment effects }\end{array}$ & $\begin{array}{l}\text { On-going; key } \\
\text { findings } \\
\text { published } \\
\text { monthly }\end{array}$ \\
\hline $\begin{array}{l}\text { Yale University Studying the } \\
\text { Unintended Consequences } \\
\text { of COVID-19 responses on } \\
\text { Family Wellbeing and Child } \\
\text { Safety }\end{array}$ & $\begin{array}{l}\text { Representative sample survey of } \\
\text { families with children } 0-18 \text { in US } \\
\text { North East region }\end{array}$ & $\begin{array}{l}\text { Child safety, health, } \\
\text { wellbeing, educational } \\
\text { outcomes }\end{array}$ & On-going \\
\hline $\begin{array}{l}\text { University of Oxford The } \\
\text { Impact of COVID-19 on } \\
\text { Economic Inequality and } \\
\text { Employment Progression }\end{array}$ & $\begin{array}{l}\text { Longitudinal survey of a } \\
\text { representative sample of UK } \\
\text { workers }\end{array}$ & $\begin{array}{l}\text { Impact of restrictions } \\
\text { on employment and } \\
\text { living standards }\end{array}$ & On-going \\
\hline
\end{tabular}





\section{CHAPTER 2}

\section{Family and Peer Relationships}

\subsection{INTRODUCTION}

Close family relationships may be put to the test during COVID-19 restrictions. Increasing economic strain, job loss, physical confinement, working from home, social isolation and lack of access to formal and informal childcare are likely to have a notable impact on family dynamics and the quality of relationships. These factors are likely to affect children's behaviour and wellbeing (see Chapter 4). This chapter explores emerging research on the implications of the COVID-19 pandemic for various aspects of family relationships and interactions, placing these in the context of pre-COVID-19 patterns. Section 2.2 focuses on the quality of family and peer relationships and child outcomes, while Section 2.3 examines the indirect effects on child outcomes.

\subsection{THE QUALITY OF FAMILY RELATIONSHIPS AND CHILD OUTCOMES}

High-quality relationships within the family are extremely important for child development (Ackerman et al., 2013; Moos, 1986). The quality of the parent-child relationship is highly related to child socio-emotional and cognitive outcomes, and plays a strong protective role in situations of economic adversity (Nixon, 2012; Nixon et al., 2019). Thus, any changes in the nature of parent-child relationships during the pandemic could have longer-term implications for child and adolescent development. ${ }^{8}$ This relationship can be influenced by various direct factors, including marital satisfaction (Nixon, 2012) and personality (Fahey et al., 2012) as well as indirect factors (e.g. parental stress, wellbeing).

Using Growing Up in Ireland (GUI) data in the pre-COVID-19 period, Nixon (2012) points to relatively high levels of marital satisfaction across the population of parents. The most recent information released by the Central Statistics Office (CSO) in April 2020 (CSO, 2020b) shows that levels of satisfaction with personal relationships (which include but are not limited to family) have changed during the pandemic. There was a significant decline in average satisfaction with personal relationships, from 8.6 in 2013 and 2018 to 7.7 in April 2020. ${ }^{9}$ Furthermore, the percentage rating their satisfaction with their personal relationships as 'low' increased to 14 per cent for males and 18 per cent for females, from just over 5 per cent of males and 4 per cent of females in 2013 and 2018. Levels of satisfaction with personal relationships in families with children have deteriorated over time, with just 41 per cent reporting 'high satisfaction' in April 2020 compared to 61 per

\footnotetext{
${ }^{8}$ While other literature deals with the impact of crises (such as war and political uncertainties) on parent-child relationships, it is less relevant to discussing this relationship in Ireland at the time of the pandemic.

${ }^{9}$ The scale is from 0 'not at all satisfied' to 10 'completely satisfied'.
} 
cent in 2018 (CSO, 2020a). A large proportion of respondents were concerned about household stress resulting from confinement, with 17 per cent saying they were very concerned and 60 per cent that they were somewhat concerned. Such concerns were less commonly reported by those with a third-level education and those who reported fewer concerns about financial issues. Concerns were greater among those living in private rented or more overcrowded accommodation (see below). Almost a third of adult respondents were extremely or very concerned about maintaining social ties during the pandemic, with 48 per cent being somewhat concerned. For some, the consequences of lockdown have been much more serious; the Garda Síochána and other agencies have reported an increase in domestic violence ${ }^{10}$ (see Section 2.3.4).

While the pandemic has had an adverse impact on many individuals, nearly half (46\%) of Irish adults reported having increased positive family time during the restrictions. The lowest rates of increased positive family time were experienced by the $65+$ age group (CSO, 2020b). In the same vein, in the UK, a study based on a convenience sample showed that a high proportion of those currently living with partners $(81 \%)$ or children (83\%) felt generally positive about spending more time together, and 40 per cent of the parents surveyed anticipated a closer relationship with their children once the restrictions of the lockdown were lifted (YouGov, 2020). The following subsections look in greater detail at what we know about parent-child relationships and parental stress levels in the pre-COVID-19 period as a basis for exploring the implications of the pandemic for the challenges experienced by families.

\subsubsection{Parent-child relationships}

Children and young people in Ireland tend to report positive relationships with their parents. At nine years of age, the majority of children - almost four-fifths reported that they got on very well with their mother and father (McNamara et al., forthcoming), with similarly high levels found among 13 -year olds (Williams et al., 2018). At $17 / 18$ years of age, young people also tend to report positive relationships, but levels of conflict are rated as moderate (Watson et al., forthcoming). For younger children, information on the quality of the relationship is collected from parents. Both mothers and fathers tend to report high levels of closeness and low levels of conflict with the child (between the ages of 3 and 9) as well as indicating a parenting style generally characterised as warm and consistent (GUI Study Team, 2018; McNamara et al., forthcoming). The quality of parent-child relationships does not tend to vary by socio-economic characteristics, so positive relationships are apparent across all social groups (McNamara et al., forthcoming;

\footnotetext{
${ }^{10}$ www.irishtimes.com/news/crime-and-law/domestic-violence-reports-up-30-in-some-areas-since-lockdownsays-garda-1.4238362. https://www.irishtimes.com/news/crime-and-law/rapid-and-sustained-increase-inchildren-reporting-domestic-violence-since-covid-19-1.4260439; www.policingauthority.ie/assets/uploads/documents/Policing_Performance_by_the_Garda_S\%C3\%ADoch\%C 3\%A1na_in_relation_to_COVID-19_Regulations_20200604.pdf
} 
Watson et al., forthcoming; Fahey et al., 2012). The quality of the parent-child relationship is highly related to child socio-emotional and cognitive outcomes, and plays a strong protective role in situations of economic adversity (Nixon, 2012; Nixon et al., 2019). Thus, any changes in the nature of parent-child relationships during the pandemic could have longer-term implications for child and adolescent development.

Despite largely positive parent-child relationships, some parents experience stress in their role and may suffer from depression more generally. By the age of 17 , almost a quarter (23\%) of young people in the GUI study had mothers who had depressive symptoms in at least one wave of data collection (since the child was aged nine). ${ }^{11}$ This was strongly structured by social background, with levels varying from 14 per cent for the professional group to 40 per cent of the never employed ${ }^{12}$ (GUI, own analyses). A decline in economic circumstances, such as being in arrears and/or having to cut back on necessities, is associated with an increase in maternal depression (Nixon et al., 2019). Parents who experienced psychological distress tended to become harsher in their parenting style, showing less warmth to their children. This more distant interaction, in turn, was linked to children feeling less happy and more anxious, and displaying poorer conduct (Nixon, 2012; Nixon et al., 2019). Thus, an increase in the reports of anxiety and depression in adults during the pandemic restrictions (see Chapter 4 ) is likely to a have a very significant impact on the emotional wellbeing of children and young people - an issue that is discussed further in the following section.

\subsubsection{The child's relationship with other family members and peers}

The previous section looked at how children and young people get on with their parents. However, young people are also embedded in broader social networks, including siblings, extended family members and friends. The nature of these relationships before COVID-19 can be gauged from GUI data on the experiences of nine-year-olds (Cohort '08, wave 5) in Ireland. A substantial majority (89\%) of these nine-year-olds had brothers or sisters living in the household. The majority (73\%) of parents reported that their child got on well with their siblings, with 25 per cent reporting mixed results and 2 per cent reporting either negative relationships or that the children did not see their siblings. These patterns are important as, during the height of the restrictions, children could not socialise with other children outside their immediate household.

Exploration of the relationship dynamics by social class shows that children from professional or managerial backgrounds were more likely to get on well with their siblings (both 77\%) compared to children from families that never worked (63\%). Lone parents were also somewhat less likely to report children getting on well with

\footnotetext{
${ }^{11}$ This finding is based on Cohort '98 involving three waves of data collection: at the ages of 9, 13 and 17/18.

12 The 'never employed' group refers to families where neither the mother nor father has held a job from which social class can be classified; these households tend to be a highly disadvantaged group.
} 
their siblings than those in two-parent families (64\% vs $75 \%$ ). Social distancing and cocooning of the elderly during the pandemic mean that the opportunities for faceto-face child-grandparent interactions are limited. The Growing Up in Ireland study (Cohort '08, wave 5, age 9) analysis shows that the relationship with grandparents is important for young people; many see their grandparents every day or most days of the week, despite the fact that just 5 per cent of nine-year-olds live with anyone other than their nuclear family. The class differentiation in frequency seeing grandparents or aunts/uncles holds when this is taken into account.

Friendships are important for the social development of children and adolescents. The GUI study shows that among Cohort ' 98 , only a small per cent of mothers (2\%) reported that their nine-year-old child had no close friends, while 6 per cent indicated that their child had just one close friend (Williams et al., 2009). Most mothers reported that their children spent time with their friends outside school at least two days a week. The size of the friendship networks tends to expand between 9 and 13 years of age, especially for young people from more disadvantaged backgrounds (Smyth, 2017). The size of the friendship network is found to remain stable between 13 and 17 years of age (McNamara et al., forthcoming). The largest single group had between 3 and 5 friends at 13 and 17 years of age. Young people from less educated families tend to give higher ratings to their friendship quality in terms of trust and communication.

Lack of direct interaction with their friends and other family members as a result of pandemic restrictions is likely to have a significant impact on children and young people (Markowska-Manista and Zakrezewska-Oledzka, 2020). A survey based on a convenience sample of 683 adolescents in the US, recruited using social media (Oosterhoff et al., 2020), shows that the pandemic has strongly affected the lives of young people, limiting their activities and movement. However, the youth in the study adhered to physical distancing, not wanting to get sick themselves or be responsible for others getting sick; generally following rules set by their parents. In the same vein, an experiment in Ireland among the adult population indicates that the thought of infecting vulnerable people or large numbers of people can motivate social distancing (Lunn et al., 2020). New CSO data also shows that, while level of compliance with public health measures was lower among younger age groups, the decline between April and June was greater for the 35-54 age groups. In the US, some young people responded that they adhered to social distancing because of the lack of more attractive options. Pandemic-related threat was shown to prompt feelings of anxiety and depressive symptoms in the young people. Peer pressure to exercise social distancing was associated with greater depressive symptoms. Control motivations (government- and parent-sanctioned rules) were associated with a greater sense of belonging. A subset of youth $(25 \%)$ reported wanting to be at home regardless of the social distancing restrictions. These findings indicate that young people's experiences and behaviours during the pandemic are influenced by a range of factors (Oosterhoff et al., 2020). 
In their commentary based on previous studies, Moroni et al. (2020) note that the social isolation of children from their friends and teachers may affect their mental health, wellbeing, and behaviour more generally. A likely outcome of the COVID19 pandemic is that any psychological issues for children will become amplified, especially for some groups of children and young people. A survey of 241 parents of school-aged children with an ADHD diagnosis in China indicated that children's ADHD symptoms were significantly worse during the COVID-19 outbreak than previously (Zhang et al., 2020). In Ireland, Barron and Emmet (2020c) note that the associated effects of the pandemic, in terms of break in routine and lack of support, have had a negative impact on children with special educational needs, as well as on their parents. There is also evidence that social isolation is more likely to affect marginalised children and young people, including those in care, who have reduced contact with their key workers (Larkins et al., 2020). This group is also particularly affected by decisions to close public parks and play facilities, since more disadvantaged groups are more likely to be living in unsuitable accommodation that lacks outside space. Mental and physical health is closely linked to one's physical activity. There is some evidence that, during the pandemic, children's physical activity has decreased, with a notable number of young people $(39 \%)$ reporting spending no time or less than 30 minutes being physically active in the last 24 hours (Barron and Emmet, 2020a).

In order to ease social isolation, official advice in many cases is to find alternatives by using various social media platforms (Long, 2020). In Ireland, the use of social media during the lockdown increased among children and young people (Barron and Emmet, 2020a; Mohan et al., 2020). It is important to note that access to such technologies is unevenly distributed across social groups and regions (Blank et al., 2020) and the impact of its use is not always positive, as cyber-bullying may occur. As many child support networks have limited their services, alternative ways of reaching young people in need have been put in place. For example, in Serbia, children can use a specific emoticon and share it with peers as a sign that they are experiencing difficulties. This provides a quick message to teachers and peers that children need protection (Larkins et al., 2020). Research shows that, in addition to spending time on social media, children and young people also used other types of technology for entertainment, with the biggest increase being in watching TV/Netflix/films (Barron and Emmet, 2020a, b). The latter study also indicates that parents tend to under-estimate children's use of technologies, compared to children's own reports. Since they are unable to have face-to-face meetings with their friends, social media platforms may serve a valuable role for young people in maintaining friendships.

There has been a lack of systematic evidence in Ireland on the effects on children and young people of separation from their extended family and friends. A nonrepresentative study by Barron and Emmet (2020a) in Ireland indicates that not being able to have face-to-face contact with friends was the single hardest impact of social restrictions on children and teenagers. This study also indicates that, while 
younger children turn to parents during the pandemic, teenagers consider their friends an important source of support. Pre-COVID-19 research suggests that any negative effects of restrictions on seeing friends are likely to affect disproportionately young people from more disadvantaged backgrounds as they have larger friendship groups and rate them more highly. Similarly, more disadvantaged groups had more regular face-to-face interaction with their grandparents and extended family members pre-COVID-19 and are more likely to be missing such interaction, if they are not living in the same household.

\subsection{THE INDIRECT EFFECTS ON CHILD OUTCOMES}

While relationships within the extended family, parent-child interactions and relationships with friends are likely to have a direct impact on children, other indirect factors that influence the lives of parents are, in turn, also likely to shape the lives of children. The following sections explore the main indirect effects on child outcomes.

\subsubsection{Economic and work-related challenges}

Chapter 1 described the scale of employment loss and resulting income decline resulting from the pandemic restrictions in the short term. Economic and workrelated strain is likely to affect children and young people in terms of access to material and time resources in the family. A study based on a convenience sample in the UK of 5,000 parents/carers and young people (aged 11-16 years) since the onset of COVID-19 reveals that work and related economic challenges are perceived as the most frequent source of stress for parents (Waite et al., 2020). In Ireland, even by April, 18 per cent reported that the pandemic had had a major or moderate negative financial impact, with a further 19 per cent reporting a minor negative impact (CSO, 2020b). The corresponding figures for households with children were 23 per cent (major/moderate negative impact) and 21 per cent (minor negative impact). Not surprisingly, a negative impact was more commonly reported by those who had become newly non-employed. By June, 22 per cent of respondents reported a drop in income since the restrictions, with higher rates (29\%) for households with children (CSO, 2020f).

At present, an unprecedented number of individuals in Ireland are working remotely due to workplace closures, while, before the COVID-19 period, just 14 per cent of employees worked from home in some formal capacity (mostly in the education, ICT and finance sectors) (Redmond and McGuinness, 2020b). Couples with children were more likely to work from home compared to lone parents before the pandemic (Redmond and McGuinness, 2020b). Almost half (47\%) of the population have had their employment affected by COVID-19. Of this group, just over a third (34\%) have started remote working from home and 12 per cent have increased the number of hours working remotely (CSO, 2020a, b). While working from home may alleviate childcare difficulties, given school and childcare closures, there is also potential to exacerbate conflict, especially when long working hours 
and other responsibilities collide. For some, it may be difficult to disengage from work and maintain a clear difference between work and other domains (Dockery and Bawa, 2020). Earlier studies in Ireland (Russell et al., 2019) and Australia (Dockery and Bawa, 2014a, b) show a strong association between working from home and long work hours. When different roles compromise each other, it can lead to stress and a subsequent deterioration in family relationships. Satisfaction with working from home is also gendered; men who work from home tend to have higher overall job satisfaction while their partners feel less satisfied with the division of household tasks (Dockery and Bawa, 2014a). In Ireland, the CSO (2020d) analysis shows that, among female respondents working from home, 49 per cent wanted to return to their place of work after the lifting of the current restrictions, compared to 32 per cent of men, possibly indicating current role overload at home as mothers remain the main carers of children.

\subsubsection{Time and division-of-labour challenges}

Time is a valuable resource and is likely to affect family relationships, and, indirectly, the lives of children. A large body of research in Ireland and internationally shows large gender differences in the time spent on childcare and housework before the pandemic. According to the latest Gender Equality Index (European Institute for Gender Equality, 2020), gender inequalities in time use are persistent. Females are more likely to engage in unpaid care work: almost 38 per cent take care of children, grandchildren, older people and/or people with disabilities every day for one hour or more compared with 25 per cent of men. Discussing key trends in the gender division of labour across 13 developed countries over a 50-year period, Altintas and Sullivan (2016) found a continuing, albeit uneven, long-term trend towards greater gender equality, although the process was very slow. In line with Irish studies (discussed below), evidence from a 2012-2013 study of parents in Germany shows that the amount of time that parents spent with their children tended to be much greater for mothers than for fathers (Jessen and Waights, 2020). Across Europe, just 34 per cent of men are engaged in cooking and housework every day for one hour or more, in comparison with 79 per cent of women (European Institute for Gender Equality, 2020, p.14). Analysing data from more than 8,500 heterosexual couples interviewed for the UK Household Longitudinal Study between 2010 and 2011, McMunn et al. (2020) found that women do approximately 16 hours of household chores every week, while men do closer to six. When both partners were in full-time employment, women were found to be five times more likely than men to spend at least 20 hours a week doing household chores. In Ireland, drawing on data from the Irish National Time-Use Survey conducted in 2005, McGinnity and Russell (2008) found that the distribution of paid and unpaid work in Ireland varied considerably between men and women, with the latter spending substantially more time on caring and household work during the week, but also at weekends. In fact, women's unpaid work and caring time during the week and weekends remained virtually unchanged, leading to a gender gap in time devoted to leisure activities at 
weekends. These patterns remain unchanged, with more recent data indicating that women in Ireland report doing an average of just under 20 hours of housework per week while men report an average of seven hours (Russell, Grotti et al., 2019).

Before the pandemic, parents were highly reliant on formal and informal sources of support in caring for their children. Among those parents using regular childcare, 40 per cent rely on relatives when the child is nine months, 23 per cent at age 3 and 45 per cent at age 5 , with relatives playing a significant role in supplementing formal care even when children are in school or centre-based provision (Russell et al., 2018). The use of centre-based provision increases from 26 per cent at 9 months to 53 per cent at 3 years of age (prior to Early Childhood Care and Education $\{E C C E\}$ Scheme eligibility) among those using regular non-parental care. Take-up of the ECCE scheme is near universal, with over 90 per cent of eligible children taking up their places (McGinnity et al., 2015).

An emerging literature points to the gender dimension of the pandemic, with women assuming more of the care responsibilities resulting from the closure of childcare settings and schools (Alon et al., 2020). Drawing on a survey based on a convenience sample of 1,249 Canadian parents with a residential partner of the opposite sex and at least one resident child under age 18 during early May 2020, Shafer et al. (2020) found that fathers in Canada spend almost 70 per cent of the hours of mothers on housework and 60 per cent of the hours on childcare. Overall, both mothers' and fathers' reports indicate that parenting has become slightly more equal during the pandemic than before it. In contrast, in an online (volunteer) time-use survey in England, Andrew et al. (2020) find stark gender differences in the time spent on paid work, childcare and housework during the pandemic. Despite the persistence of gender differences in the period of pandemic restrictions, childcare is the most frequently reported activity during waking hours for both parents. A good deal of this time ( $56 \%$ for mothers, $61 \%$ for fathers) is spent on 'passive childcare' (keeping an eye on the children) rather than 'active childcare', such as doing schoolwork or playing together. Mothers report being interrupted for childcare during 57 per cent more of their paid work hours than fathers.

Time investment on behalf of parents in their child's educational activities while working inside or outside the home during the pandemic may also affect family relationships and feelings of stress. Chapter 3 provides a more detailed discussion of home-schooling during the period of school closures. The situation may be more difficult and stressful in families where mothers have experienced or are experiencing mental health problems (Moroni et al., 2020), ${ }^{13}$ or when parents report behaviour difficulties; for example, among children with special educational

\footnotetext{
${ }^{13}$ This study is a commentary based on previous research.
} 
needs (SEN) (Waite et al., 2020). ${ }^{14}$ Barron and Emmet (2020c) note that parents of these children are concerned about the regression of their child's behaviour and social skills during the isolation period, which is likely to influence their own stress levels.

Some help with household chores is often provided by young people, as shown by the GUI study of nine-year-olds (Cohort '08). Here too, a gender dimension is evident, with girls more likely than boys to report helping 'very often'. Overall, 77 per cent of girls and 72 per cent of boys helped with at least one of these chores 'very often' (GUI Study Team, 2018b). There is no systematic evidence available yet on the involvement of children and young people in domestic labour during the pandemic, but it is likely that child involvement in different family chores will have increased during the lockdown, perhaps especially for those whose parents are key workers or for those with younger siblings.

Due to the closure of schools and childcare facilities, as well as the cocooning requirement for older relatives or grandparents, almost a quarter (24\%) of persons in Ireland aged 35-44 reported experiencing childcare issues (CSO, 2020b). In addition, more females (21\%) than men (15\%) are caring for a dependent family member or friend, with persons in the 45-54 age group reporting the highest rates of caring (31\%) as a result of COVID-19. A higher percentage of women are finding it more difficult to work from home with family around than men (11\% compared to $9 \%)$. The situation is likely to be particularly challenging for essential workers who are required to continue going to work; the majority $(70 \%)$ are female and just over half of these workers have children, two-thirds of these having a youngest child aged 14 or below (Redmond and McGuinness, 2020a). Essential workers are more likely to be lone parents than the general population and, where they have a partner, 80 per cent have a partner in paid employment (ibid.).

Strain from the quarantine is likely to have an adverse impact on the wellbeing of both parents and children (Spinelli et al., 2020) (see Chapter 4). Based on a convenience sample, an online survey of 854 parents of 2-14-year-old children in April 2020 in Italy showed that role multiplicity (balancing personal life, work, and upbringing of children) without outside help may affect parents' ability to be supportive caregivers. In the same vein, working parents in Poland reported that, due to the necessity to combine work with childcare, interaction between parents and children was becoming more tense (Markowska-Manista and ZakrezewskaOledzka, 2020).

\footnotetext{
${ }^{14}$ The preliminary findings are based on 5,000 participants in the online Co-Space study in the UK, which is not nationally representative.
} 


\subsubsection{Overcrowding and living arrangements}

How families cope during the pandemic may also be linked to their living arrangements. Overcrowding and unsatisfactory living arrangements are likely to affect individuals' quality of life, especially when forced to live under lockdown during the pandemic. Using the top decile of the distribution of persons per room as the definition of overcrowding, Grotti et al. (2018) found that younger people, households with children and renters were more likely to experience overcrowding. Across nationality groups, more overcrowding was evident among EU12 and particularly non-EU migrants, at 24 and 32 per cent respectively. As expected, overcrowding is more common in urban (13\%) than rural areas (6\%), especially in Dublin (16\%). The authors also point to a negative linear relationship between income position and the experience of overcrowding; people in the bottom income quintile are four times more likely than those in the top quintile to live in such accommodation (ibid.).

The Irish Refugee Council has highlighted the situation of people living in direct provision - a system that accommodates those seeking international protection while their asylum claims are being processed. In April 2020, there were 7,400 people in direct provision and emergency accommodation for asylum-seekers. ${ }^{15}$ The fears of asylum-seekers of increased risk of infection due to overcrowding and inability to keep social distance have been well documented in the media. Some insights into the experiences of young people living in direct provision is provided by a recent report showing that the demand for places in these centres has increased over time, with greater demand for such accommodation than places available, resulting in many individuals living in unsuitable and overcrowded settings (Office of the Ombudsman, 2020).

The National Traveller Accommodation Consultative Committee (NTACC) annual report 2013 showed that a significant minority of the Traveller population live in unauthorised sites, basic service bays, permanent halting sites, transient sites or shared houses, and need better accommodation provision (NTACC, 2013). Over half of Travellers live in overcrowded conditions (Watson et al., 2017). Recently published research detailing the socio-economic circumstances of the Roma Community across the island of Ireland has identified extremely high levels of housing deprivation and overcrowding (Pavee Point and Department of Justice, 2018). The research found that 45 per cent of these households did not have enough beds for everyone and 24 per cent were comprised of eight people or more. This latter figure compares to a rate of just 1.3 per cent for the entire Irish population.

A study based on a convenience sample of 1,681 adults in the UK, conducted in March 2020, showed that satisfaction with living arrangements varied by age.

\footnotetext{
${ }^{15}$ See: www.irishrefugeecouncil.ie/Listing/Category/direct-provision
} 
Those aged over 65 felt more positive about their circumstances compared to young people between 18 and 24 who felt less happy about their situation (YouGov, 2020). Dissatisfaction with accommodation and/or overcrowding were also associated with poorer levels of wellbeing (see Chapter 4). Given this pattern, it is likely that some groups, such as Travellers, Roma and non-EU migrants, may experience greater stress during the restrictions as a result of their overcrowded accommodation.

\subsubsection{Domestic violence}

Increased strain during economically challenging times may lead to an increase in violence within relationships and an adverse impact on children and young people. An EU-wide survey by the European Union Fundamental Rights Agency (FRA), Violence Against Women, showed that, in 2014, 33 per cent of respondents in Ireland thought that violence against women was very common and 50 per cent thought it was fairly common. Forty-one per cent of Irish women knew someone in their circle of family or friends who had experienced intimate partner violence (FRA, 2014). The Women's Aid Impact Report (2018) found that, in 2018, 16,994 disclosures of domestic violence against women were recorded during contacts with Women's Aid Direct Services.

Emerging evidence indicates that family violence in the home may be increasing during the COVID-19 restrictions. This trend is associated with a number of interlinked factors, including economic stress, difficult relationships and reduced or non-existent support structures (Usher et al., 2020). In Ireland, the number of calls for help relating to domestic violence increased 25 per cent compared to the previous year, with a new Garda initiative resulting in more than 100 people being charged with these offences in the last two weeks of May (Irish Times, 9 June 2020). In the CSO (2020b) Social Impact of COVID-19 survey, 6 per cent of adult respondents were somewhat or very concerned about violence in the home during the restrictions.

Extended isolation and social/physical distancing may have a detrimental impact on some children at risk of neglect and abuse. Larkins et al. (2020) reported increases in exposure to violence and abuse as well as more contacts with emergency child helplines in four countries. The findings may not reveal the true picture as some children may not be in circumstances where they have an opportunity to seek help or can do so safely. Opportunities to spot signs or hear about children's experiences have diminished, compounded by the lack of outside oversight in terms of access to professionals such as teachers, general practitioners, health visitors, and social and youth workers (Humphreys et al., 2020; Usher et al., 2020). In 2019, TUSLA, the Child and Family Agency, received a total of 19,087 referrals for various forms of suspected abuse or neglect against 
children. ${ }^{16}$ There are fears that a significant number of children are vulnerable to abuse and neglect during the current pandemic, with referrals reported to have decreased significantly during April and May due to the limited interaction of children with other adults in the community. ${ }^{17}$

The current situation may elevate increases in substance abuse, with 27 per cent of those in households with children reporting an increase in alcohol consumption (CSO, 2020b), ${ }^{18}$ which may contribute to partner violence. Children's exposure to this may lead to serious emotional and behavioural problems, resulting in oppositional behaviour among children which may in turn prompt harsh responses and reprimands from parents (Humphreys et al., 2020).

\subsubsection{Parenting challenges and activities with children}

In addition to the need to spend more time with children (see above), the lockdown and physical distancing rules limit the activities parents can do with their children outside the home. GUI research (wave 5 for Cohort '08 in 2017/18) shows that, before the pandemic, most parents of nine-year-olds took their children on educational visits (museums, farms, etc.). Other activities included going shopping, swimming, seeing a sporting event and taking their children to a library (Watson et al., forthcoming). Children from more advantaged families were more likely to take part in most of these activities compared to those from families where parents were never employed. While mothers were asked about general activities with the child, fathers were specifically asked about taking their children on outdoor pursuits. The majority of fathers (96\%) engaged their children in outdoor activities such as going for a walk, going cycling or hiking, with no notable differences by social class background.

The GUI study of nine-year-olds also shows the extent to which parents spent time having meals together and generally chatting to their children. A large proportion of parents $(67 \%)$ reported eating a meal together as a family every day, with parents who were never employed more likely to do so compared to professional parents ( $83 \%$ vs $64 \%$ ). Most parents ( $82 \%$ ) also chatted to their children about everyday things every day. Parental interaction with children was high across all social groups. Parents also involved their children in various household activities such as cooking and cleaning. Parents who were never employed were more likely to engage their children in such activities 'every day' compared to professional parents (41\% vs $27 \%$ ). It is likely that during the lockdown the time spent on sharing meals and interacting with children has increased (especially in the case of younger children) while some family outdoor pursuits have decreased, though walking and

\footnotetext{
${ }^{16}$ See www.thejournal.ie/tulsa-received-52-child-protection-referrals-every-day-last-year-3654883-0ct2017/

${ }^{17}$ See: www.thejournal.ie/child-abuse-and-neglect-tulsa-drop-in-referrals-5093604-May2020/

${ }^{18}$ While the data indicate an increase in alcohol consumption, it remains unclear what the level of consumption was before or during the pandemic. However, research from the UK indicates that problematic (binge) drinking increased during the pandemic (Niedzwiedz et al., 2020).
} 
cycling are likely to have continued (see Chapter 4).

\subsection{SUMMARY}

This chapter has looked at a range of factors that affect the lives of families and children during the pandemic restrictions. It is too early to look at the effects of the changed economic circumstances on children and young people. However, research on the previous recession provides useful insights into the likely impact. The sharp rise in unemployment has resulted in economic stress in many families, especially as, for some families, financial strain is allied with school closures, loss of childcare opportunities and the necessity to combine working from home with home-schooling, childcare and other tasks. However, longer-term implications may not match those of the previous recession as it is difficult to estimate the trajectory of the economy, and the levels of austerity experienced during the previous recession may not be replicated. This being said, the combined stressors experienced by families at present are likely to have an adverse impact on parental mental wellbeing, which is likely, in turn, to affect children's relationships and outcomes. Economic and work-life balance stressors may be exacerbated by selfisolation policies that increase social isolation, especially for more disadvantaged groups. Questions remain about the persistence of these trends as the economy enters a new recession. The harsh impacts will not be evenly distributed across the population, with the young and low-income earners being the hardest hit (see Chapter 1).

In the time of COVID-19, an increasing number of workers find themselves managing their job, childcare and relationships while lockdown and social distancing measures apply. In cases where only one of the parents can stay at home, they face an extra burden. Increased time at home can place additional stress on family relationships, and may make negative situations worse, affecting the wellbeing of family members. Frontline staff and health professionals are likely to have additional concerns related to contracting the virus (see Walsh et al., 2020). Emerging evidence indicates that disadvantaged families and families with children with special educational needs are likely to struggle more under current circumstances.

The situation is equally difficult for children and young people who are distanced from their friends due to the closure of schools and early-years facilities. The imposed restrictions mean that young people are deprived of opportunities to engage in normal childhood activities, such as going on trips with their parents, going swimming, and visiting grandparents and relatives. This may be particularly difficult for very young children who may not understand the change in their routines.

While the current situation starkly highlights existing inequalities in society (by 
social class, family structure, special educational needs and ethnic minorities) and the adverse impact of COVID-19 for some disadvantaged groups, there are also some positive elements, as some (albeit more advantaged) families find that the current situation is bringing families closer together and, at least for some, there is more time to spend as a family unit. The chapters that follow look at the impact of the pandemic on other aspects of children's lives. 


\section{CHAPTER 3}

\section{Formal and Informal Learning}

\subsection{INTRODUCTION}

The education and care of learners enrolled in pre-primary, primary, lowersecondary, upper-secondary and tertiary levels of education have been affected by the closure of educational institutions across many countries due to COVID-19 (UNESCO, 2020). Online platforms have replaced face-to-face classroom interactions to ensure continued learning; student assessments have moved online, or are, in some cases, cancelled; and parents have been balancing work commitments with home-schooling obligations, childcare and caring for elderly relatives. This chapter addresses the main challenges for formal education and informal learning, reviewing newly emerging knowledge as well as existing research from Ireland and abroad. Section 3.2 focuses on the impact of the pandemic on formal education, while Section 3.3 considers learning outside school in the form of reading and other cultural activities.

\subsection{FORMAL EDUCATION}

\subsubsection{Educational inequalities in Ireland}

There is a strong relationship between educational attainment and adult life chances; those with higher education qualifications have higher incomes, and better health and quality of life (Belfield and Levin, 2007). The link between education and later outcomes is especially strong in Ireland, with a high rate of earnings return to third-level qualifications by comparative standards (OECD, 2020). Research has consistently shown persistent inequalities in educational attainment by socio-economic background (see, for example, Blossfeld et al., 2016, 2017), whether measured in terms of social class and/or parental education (Bukodi and Goldthorpe, 2013) - patterns that ensure enduring inequalities in outcomes in adult life.

Such inequalities are evident in Ireland. Social background differences are apparent even at school start, with inequalities in vocabulary test scores as well as the skills and dispositions to facilitate learning (Smyth, 2018). Later in primary school, there are clear differences in English and maths test scores by socioeconomic status (Eivers et al., 2010). Junior Certificate performance varies markedly by household social class and maternal education. There is a gap of over one grade point ${ }^{19}$ per subject between the most and least advantaged groups (GUI Study Team, 2019). Rates of second-level completion have improved markedly in

\footnotetext{
${ }^{19}$ One grade point is the equivalent of getting A versus B grades across all subjects in the Junior Certificate
} exam. 
recent years (DES, 2019), but the group of young people who drop out of school before the Leaving Certificate are disproportionately from disadvantaged backgrounds (GUI Study Team, 2019). At Leaving Certificate level, there is a very large gap (over 100 CAO 'points') in performance between those from the professional and lowest-skilled social classes (GUI Study Team, 2019). Rates of participation in higher education are now relatively high across all social groups, although variation by family background is still apparent. There are particularly high levels of third-level education participation among those whose mothers have degrees (86\%) compared with those whose mothers have Junior Certificate education or less (48\%) (GUI Study Team, 2019). The concentration of disadvantage in a school has an additional impact on young people's outcomes (Smyth et al., 2015); even controlling for individual background, those in schools serving predominantly disadvantaged populations achieve lower test scores and lower exam grades, and are less likely to go on to higher education (McCoy et al., 2014; McNamara et al., forthcoming). Vulnerable students are less likely to make successful transitions throughout their school careers and rely more on schoolbased support and guidance regarding their educational pathways (McCoy et al., 2014).

Other dimensions of inequality are evident in the Irish educational system. Immigrant children's achievement in reading is influenced by their linguistic background. Students from a non-English speaking background have significantly lower scores than students from an English-speaking background, although this pattern does not hold for mathematics (Darmody and Smyth, 2018). Both first- and second-generation immigrants who speak another language at home have significantly lower reading scores than Irish students (Darmody and Enright, forthcoming). Watson et al. (2017) found that just 1 per cent of Travellers had a degree, and only 8 per cent of working-age Travellers had stayed at school up to Leaving Certificate level compared with almost three-quarters of the rest of the population. Students with special educational needs (SEN) are also in danger of being left behind and not achieving their full potential. There is a higher concentration of these students in DEIS schools ${ }^{20}$ (Banks et al., 2015). Existing inequalities in education are likely to be exacerbated by school closures, the curtailment of support services and restrictions put in place during the COVID-19 pandemic - an issue that is discussed further in the sections that follow.

\subsubsection{School closures}

An unprecedented number of children and young people across the world are currently not attending school or did not attend school for a protracted period of time because of measures put in place by governments in an attempt to slow the

\footnotetext{
${ }^{20}$ These schools serving socio-economically disadvantaged populations are provided with additional resources through the programme, Delivering Equality of Opportunity in Schools (DEIS) - the Action Plan for Educational Inclusion.
} 
spread of COVID-19. According to Eurydice (2020) data, ${ }^{21}$ most European countries closed schools, at least temporarily (see also Chapter 1 ). Following school closures at the beginning of March 2020 in Italy, a country severely affected by COVID-19, several other countries followed suit by the end of March. Sweden and Iceland adopted social distancing and hygiene measures rather than mandating school closure. There has been much debate on the impact of school closures on virus spread (Viner et al., 2020; Rashid et al., 2015) and how this can be balanced against the potential long-term consequences of prolonged school closures, especially for disadvantaged groups (Zheteyeva et al., 2017; Andrew et al., 2020; Eyles et al., 2020).

With a dearth of current, published empirical studies, as the situation is still unfolding, much of the literature draws on previous research evidence on school closures due to summer breaks, previous pandemics and natural disasters or school strikes. There have been a number of research studies, mainly in the United States, on 'summer learning loss' (that is, the decline in skills because of a break from learning), with much of this work focusing on how summers contribute to race/ethnic or socio-economic (SES) gaps. Looking at primary school students in the US, a study by Atteberry and McEachin (2020) found that students, on average, do lose ground during the summer period in both maths and English, with a little more than half of students exhibiting such losses. The authors argue that these consecutive losses add up to a sizeable impact on the position of these students in the achievement distribution. Learning loss is a matter of concern as it is likely to contribute to the widening of the gap between advantaged and less advantaged students. Based on US data on the effects of summer learning loss, Kuhfeld et al. (2020) present various projections of COVID-19-related learning loss, indicating that, when schools resume in the autumn, students are likely to return to school with approximately 63-68 per cent of learning gains in reading and 37-50 per cent in maths relative to a typical academic school year. These are average estimates as some students are likely to experience less learning loss, depending on their previous academic achievement. Research on hurricane-related school closures also indicates losses in learning. For example, the displacement effect of Hurricane Katrina led to significant drops in achievement in the subsequent year (Sacerdote, 2012), and similar effects were found after other natural disasters (Pérez-Pereira et al., 2012; Tatsuta et al., 2015). Evidence on the effects of prolonged (or recurrent) school closures due to teacher strikes indicates a decline in test scores or grades among students (Baker, 2013; Jaume and Willen, 2019), with the greatest impact for more disadvantaged and lower-achieving students (Wills, 2014) and in disadvantaged schools (Johnson, 2011).

Recognising the severity of the prolonged school closures, governments across the world have put measures in place to enable the continued education of children

${ }^{21}$ See: https://eacea.ec.europa.eu/national-policies/eurydice/content/how-covid-19-affecting-schoolseurope_en 
and young people, with various degrees of success (Dreesen et al., 2020). The main approach has been to move teacher-led learning online (see Section 3.2.5). The situation caused by COVID-19 has exposed the uneven distribution across and within countries of technology that could be used to facilitate remote learning over a prolonged period (Dreesen et al., 2020) and the ability of some children to access learning remotely (Inclusion Ireland, 2020).

While the current situation is likely to have long-term consequences for all learners and their families, it will have a particularly detrimental impact on disadvantaged children (Burgess and Sievertsen, 2020), children in alternative care arrangements, care-leavers, children considered at risk due to their family situation, children experiencing poverty, children with disabilities, and migrant, asylum-seeking and refugee children (Larkins et al., 2020), who may find the alternative arrangements put in place by schools more challenging due to limited resources and lack of support. In Ireland, principals and teachers in DEIS schools report much lower levels of student engagement in remote learning than in non-DEIS schools during the period of school closure (Mohan et al., 2020; Bray et al., 2020). The current situation in its unprecedented scale is likely to exacerbate existing educational inequalities in society. In addition to the challenges associated with teaching and learning, education in the home is affected by other factors, including having a safe home environment, sensitive or responsive parenting (understood as family interactions in which parents are aware of their children's emotional and physical needs and respond appropriately and consistently) and food security (Conti, 2020).

School closures are also likely to affect the health and wellbeing of young children (see Chapter 4 for a detailed discussion) as they provide a place not only for learning but also food security. School lunches are associated with improvements in academic performance, while food insecurity (including irregular or unhealthy diets) is associated with low educational attainment and a negative impact on the physical health and mental wellbeing of children (Lancker, 2020).

\subsubsection{Participation in early-years education and care}

Early-years education has been found to have a strong impact on social mobility and to help narrow the attainment gap (Cullinane and Montacute, 2020). A representative study, Early Education Use and Child Outcomes (Melhuish and Gardiner, 2018), in the UK shows the positive impact of participation in early-years education on the cognitive and socio-emotional outcomes of children at four years of age. Better non-verbal reasoning ability and socio-emotional outcomes were found among those who spent more time in formal group settings (such as nursery classes and day nurseries). Language development was enhanced among those who spent more time being cared for by relatives and friends while more hours with childminders were associated with lower levels of emotional symptoms (ibid.). 
In Ireland, early childhood care and education for children of pre-school age is provided by the Early Childhood Care and Education (ECCE) Scheme. The scheme is available for children aged 2 years, 8 months until they transfer to primary school. Supported by state funding, the participating centres and playschools provide a pre-school service free of charge. Early-years care is also provided by relatives and childminders (see Chapter 2 for a more detailed discussion on childcare). Drawing on the Growing Up in Ireland study data, Russell et al. (2016) found that the impact of the type of childcare and hours spent in care at age three explained a very small proportion of variation in children's socio-emotional outcomes (less than 1\%), a finding different from that of the UK study discussed above. Rather, other factors, such as the child's health, gender, socio-economic background, family structure, and other family characteristics (such as parenting style and parental stress), had a greater impact on children's socio-emotional development. ${ }^{22}$ The authors also found greater difficulties among boys, children living in households experiencing financial difficulties and those living in less safe neighbourhoods.

On 12 March 2020, all early-years providers in Ireland closed due to COVID-19, and the responsibility of providing early learning opportunities fell predominantly onto parents. Chapter 2 has discussed available evidence which suggests that gender inequalities in care responsibilities have increased during the period of the pandemic restrictions. The situation is likely to have a more severe impact on essential workers. The latter group make up more than 22 per cent of workers in Ireland, while health professionals make up 7 per cent of the workforce (Redmond and McGuinness, 2020a). Just over half of essential workers have children while 9 per cent are lone parents - higher than the 5 per cent national rate. A Government scheme to provide childcare in the homes of some 5,000 essential workers was announced in May. However, due to logistical difficulties, the take-up was too low for the scheme to be viable and it was cancelled. In addition, social distancing and cocooning measures have made it impossible to avail of relative or grandparent care. Early-years providers resumed operations on 29 June 2020 but it is as yet unclear how many centres have reopened, or what is the reduction in the number of places available.

\subsubsection{Home-schooling and related challenges}

Educating their children at home has been a choice made by some parents around the world, a process made easier by rapidly developing digital technologies. The number of children who were home-schooled by choice in Ireland before the COVID-19 outbreak was small - just under 1,500 in 2019 (see Doyle, 2020). Due to the COVID-19 restrictions and school closures, the onus of supporting children's

\footnotetext{
${ }^{22}$ In this study, socio-emotional outcomes were assessed based on their prosocial skills (e.g. sharing, kindness to younger children) and socio-emotional difficulties (e.g. conduct problems, emotional difficulties, hyperactivity/inattention and peer problems), measured using the Strengths and Difficulties scale, as reported by their mothers and teachers.
} 
learning is now on parents and carers. Evidence from the pre-COVID-19 period indicates a high level of involvement of parents in Ireland in supporting their child's formal learning ${ }^{23}$ through attending parent-teacher meetings and helping their child with their homework. GUI data shows that just over half of parents reported 'always' or 'nearly always' helping their nine-year-old child with homework, while another 20 per cent did so 'regularly' (Williams et al., 2018). This was common across all social groups, but somewhat less prevalent among more disadvantaged groups. A substantial change is evident as young people make the transition to second-level education, with just 8 per cent of 13-year-olds' primary caregivers providing homework assistance 'always' or 'nearly always', and 15 per cent doing so regularly. The most frequent reasons given for 'never' helping were that the 13year-olds did not need or want assistance. Families were more likely to help with homework where the 13-year-old had a special educational need (Smyth, 2017).

While parents have always played an important part in the education of their children, their role has been complementary to that of the school. With COVID-19 restrictions in place in all areas, it is likely that prolonged learning in the home will be more challenging for some families (e.g. more disadvantaged groups, children with SEN, migrant children) regarding the extent to which they are in a position to assist their child's learning or have the resources and skills to do so. The age of the child and the stage of their schooling also play a role in the input required from the parents.

In Northern Ireland, an online survey based on a convenience sample of just over 2,000 parents'/carers' experiences of home-schooling during the COVID-19 school closures revealed that parental education level had a significant impact on the experience of home schooling. Parents with higher levels of educational attainment were more likely to teach their children directly or actively support their learning (Walsh et al., 2020). This study indicated that three parents in five reported that their children's level of motivation to learn had deteriorated. The authors also found that age of children tended to be a factor regarding their reaction to home-schooling. While older children were more likely to prefer learning in school, younger children preferred the home environment. Two UK studies reached very different conclusions on the scale of parental investment in home-schooling, with much more time spent on home-schooling in the study based on a convenience sample (Andrew et al., 2020) than on a nationally representative study (ONS, 2020). A study by the Institute for Fiscal Studies (IFS), ${ }^{24}$ using a large convenience sample (albeit reweighted), found that families in the highest-fifth income category spend 5.8 hours a day on educational activities, compared to their peers in the poorest fifth of households ( 4.5 hours). The authors

\footnotetext{
${ }^{23}$ The crucial role of parents in their child's informal learning is discussed in Section 3.4.

${ }^{24}$ The study is based on an online survey of 4,157 parents in England with children in eight different school years aged between 4 and 15 . The respondents were diverse in terms of their gender, education, region, marital status and work status. The data were reweighted to ensure that the study was representative of parents and children in England as a whole.
} 
concluded that, if schools remain closed for at least 34 days, students in the more affluent families would gain more than seven full school days' worth of extra learning time (Andrew et al., 2020). This study indicated that secondary students were more likely to take part in online lessons than those at primary level. Many parents (almost $60 \%$ for primary students and almost half for secondary students) reported finding it hard or very hard to support their children's learning. Using a smaller but representative sample, the Office for National Statistics (ONS, 2020) found that home-schooled children spent an average of 11 hours learning per week. The most common resources used were digital devices provided by parents (73\%), school-provided digital resources accessed through online learning platforms (61\%), and digital online learning resources found by parents (49\%). Around four in ten (39\%) adults with dependent children said their children were struggling to continue their education because of lack of motivation, lack of guidance and support, and parental capacity to support them. The Andrew et al. (2020) study found that parents with lower levels of educational attainment (below degree level) reported lower levels of confidence in managing home-schooling, while essential workers were least able to spend time on home-schooling their children. The ONS study did not provide a breakdown by family characteristics.

The most systematic evidence to date has been based on the nationally representative UK Understanding Inequalities data which, unlike other studies, distinguishes between educational levels in reporting the patterns found (Benzeval et al., 2020). The time spent on schoolwork varied by level, with 12 per cent of primary students spending four or more hours per day compared with 28 per cent of secondary students and 23 per cent of those in post- 16 education. ${ }^{25}$ Parental involvement also varied markedly across levels, with 45 per cent of parents helping primary students for two or more hours a day compared with 14 per cent doing so at secondary level and only 2 per cent having such involvement for post-16 students. Most students received offline work (such as assignments or worksheets) from their school but only 32 per cent had one or more live online lessons per day.

A survey by Amárach in Ireland (see Doyle, 2020), carried out about three weeks into lockdown, revealed little difference in the time spent on home-schooling by parents' education. Parents with both higher (post-graduate/degree level) and lower levels of education reported spending 1-2 hours per day home-schooling their children. However, some parents (about one-fifth) spent less than 30 minutes on teaching their children. As Doyle argues, these figures are substantially less than a typical school day and bring time lost sharply into focus. It is important to note that these results do not differentiate between primary and second-level schools. The situation could be rather different for both sectors, especially given preCOVID-19 patterns of differential involvement of parents in helping with

\footnotetext{
${ }^{25}$ Post-16 education includes all post-16 learning; that is, A-levels, further education, vocational training and work-based learning.
} 
homework/study. Another survey conducted by Amárach on 2 April (see Doyle, 2020) indicated that there is a universal concern among parents across different social classes about the impact of home-schooling on their children. The CSO (2020b) study showed that 46 per cent of those in households with dependent children were extremely or very concerned about the pandemic's interruption of education, and a further 43 per cent were somewhat concerned. Levels of 'extreme' concern were more than twice as high among those living in the most disadvantaged areas. School closure will also have affected access to additional support for some groups of students provided through schools, including literacy/numeracy supports through the DEIS programme, learning supports and supports for those for whom English is a second language.

Next to disadvantaged families and children, long-term home-schooling is also particularly likely to affect students with special needs (Mohan, et al., 2020). A survey conducted based on a convenience sample by Inclusion Ireland (2020) shows that some children with behavioural issues, intellectual disability or with poor attention skills find home-schooling difficult, requiring support from a skilled teacher, rather than a parent (Inclusion Ireland, 2020). In many cases, there are also other children in the family whose needs must be catered for. In addition, since COVID-19 restrictions have been put in place, a large proportion of HSE therapy appointments have been cancelled/rescheduled or moved to a virtual appointment where possible. Furthermore, many referrals come through schools or TUSLA and have stopped. Considering these issues, for many children with disabilities getting back to school will be challenging.

While there is currently little empirical evidence available on migrant/refugee/asylum-seeking children, it is likely that their education may equally be compromised under the current conditions (You et al., 2020). In fact, many refugee children have already had disrupted education, and are thus now likely to fall even further behind. Many are likely to have difficulties rejoining education due to their lack of educational technology and thus opportunities to engage in online education (Save the Children, 2020). A school's ability to provide opportunities for distance learning significantly affects the learning engagement and academic progress of students (Mohan et al., 2020). A study in the UK shows that school provision for distance learning fully explains the gap between children of Pakistani and Bangladeshi heritage and their peers (Bayradkar, et al., 2020).

Changes to the home environment due to parents and guardians working from home, uncertainty about state examinations, and personal issues were seen as having a considerable impact on individual situations in an online convenience sample survey of parents of second-level students (NPCPP, 2020). In several jurisdictions, the government cancelled state exams, and student grades that determine their university entrance have been decided by entirely new systems of school-based assessments. There is some concern that the system to award grades 
in lieu of exams risks disadvantaging students from lower socio-economic backgrounds (Cullinane and Montacute, 2020). In Ireland, after some deliberation, Junior Certificate exams were cancelled, while for Leaving Certificate exams a decision was made to postpone the Leaving Certificate and to offer students a system of calculated grades. ${ }^{26}$ Calculated grades are based on school reports of students' performance, adjusted to take account of national data on students' performance in examinations over a period of time. ${ }^{27}$ Second-level principals report considerable stress and challenges around motivation and engagement among students over the uncertainty in relation to state exams, especially in DEIS schools (Mohan et al., 2020).

\subsubsection{Home-school links to support student learning}

As a response to school closures for an undetermined length of time, principals and teachers have had to act swiftly to ensure continuity of education for their students. In Ireland, an Amárach survey on 6 April (see Doyle, 2020) found that most parents reported receiving text messages or emails (80\%) from their child's school, and more than a half were receiving resources directly from the teacher. ${ }^{28}$ However, only about a quarter of children were accessing virtual classes and onethird were communicating with their teachers through educational apps which allowed teachers to assign work and share videos/documents, and students to upload assignments. Children of parents with lower levels of education were significantly less likely to report receiving resources from their teacher, use educational apps, and use RTE's Home School Hub.

Research on Irish primary schools (see Burke and Dempsey, 2020; Dempsey and Burke, 2020) shows that over 70 per cent of them reported putting in place measures to contact their students daily or every other day. In line with Doyle (2020), the authors report that most schools relied mainly on email, as well as various online platforms. However, the persisting digital divide makes the delivery of communications and distance learning challenging. At second level, principals have reported schools using live online videos and virtual platforms but pointed to challenges in using technology in areas characterised by lower coverage of highspeed broadband and lower average household income (Mohan et al., 2020). The abrupt transition to remote learning affected some activities more than others, with group work and practical work (generally seen as more engaging by students) suffering more. This was especially evident in DEIS schools and in areas with low high-speed broadband coverage and/or lower incomes (Mohan et al., 2020).

There are disparities in education practice between countries and between schools

\footnotetext{
${ }^{26}$ At the time of writing, it is not clear how many students from the current cohort will choose to sit their postponed Leaving Certificate exams or may repeat the school year. The latter will have implications for the resources needed by second-level schools.

${ }^{27}$ See: www.gov.ie/en/publication/06a3c-calculated-grades-a-guide-for-leaving-certificate-students-2020/

${ }^{28}$ It is worth noting that these analyses do not distinguish between primary and second-level students.
} 
within jurisdictions. While live online classes are used by some countries, they are relatively rare in others (see Markowska-Manista and Zakrezewska-Oledzka, 2020, on the Polish context). Live interaction with teachers, even on a weekly basis, was listed as the most desired support by parents in Northern Ireland. Studies in the UK, largely based on convenience samples, found significant differences between schools in their provision of online classes. Students in private schools were much more likely to have daily online classes and access to online videoconferencing with teachers (Andrew et al., 2020; Cullinane and Montecute, 202029). Even in state schools, higher-income parents were more likely than low-income parents to indicate that their children received active help from the school (Andrew et al., 2020; Cullinane and Montecute, 2020). In China, a government programme, 'School's Out, But Class's On', 30 to provide guidance to elementary and middle school teachers and children on how to study online was made available across schools. The programme highlights the importance of parents in educating their children during the lockdown, with schools working in close cooperation with families and providing guidance (Xia, 2020). One middle school in Changyuan County, Henan Province adopted a six-step teaching approach to guide students' learning at home, whereby parental supervision was guided by the teachers (Cai and Wang, 2020). However, teachers' approach to providing online learning material was found to vary, despite guidelines (Zhou et al., 2020).

Providing distance education for young people has been challenging for teachers and school principals. However, a study in Ireland (see Mohan et al., 2020) showed that teachers and principals made every effort to respond to the challenge by moving to distance learning; schools that already had some online systems in place were in a better position to accommodate the change. However, the study also points to barriers to distance learning, including the skills and confidence of teachers in providing online learning opportunities, as well as variation between DEIS and non-DEIS schools in access to digital devices, and differences between urban and rural areas in the availability of high-speed broadband. Some parents in Poland called for training for teachers in the use of digital tools and criticised instances where only homework was being set for children, in the absence of online platforms (Markowska-Manista and Zakrezewska-Oledzka, 2020). The need for support for teachers to deliver distance education has also been highlighted in Ireland (Dempsey and Burke, 2020a; Mohan et al., 2020). In addition, the workload of primary school principals has been found to have increased, particularly among teaching principals, who reported lower levels of wellbeing across all dimensions when compared with administrative principals (Dempsey and Burke, 2020a).

\footnotetext{
${ }^{29}$ The responses are provided by a Teacher Tap Survey that collects online responses from over 7,000 teachers several times a week. See: https://teachertapp.co.uk/monitoring-covid-19-readiness-in-schools/

30 The concept originated from a series of documents from the Chinese Ministry of Education that highlighted the need of teachers to continue education online, including teaching, tutoring and homework corrections. See also: http://scineer.bonoi.org/sites/default/files/files/Article1-SIEF-V5N2-31March2020-XQC.pdf
} 


\subsubsection{Parental satisfaction with support from schools}

While several studies have explored the home-school interface and studentteacher interaction, there has been a dearth of research exploring parents' satisfaction with the practical educational support their children received from schools before the pandemic. In Northern Ireland, some evidence has emerged in the area of special educational needs, indicating relatively high levels of satisfaction, especially in relation to keeping parents informed about their child's progress (Armstrong et al., 2010). Since school closures, the Department of Education and Skills (DES) has issued guidelines for ensuring continuity of learning to schools and included a number of resources on its website, and Education Centres across the country have been playing a role in providing online support and training to teachers. Much of the current support and education is delivered from teachers' own homes. Variability in access to high-speed broadband, digital devices and the skills to deliver online learning is likely to affect the delivery of teaching to children, who, in turn, may be affected by similar challenges. Communication between teachers and children varies by social class; children of parents with lower levels of education are less likely to receive resources from their teacher compared to higher-educated parents and, among those receiving such resources, textbooks are less likely to be received by less advantaged families. A survey based on a convenience sample of parents of students in junior and senior cycle indicated that an overwhelming majority (94\%) of young people were using a combination of textbooks and digital tools during home-schooling and nearly all (99\%) received communications in relation to continuing education at home either via school email, text message or some digital platform (NPCPP, 2020). Most parents and guardians (79\%) in this online survey had experienced no difficulties in communicating with schools. A range of technological devices were being used, including laptops, tablets and mobile phones, and most young people $(80 \%)$ had unlimited access to their devices and had no issues with broadband. ${ }^{31}$ However, 30 per cent of households still experienced issues with connectivity.

A recent volunteer survey of parents in Ireland (also based on a convenience sample) has shown that the support children with special educational needs receive from the school/teacher tends to vary, with 35 per cent of parents reporting as a barrier to home education both a lack of access to suitable educational materials and a lack of clarity on what is expected/lack of guidance (Inclusion Ireland, 2020). Some children have daily classes via online platforms and access to educational materials and digital materials from their teacher, while others have limited or no contact or provision of learning opportunities. Parents report finding it challenging to provide education to children with special educational needs while also trying to work from home, work on the front line and isolate at home, or care for other children or elderly adults (Inclusion Ireland, 2020). Challenges in delivering remote teaching were also reported by principals in

\footnotetext{
${ }^{31}$ As discussed in Chapter 1, the self-selected nature of the sample may mean that the picture provided is overly positive.
} 
special schools (Burke and Dempsey, 2020). To ensure that COVID-19 does not exacerbate educational inequalities further, it is important that resources be in place to support all families, especially those with more disadvantaged backgrounds and those with special educational needs.

In the UK, a study based on a convenience sample shows that the extent to which parents were confident in providing home learning varied by parental levels of educational attainment. More than three-quarters of parents with a postgraduate degree and just over 60 per cent of those with an undergraduate degree felt confident directing their child's learning, compared to less than half of parents with A-level or GCSE-level qualifications (Cullinane and Montecute, 2020). The input parent felt they needed from schools included live teaching and pre-printed resources. Live interaction with teachers, even on a weekly basis, was listed as the most desired support.

\subsubsection{Learning resources in the home}

To deliver meaningful home-schooling, parents and carers need to be supported by schools and teachers (see above) and have the resources and skills to do so. The Growing Up in Ireland study provides insights into the educational resources (e.g. access to books, computer) already present in the family home, indicating that access to such resources differs by family social class and educational background (Williams et al., 2009).

Evidence emerging at the time of the COVID-19 restrictions shows that primary school principals report that some children are unable to engage with distance learning due to lack of access to devices and/or broadband, and they express concerns about some children staying at home without the supports they usually receive in school (Burke and Dempsey, 2020). In Northern Ireland, Walsh et al. (2020) note that many families have serious difficulties in supporting their child's learning over a prolonged period due to the lack of or limited digital resources (e.g. printers, computers, slow broadband). COVID-19 has revealed a digital divide between learners globally. Technological inequalities exist between and within countries. While in most developed countries most students could be considered 'digital natives', having been consistently exposed to digital technologies, the extent to which young people have access to online learning tools and devices outside school varies (Burke and Dempsey, 2020; Larkins et al., 2020). When schools move to e-learning full-time, the digital divide widens between disadvantaged and better-off schools and families (Eyles et al., 2020). A study in Poland showed that 45 per cent of children have their own computers, indicating that 55 per cent of children in the families from the research sample were unable to work on the tasks sent by teachers in real time or have to share the computer with their parents (who also frequently work online) and their siblings during the pandemic restrictions (Markowska-Manista and Zakrezewska-Oledzka, 2020). Students can only benefit from online learning when they have access to high- 
speed broadband at home and at school and access to digital devices. Ireland's National Digital Strategy saw increased investment in a national rollout of highspeed broadband to all second-level schools in the country. While access to highspeed broadband benefitted the teaching and learning experience in schools, ICT use tended to vary between DEIS and non-DEIS schools (McCoy et al., 2016). A representative study of Irish second-level schools has highlighted a continuing digital divide in Ireland (Mohan et al., 2020). The authors found that nearly half of the schools in the study have experienced difficulties with both high-speed broadband and digital devices. As in the study by McCoy et al. (2016), the issues were more prominent in DEIS schools. Access to digital devices in the home also varied.

In line with international and previous Irish research, GUI study data (Cohort '08, wave 5 ) show that access to technology varies by social class; children growing up in higher social class families are significantly more likely to have access to a laptop or computer at home. While 71 per cent of children from professional families have access to these devices, only 44 per cent of those whose parents were never employed do so. The findings are in line with those from the UK, showing that, in the most disadvantaged schools, 15 per cent of teachers report that more than a third of their students would not have adequate access to an electronic device for learning from home, compared to only 2 per cent in the most affluent state schools (Cullinane and Montecute, 2020). Access to technology also varies by family structure (lone parents) and income levels in Ireland. A small percentage (2\%) of households do not have any access to the internet. This is supported by a survey by Inclusion Ireland (2020) of parents of SEN students, showing that a small group of children do not have access to any form of technology to engage in virtual/online schoolwork. In addition, online education was not deemed suitable for children with complex needs who cannot access education unless it is provided in person.

International studies have also indicated that children living in less advantaged families often lack a quiet place to study. Lancker (2020) notes that children from lower-income households are likely to struggle to complete homework and online courses because of their precarious housing situations. This is borne out by the GUI data which show that nine-year-olds from lower-income families are more likely to live in accommodation that is not suitable for family needs; 15 per cent of older students (aged 17) do not have their own bedroom. Lack of private space varies by social class, with those from semi-unskilled families or where the parent(s) were never employed more likely not to have their own bedroom. The situation is exacerbated by the closure of libraries and other public spaces that young people could use to study.

Inequalities in support and resources among families are reflected in the amount and quality of work received back by teachers. Cullinane and Montecute (2020) show that 50 per cent of teachers in private schools in England report they are 
receiving more than three-quarters of work back, compared with 27 per cent in the most advantaged state schools, and just 8 per cent in the least advantaged state schools. Twenty-four per cent of teachers report that fewer than 1 in 4 children in their class are returning work they have been set. Teachers in the most disadvantaged schools are also more than twice as likely as those in advantaged schools to report that work their students are submitting is of a much lower quality than before ( $15 \%$ vs $6 \%)$. When asked how to mitigate against some students falling behind, most teachers recommended the provision of digital devices or stationery and curriculum resource packs to compensate for lack of access to computers and other technological devices.

\subsubsection{Further and higher education}

Further and higher education institutions (HEIs) have also moved to online learning during the pandemic restrictions (the specific situation of apprentices during the pandemic is discussed further in Chapter 5). At present there are no studies available in the Irish context to assess the impact of the pandemic on the student experience. A synthesis of information on 20 countries shows similarities as well as variation in the approach taken in higher education. While some jurisdictions have opted for a country-wide closure of institutions, others have adopted less stringent measures. In all cases the focus has been on providing opportunities for online teaching and learning (Crawford et al., 2020). In Ireland in March, contingency plans were drawn up across HEls, which included delivering classes to students online and conducting exams over the internet. However, the same difficulties are likely to be experienced as in other sectors with regard to the digital divide (Sahu, 2020). Furthermore, while HEls had typically used online platforms for delivering and planning courses, commentators emphasise the distinction between online learning and emergency remote teaching (see, for example, Hodges et al., 2020), where courses planned for face-to-face teaching had to be quickly redirected to virtual provision. The transition to an online mode has posed challenges for staff in dealing with the existing technology to deliver lectures and tutorials. Computers and other IT equipment are now likely to be in heavy demand from all who are learning or working from the home - posing a challenge for both delivering learning material as well as students learning at home. As with other sectors in the education system, there is a danger that some students will be adversely affected by the digital divide. In addition, the type of learning in HEls differs, with particular issues about how to deal with lab work, practicals, music or art courses online (Sahu, 2020). Furthermore, the move from face-to-face teaching to online delivery may have a serious impact on assessment and evaluation. Closed campuses also mean no accommodation for some students and particular difficulties for international students. This stress may lead to unfavourable effects on the learning and psychological health of students. Based on cluster sampling, a survey of Chinese HEl students (see Cao, 2020) found that economic factors as well as delays in studies were associated with anxiety symptoms in students. At the same time, further and higher education students are more likely to be self-directed learners 
and require less frequent contact time with their lecturers and tutors, which may protect them from some of the negative effects experienced by younger students.

\subsection{LEARNING OUTSIDE SCHOOL}

Previous sections have discussed educational inequalities in Ireland and the way in which school closure has likely contributed to a growing gap in outcomes between more and less advantaged children and young people. Parents have been coping with the new challenges of home-schooling but, even prior to the pandemic, were the foundation of their children's learning from infancy onwards. This section draws on GUI data to look at children's learning outside school, and, in particular, aspects of the home learning environment (such as reading and engaging in other cultural activities) and participation in structured cultural activities such as music and drama lessons or clubs.

There is clear social differentiation in children's exposure to, and engagement in, cultural activities. Children in more advantaged families are more likely to be read to (when younger) and to read for pleasure in middle childhood, adolescence and early adulthood (Smyth, 2016b; Smyth, forthcoming). Gender differences are also apparent, with girls more likely to read for pleasure than boys. Those in more advantaged families are also more likely to be taken on cultural outings and to visit the library. Similarly, participation in structured cultural activities (such as music or drama classes) varies markedly by family background and gender. There is a clear social gradient in involvement, with children from professional/managerial, highly educated and higher-income families more likely to take part. As the majority of such activities are paid for, income acts as a barrier to participation; there are higher levels of involvement among those in the top two income quintiles (fifths). Involvement in structured and unstructured cultural activities (such as reading) is found to be associated with improved academic skills and performance among children and young people (Smyth, 2016a; Smyth, forthcoming; McGinnity et al., 2017).

Schools emerge as an important arena for access to cultural activities within and outside the curriculum, especially at second level where many schools offer music or drama classes after school (Smyth, forthcoming). By 17 years of age, the strong emphasis in DEIS schools on providing extracurricular cultural activities appears to have eliminated the gap with non-DEIS schools in participation in structured activities; this also seems to have led to this group of young people having a more positive view of the value of their education in enhancing their appreciation of art and culture (Smyth, forthcoming).

To date, there has been no systematic evidence on changes in the frequency of children reading for pleasure, painting/drawing or making music at home, though 
research is underway at Yale University ${ }^{32}$ looking at potential changes in the reading skills of children in the early years of elementary education. Two Irish studies based on volunteer samples have collected information on changes in reading and other activities during the period of pandemic restrictions. Barron and Emmett (2020a) found that a significant minority - four in ten children - reported an increase in reading for pleasure but the majority reported an increase in screen time (especially watching TV/Netflix/films and using Zoom). Egan (2020) also found an increase in screentime, with 30 per cent reporting an increase in reading. The pre-pandemic patterns found in participation in cultural activities suggest that, with the closing of early-years centres and schools, socio-economic and gender inequalities will have grown in children's access to reading and other cultural pursuits, although this might drop off over time. This is especially the case for adolescents attending DEIS second-level schools where school-based provision had helped to close the gap with non-DEIS schools in taking part in structured cultural activities and valuing the role of arts and culture in their lives. Given the relationship between cultural participation and academic development, it is likely that school closures will have contributed to an increasing gap in informal as well as formal learning. As with sports participation (see Chapter 4), there is a risk that an interruption in involvement in structured cultural activities may accelerate the decline in attendance found between 9 and 17 years of age. However, considering the greater reliance of middle-class parents on structured organised activities, which have been curtailed during the COVID-19 related restrictions, the gap between disadvantaged and more advantaged groups resulting from participation in these activities may have narrowed somewhat.

\subsection{SUMMARY}

The available evidence provided in this chapter indicates that school closures and the move to online learning will have the greatest impact on disadvantaged families and their children. While school closures have been needed in the short term, to limit the spread of the virus, policymakers and schools need to put measures in place to counter the negative impact on learners, families and teachers, especially for those in the most marginalised groups socio-economically disadvantaged, families with SEN children, migrants, refugees and others) who lack the resources or skills to engage with home-schooling.

What is to be learned from the world-wide pandemic is that all schools need to (a) have a plan in place to ensure continuity of operations that, while focusing on progress for all students, has specific supports targeting the most vulnerable groups, and (b) ensure that school principals and teachers are supported in delivering learning during challenging times (Reimers and Sleicher, 2020).

\footnotetext{
32 Ongoing study, 'Unintended consequences of COVID-19 responses on family well-being and child safety'. At the time of writing, there was no output yet from the study.
} 
Government departments need to work together to provide guidelines that reflect the realities in schools and protect learners' educational opportunities (Reimers et al., 2020). In Ireland, plans have been put in place for a July programme for children with SEN and provision for disadvantaged children in order to avoid the gap between children getting larger.

School closures increase educational inequalities and exacerbate pre-existing social inequalities. The evidence indicates that, during the pandemic restrictions, students from more advantaged families are spending longer on learning in the home, are more likely to have access to a private space, digital equipment and learning resources, and have a better home set-up for distance learning supported by parents (Doyle, 2020; Andrew et al., 2020; Lancker, 2020). COVID-19 has laid bare the difficulties experienced by some families in supporting their children's education. Over and above the educational challenges, more disadvantaged families face an additional threat as countries enter recession. Previous recessions have exacerbated levels of child poverty, with long-lasting consequences for children's health, wellbeing and learning outcomes (Cantillon et al., 2017). In addition to formal education, learning outside school is also severely affected, with limited options available to young people, especially those from disadvantaged backgrounds.

The consequences of closures of childcare and education establishments potentially extending to the 2020/2021 school year will be challenging for both learners and education providers. Recent policy challenges have included issues concerning grading and assessment of progress and providing alternative learning arrangements. As the current situation presents considerable challenges to teachers, students and families, it is essential to take all necessary steps to address deepening educational inequality. Research evidence from Ireland (see Mohan et al., 2020; Barron and Emmett, 2020c) indicates that the pandemic has had a particularly adverse effect on more vulnerable groups of children and young people. How the current situation is going to play out in the long term is hard to assess as, considering its scale and duration, there is no directly comparable precedent. However, it is likely that, while the pandemic has some impact on the outcomes of all children, the gap between the advantaged and less advantaged is likely to widen as it will be harder for the more vulnerable groups to 'catch up'. These groups are likely to need additional supports when schools and further/higher education institutions resume later in the year. In addition, further assistance and support is needed for teachers and educational institutions to address and counter the widening gap between learners. The current situation provides an opportunity to assess the impact of school closures in future research. 



\section{CHAPTER 4}

\section{Physical and Mental Health and Wellbeing}

\subsection{INTRODUCTION}

This chapter looks at the implications of the COVID-19 pandemic and related restrictions for policy on the physical and mental health and wellbeing of children and young people. Section 4.2 focuses on physical health, examining general health and the presence of long-standing conditions, physical activity, and diet and obesity. Section 4.3 examines the evidence on socio-emotional wellbeing and mental health before and during the pandemic, drawing on emerging studies in Ireland and internationally on the psychological effects of societal changes.

\subsection{PHYSICAL HEALTH}

\subsubsection{General health and long-standing conditions}

Children and young people in Ireland are generally described, and describe themselves, as healthy, but a significant minority have long-standing illnesses, conditions or disabilities. The prevalence of such conditions increases from early childhood ( $16 \%$ of 3 year olds) to middle childhood ( $24 \%$ of 9 year olds), with asthma and eczema the most commonly named conditions at this stage (Watson et al., forthcoming). The prevalence declines somewhat into adolescence and early adulthood (19\% at 13 years and $13 \%$ at 17 years), though for this age group mental or behavioural disorders (including ADHD, anxiety/stress, depression and autism) become the single largest category (McNamara et al., forthcoming). Across all ages, males are more likely than females to have a long-standing condition or disability while there is a marked social gradient in prevalence; those from families with low levels of education and income are more likely to have such a condition (McNamara et al., forthcoming; Watson et al., forthcoming). The All-Ireland Traveller Health Study indicates that Travellers rate their children's health positively but Traveller children are more likely than the general population to have hearing, sight or speech problems (Abdalla et al., 2010). As a result of these differences in the prevalence of long-standing conditions and levels of general health, usage of GP and other medical services tends to be greater among more socio-economically disadvantaged children and young people (Nolan and Layte, 2014; McNamara et al., forthcoming; Watson et al., forthcoming), although takeup levels of some preventative services such as vaccinations have been lower among these groups (Doherty et al., 2014).

Similar socio-economic gradients are evident in children's dental health, with, for example, nine-year-olds from the lowest-income households more likely to have only fair or poor dental health (12\% compared with $7 \%$ ) and to have had teeth extracted (11\% compared with $6 \%$ ) than those from the highest-income group (GUI 
Cohort '08, own analyses). Differences are even greater in the usage of dental services; 70 per cent of the highest income group visit the dentist at least once a year compared with just 49 per cent of the lowest income group.

The COVID-19 pandemic led to a redirection of acute and primary care services to dealing with the crisis, and to the cancellation of elective procedures. Fear of transmission appeared to contribute to a reluctance to attend hospital emergency departments (EDs), with a 45 per cent drop in attendance over a one-month period (Brick et al., 2020a). The largest reductions in attendance were for the youngest age groups, with a drop of 39 per cent for the under-10s and 49 per cent for those aged 10-19 years. Data on GP attendance in Ireland are not yet available but, given the figures for ED attendance and the marked declines in GP attendance seen in England, ${ }^{33}$ could be expected to have had comparable declines during the period of restrictions, in the context of the use of remote consultations to triage patients for in-person visits and the likely reluctance of parents to expose their children to the risk of transmission. Lack of contact with health services is likely to have resulted in a reduction in continuity of care for people with chronic illness and, given the socio-economic patterns discussed above, will have disproportionately affected more disadvantaged groups. The National Treatment Purchase Fund data indicate an increase in the numbers on hospital waiting lists, which is likely to result in delayed access to services even after restrictions ease, particularly for those without private health insurance. The limiting of dental services to emergency procedures during the pandemic will have delayed access to preventative visits for children and young people, with potential longer-term consequences for dental health. It is likely that the economic shock caused by the pandemic will have longerterm implications for children's health if the recession is sustained, given evidence that a reduction in parental income and/or working hours is associated with increased child health problems (Reinhard et al., 2018).

As well as affecting formal learning (see Chapter 3), school closures have constrained access to some supports for children and young people with special educational needs, given the role of the school as a site for provision of support and/or as a source of referral to specialist services. GUI data show that, among all 13 year olds from Cohort '98, for example, 9 per cent were in receipt of resource teaching and 2 per cent had a Special Needs Assistant (SNA). With school closures, children with special educational needs have not been receiving these additional supports (see Chapter 3). Access to broader therapeutic services has also been affected. For five-year-old children, 17 per cent of parents had concerns about how the child talked or made speech sounds, though over 40 per cent had not received any treatment or support for this issue (GUI Cohort '08, own analyses). The restriction of services during the pandemic is likely to have lengthened the waiting

33 https://digital.nhs.uk/data-and-information/publications/statistical/appointments-in-general-practice/april2020. 
lists ${ }^{34}$ for access to speech and language therapy - which is a matter of concern given the impact of speech difficulties on later academic and socio-emotional outcomes (McLeod et al., 2016).

\subsubsection{Physical activity}

For younger children, physical play tends to be unstructured in nature, involving playing chasing, riding a bicycle or tricycle and playing ball games, with greater involvement among lower-income groups and boys (at 5 years of age) (Murray et al., 2019). As they move into middle childhood and adolescence, structured sports activities play an increasingly important role, with relatively high levels of involvement in team and individual sports (Watson et al., forthcoming). In contrast to the pattern for unstructured play at younger ages, involvement in either kind of sports is lower among children from more disadvantaged families. In addition, team sports participation is much lower among girls than boys. There is a fall-off in participation in team sports between 13 and 17 years of age, a pattern consistent with previous research looking at team sports participation over the life-course. Involvement is found to peak in adolescence (at age 15 ) and show a rapid decline in the late teens around the point of leaving school (Lunn, 2010). In adolescence and early adulthood, high and continued involvement is greater among males and those from higher-income groups.

In spite of relatively high levels of participation in organised sports, significant proportions of children and young people in Ireland do not meet the threshold specified by guidelines for physical activity. Only a quarter of nine-year-olds are meeting WHO guidelines for physical activity, and those from lower-income households and girls are less likely to do so (GUI Study Team, 2018a). There is a drop-off on average in the levels of 'hard exercise' (that makes the heart beat faster) between 9 and 13 years of age (Williams et al., 2018). At 17 years of age, over a third (35\%) are not meeting the (less stringent) adult guidelines for physical activity, with variation by gender and socio-economic background $(43 \%$ not meeting guidelines in the lowest income group compared with $29 \%$ in the highest group) (McNamara et al., forthcoming).

GUI research points to school as a key domain for engaging in physical activity. As well as the provision of Physical Education (PE) in the curriculum, extracurricular sport is an important feature of primary and second-level schools. Almost fourfifths $(78 \%)$ of nine-year-olds were in schools where $\mathrm{PE} / \mathrm{sports}$ were seen as an important extracurricular activity. At second level, almost all (99\%) young people attended a school where team sports were offered as an extracurricular activity while 82 per cent were in schools where individual sports were offered (Nolan and Smyth, 2020). School closure and the suspension of structured sports activities are

\footnotetext{
34 In December 2019, 19,000 children and young people were on waiting lists for speech and language therapy (Irish Times, 6 December 2019).
} 
likely to have had a significant impact on activity levels among children and young people. To date, no systematic evidence has become available but insights can be derived from surveys of the adult population as well as inferences from prepandemic access to facilities. The CSO (2020b) nationally representative survey on the Social Impact of COVID-19 indicated that 95 per cent of adults reported taking exercise; of these, 32 per cent said their level of exercise had decreased while 37 per cent stated it had increased. A decrease in levels of exercise was most commonly reported by those in the oldest and youngest age-groups (53\% of those over 70 and $36 \%$ of those aged 18-34). In a random survey of adults, Ipsos MRBI (Sport Ireland, 2020) found an increase in the proportion who engaged in recreational walking over the previous seven days compared to the pre-restrictions period, but a decrease in participation in sport. Among sports, increases were reported for running, cycling and lifting weights, with reductions for the other categories. Post-restrictions participation in sport was highest among the youngest age-group (15-24). Declines in sports participation between the pre- and postrestrictions periods were greater for women and for those from the lower socioeconomic groups. Since no information was collected on the intensity or frequency of participation in sports and other activities, inferences cannot be made about the proportions meeting WHO-recommended thresholds for physical activity.

There has been little research internationally on the effects of the restrictions on children's physical activity, though Guan et al. (2020) refer to two small-scale studies (in China and South Korea) which suggest increased sedentary activity during lockdown. However, earlier international studies show that children tend to spend less time on physical activity during the summer holidays (Brazendale et al., 2018; Olds et al., 2019). The only information on changes in physical activity among children and young people in Ireland in the period since restrictions were introduced is from two volunteer surveys. Egan (2020), in a survey of over 500 parents of 1-10 year-olds, found that three-quarters of parents indicated that their children had played outside more during the lockdown and the vast majority (90\%) had engaged in sports or physical activities at least three times a week. In a volunteer survey of over 1,500 parents of children aged 4-13 years, Barron and Emmett (2020a) found that over a third of children had spent less than 30 minutes in physical activity in the previous 24 hours, with lower rates of involvement for younger children (Barron and Emmett, 2020b). Findings for the adult population also give some scope for optimism about levels of physical activity among children and young people during the pandemic. However, some caution is necessary in making inferences about the impact on children. First, children's sports participation appears to be more reliant on taking part in structured, including team-based, activities, with adults more likely to engage in individual activities such as swimming and going to the gym (Lunn et al., 2013). ${ }^{35}$ For young people, the social aspect of sports is an important motivation for participation (lannotti et

35 It should be noted that, unlike the Sport Ireland (2020) survey, sports studies of this type do not generally include recreational walking or walking/cycling for transport purposes. 
al., 2013). These team-based activities were discontinued as part of pandemic restrictions. Secondly, depending on their age, children and young people may be less independent in their activities and therefore more dependent on local facilities (even their own gardens) in taking exercise (see Barron and Emmett, 2020b). Data from the GUI Cohort '08 at age nine were used to look at the proportion who had access to a garden. A separate item was used based on whether parents reported that there were safe parks or playgrounds locally for their children. In interpreting the reports on safe parks or playgrounds, it should be noted that some of these parks may have been closed because of COVID-19 restrictions and playground facilities would have been put out of use. Thus, the data can be taken as only a rough proxy for access during the pandemic. While the majority of children have access to a garden, those whose parents have no employment history are much less likely to have such access; 5 per cent of the never employed group have no garden compared to less than half of one per cent for the professional group. Almost a quarter $(23 \%)$ of parents disagreed with the statement 'There are safe parks or playgrounds locally'. Those from the lowest income group were twice as likely as those from the highest group to report such lack of facilities. In addition, available evidence shows that sports participation (especially for team sports) tends to fall off at times of transition (Lunn, 2010). The pandemic restrictions may serve as a similar transition, with fewer young people re-engaging with organised sports after a prolonged period of absence. Indeed, some commentators have posited the possibility of a 'generation lost' to sport (Drummond et al., 2020). The paid-for nature of much organised sport (Watson et al., forthcoming) may also be a constraint for families who have experienced employment or income loss as a result of the pandemic.

\subsubsection{Diet and obesity}

Both the Growing Up in Ireland study and the Health Behaviour of School-Aged Children study document socio-economic differences in the extent to which children and young people eat healthy and unhealthy foods. The HBSC 2018 study (Kolto et al., 2020) (on 10 to 17 year olds) indicates higher levels of consumption of fruit and vegetables among those from higher social class groups, girls and younger children. Those from lower social class groups and older children are more likely to consume sweets and soft drinks than higher SES groups. Similarly, GUI data on Cohort '08 at nine years of age indicates that those from lower-skilled/never employed families were less likely than those from professional families to consume fruit ( $81 \%$ versus $89 \%$ ) and vegetables ( $70 \%$ versus $84 \%)$, but more likely to consume unhealthy foods like chips ( $42 \%$ versus $25 \%$ ), crisps ( $60 \%$ versus $51 \%$ ) and soft drinks (48\% versus $31 \%$ ) (Watson et al., forthcoming). Information on young adults (at 17) indicates similar socio-economic differences in food consumption; for example, 64 per cent of those from lower-skilled/never employed families consumed fresh fruit in the previous 24 hours compared to 85 per cent of those from the professional group while the figures for chips were 50 per cent compared with 27 per cent (GUI Cohort '98, own analyses). 
Reflecting differences in physical activity and food consumption, a socio-economic gradient in weight status is found among children and young people. At nine years of age, 32 per cent of those in the lowest income group are overweight or obese compared to just 14 per cent of the highest income group (GUI Study Team, 2018a). Similar (though not as pronounced) differences are found among 17 year olds ( $29 \%$ compared with $22 \%$ overweight or obese) (McNamara et al., forthcoming). At the same time, there is evidence from the HBSC study that just under a fifth of children and young people report ever going to school or to bed hungry because there is not enough food at home, a pattern that is more common among those from lower social class groups, boys and younger children (Kolto et al., 2020).

The pandemic restrictions will have led to more consumption of food at home and possibly healthier home-cooked food. However, available evidence points to generally more negative effects on diet. In the CSO (2020b) survey on the Social Impact of COVID-19, 45 per cent of adults in Ireland reported an increase in their consumption of junk food and sweets while only 12 per cent indicated a decrease, with the greatest increase among the youngest age group (69\% for those aged 1834 ) and in households with children (51\%). The findings suggest comfort eating, as the increases were greater for those who reported feeling lonely, depressed or nervous. One month later, CSO (2020f) found that 41 per cent of adults reported weight gain since the onset of the COVID-19 pandemic. Rates of weight gain were higher (at 48\%) among adults in households with children as well as those who had experienced a drop in income (47\%) and those living in very disadvantaged areas (46\%). While no evidence is available for children's own consumption, it is likely to mirror that of the adult population, suggesting an increase in the consumption of less healthy foodstuffs and a potential change in weight status since the restrictions.

School closures are also likely to have affected food consumption. GUI research suggests that schools can be an important arena in relation to nutrition by directly providing school meals and/or by encouraging healthy eating among students (Nolan and Smyth, 2020). Overall, 13 per cent of primary students have access to a breakfast club while 20 per cent are in schools providing free lunches, with provision being much more common in DEIS than non-DEIS schools. Just over a fifth of those whose parents are not employed have access to a breakfast club and 40 per cent to free lunches, indicating the importance of school meals for this group. Over a quarter (27\%) and just under a fifth (18\%) of the 17-year-olds had attended second-level schools providing a breakfast club and free lunches respectively again a more common phenomenon in DEIS schools. In recognition of the role of schools in nutrition, the Department of Education and Skills issued guidelines in March 2020 to encourage schools to arrange delivery of food to families of children in their schools in collaboration with local community groups or An Post, a measure which has been extended to cover the summer months. Mohan et al. (2020) found that 95 per cent of DEIS second-level schools had made arrangements for the provision of free meals to their students, while 5 per cent of DEIS schools did not 
participate during the restrictions although they usually did. Among non-DEIS second-level schools, 8 per cent continued to provide free school meals, while 3 per cent of schools that usually participated were not providing them. No data are yet available on the level of provision in primary schools.

The employment and economic shock associated with the pandemic is also likely to affect consumption and weight status among children and young people. Using GUI data, Briody (2020) finds that one or both parents becoming unemployed is associated with reduced involvement in paid-for physical activity, increased consumption of less healthy foods and an increase in the likelihood of being overweight or obese. To the extent that this pattern is wholly driven by income loss, the higher-level Pandemic Unemployment Payment (PUP) may have played a protective role, at least in the short term. Nonetheless, relatively high levels of unemployment are expected for a significant period (McQuinn et al., 2020) and, as PUP is phased out, the largescale employment loss is likely to lead to poorer child health overall.

\subsection{MENTAL HEALTH AND SOCIO-EMOTIONAL WELLBEING}

Information on children's and young people's socio-emotional wellbeing and mental health is available from the Growing Up in Ireland, My World (Dooley et al., 2019) and Health Behaviour of School-Aged Children (Kolto et al., 2020) studies. They show consistent evidence of greater levels of anxiety and more depressive symptoms among female than male adolescents as well as higher levels of such difficulties among older age- or school year-groups. The My World study does not report findings by social background but both HSBC and GUI show socio-economic variation in the patterns found, with poorer mental health found among lower social class groups (Kolto et al., 2020; Williams et al., 2018). For younger children, the Piers-Harris 'freedom from anxiety' scale shows higher (more favourable) levels for males and for those from higher social class groups (Smyth, 2016b). The Strengths and Difficulties questionnaire, which offers a broader perspective on socio-emotional wellbeing, indicates a greater prevalence of difficulties among males than females at all ages, except at the transition to adulthood (17/18 years). Socio-emotional difficulties are more prevalent where parents have not been in employment and least prevalent for children and young people in professional families.

\subsubsection{Psychological wellbeing among the adult population}

Alongside the effect of school closures on formal learning (see Chapter 3), a dominant strand in the emerging literature on the pandemic relates to its effects on mental health and wellbeing. A review of studies shows that anxiety, depression and stress are common reactions to the pandemic (Rajkumar, 2020). An analysis of Google Trends data globally (Brodeur et al., 2020) indicated an increase in online searches relating to the terms loneliness, worry and anxiety, as well as boredom. 
Many of the studies have relied on convenience (volunteer) samples. However, representative studies from Britain (the Understanding Society study) show a very large decline in mental wellbeing ${ }^{36}$ during the pandemic restrictions. This decline has been much greater for young adults and for women compared to men (Niedzwiedz et al., 2020), with the gender gap related to women's care load (including time home-schooling) and increased feelings of loneliness (Etheridge and Spantig, 2020). The findings point to an increase in mental health inequalities; the deterioration in wellbeing is much greater among those who had poorer mental health pre-COVID-19 (Banks and Xu, 2020). Increases in mental health problems have been greater among those living with dependent children (under 15 years of age) (Banks and $\mathrm{Xu}, 2020$ ). Women, young adults and those with lower levels of income or education were also more likely to report feelings of loneliness during the restrictions (Bu et al., 2020). Studies based on convenience samples across a range of countries (including China, Spain, Poland, Iran and the UK) indicate increased levels of depression, anxiety and/or loneliness as a result of the pandemic, with greater difficulties among those in younger age groups and women (Ahmed et al., 2020; de Quervain et al., 202; Liang et al., 2020; Limcaoco et al., 2020; Moghanibashi-Mansourieh, 2020; Okruszek et al., 2020; Wang et al., 2020). Some of these studies have indicated greater difficulties among those with lower levels of education or income (Liang et al., 2020; Shevlin et al., 2020). As in the preCOVID-19 period, social support is found to have a protective effect (Okruszek et al., 2020; Xiao et al., 2020).

Reviews of earlier research studies on the effects of quarantine (for example, because of Ebola or SARS) have indicated an increased risk of post-traumatic stress disorder, acute stress disorder or depressive symptoms (Brooks et al., 2020; Hossain et al., 2020). One US study (Sprang and Silman, 2013) showed very high rates of PTSD among children who had been quarantined because of H1N1. A review of research on social isolation and loneliness showed a clear association with mental health problems for children and adolescents (Loades et al., 2020; see also Urbina-Garcia, 2020), leading the authors to conclude that 'children and adolescents are likely to experience high rates of depression and probably anxiety during and after social isolation ends' (p.2). However, there is limited evidence on the duration of the effect of the quarantine, and the review by Loades et al. (2020) includes both studies on the effect of peer social isolation (in 'normal' times) and those on the effects of quarantine-related isolation.

More specifically, a review of research (Calati et al., 2019) shows a relationship between social isolation and suicide incidence. One Hong Kong study indicated an increase in suicide rates among older people related to social isolation during the SARS pandemic (Cheung et al., 2008). One US online (volunteer) study showed an association between negative COVID-related experiences (such as distress, fear of

\footnotetext{
${ }^{36}$ Mental wellbeing was assessed on the basis of responses to the General Health Questionnaire and was often termed 'psychological distress' in earlier studies.
} 
infection and the effects of restrictions) and suicidal ideation over the previous month (Ammerman et al., 2020).

Available evidence suggests that emotional reactions to the pandemic are dynamic in nature. A UK study (Fancourt et al., 2020) has tracked changes since the lockdown among a large volunteer panel survey. Their findings show relatively stable levels of depression but declining levels of anxiety since the initial lockdown period. Both depression and anxiety are found to be more prevalent among individuals aged 18 to 29 , those on lower incomes and those living in more overcrowded households. They are also somewhat higher among those living with children. The reported incidence of self-harm is also higher among younger people and those on lower incomes. Loneliness levels have been stable over the period but consistently higher among younger adults and those on lower incomes. Another study, based on a representative sample in the UK, showed a spike in rates of depression and anxiety after the lockdown announcement; as with other studies, rates are found to be higher for women than men, among younger adults and those on lower incomes (ONS, 2020).

Similarly, in Ireland, when asked to indicate whether they had experienced certain feelings (such as anxiety, enjoyment) in the previous day, respondents to the Amárach (2020a) volunteer survey reported high levels of worry at the beginning of the period of restrictions, with some decline over time. In contrast, reported feelings of sadness and loneliness have fluctuated but not decreased over time during the period of the lockdown. There is some evidence that positive emotions (such as happiness) have been reported more than negative emotions since late May, though around a third still report having felt worried or anxious 'a lot' in the previous day. The proportion of adults reporting sleep difficulties has increased since the pre-COVID-19 period, while higher proportions report unmet needs for intimacy, security, community and meaning (Amárach, 2020b). Young adults (1824) were more likely than other age groups to report such unmet needs. Looking at reports of emotions on a single day, Lades et al. (2020) found that, among Irish adults, ${ }^{37}$ time spent outdoors, exercising, pursuing hobbies and taking care of children were associated with positive affect and reduced negative feelings. In contrast, home-schooling children and using social media were ranked low in terms of positive emotional experiences.

Systematic evidence on adult experiences of the pandemic has been provided through the CSO (2020b) Social Impact of COVID-19 survey. Compared to the situation in 2018 , there has been a substantial decline in overall life satisfaction as well as satisfaction with personal relationships. The proportion describing themselves as very nervous (all, most or some of the time) increased from 18 per cent to 35 per cent, being downhearted or depressed from 13 to 32 per cent and feeling lonely from 17 to 27 per cent. Correspondingly, there was a decline in the

\footnotetext{
${ }^{37}$ The research was conducted using a market research company access panel.
} 
proportion feeling happy all or most of the time from 80 per cent in 2018 to 62 per cent in April 2020. Significant differences were evident by gender and age. Women and those in the youngest age group (18-34) showed the poorest wellbeing and greatest decline over time.

A survey of adults in Ireland based on quota sampling found significant levels of depression and generalized anxiety, with over a quarter of respondents identified as at risk of either anxiety or depression ${ }^{38}$ (Hyland et al., 2020). Anxiety/depression was more prevalent among younger adults and females as well as those who had experienced loss of income resulting from the pandemic, and those who had direct experience of the virus (themselves or someone close to them having contracted it).

\subsubsection{Psychological wellbeing among children and young people}

There are a number of emerging studies on the psychological wellbeing of children and young people in the midst of restrictions. In Italy and Spain, in a convenience sample of parents (Orgilés et al., 2020), the vast majority (86\%) reported changes in the behaviour of their children (aged 3 to 18), especially difficulty concentrating $(77 \%)$, boredom $(52 \%)$, irritability (39\%), restlessness (39\%), nervousness (38\%), feelings of loneliness (31\%), uneasiness (30\%) and worries (30\%). A small study in one Chinese province showed a variation in the nature of child difficulties by age group (Jiao et al., 2020). Younger children (aged 3-6) were more likely to display clinginess and articulate fears that family members would become ill. Older age groups (6-18 years) were more likely to display inattention, with irritability common across all age groups. A small-scale study of parents in Sardinia indicated similar problems, with over half of children (aged 4 to 10) showing increased irritability and around a fifth displaying mood swings and having sleep problems (Pisano et al., 2020). As in the pre-COVID-19 period (see Chapter 2), levels of parental stress (individual and dyadic) have been found to act as an important mediator of circumstances on children's emotional and behavioural difficulties, at least in one Italian study of parents of 2 to 14 year olds (Spinelli et al., 2020).

A UK volunteer study on those aged 13 to 24 shows young people were enjoying spending time at home but at the same time were suffering from increased anxiety, with especially high rates of anxiety and trauma among the children of key workers (Levita, 2020). While no comparable information is available on the psychological wellbeing of the children of key workers in Ireland, the same pattern is likely to apply. This could be a sizeable problem, given that over half of essential workers in Ireland have dependent children (Redmond and McGuinness, 2020a). Zhou et al. (2020) showed high levels of anxiety, stress and depression among high-school students in China, especially females. A study of undergraduate Swiss students

\footnotetext{
${ }^{38}$ Depression was assessed using the Patient Health Questionnaire- 9 while anxiety was identified using the Generalized Anxiety Disorder 7-item Scale.
} 
(Elmer et al., 2020) indicated increased levels of stress, anxiety, loneliness and depressive symptoms compared to pre-COVID-19 measures, with a greater increase for female than male students. College students in China (Liu et al., 2020) also found increased levels of anxiety and depression. In a survey of young people with a history of mental health needs (YoungMinds, 2020), almost a third felt that the pandemic had made their mental health 'much' worse, while half described it as making it 'a bit' worse.

The research on children and young people in Ireland to date has largely relied on 'volunteer' or convenience sampling, making it difficult to generalise about socioemotional difficulties in the population as a whole (see Chapter 1 ). Nonetheless, the studies point to a number of issues being reported by young people. In an online survey by the Young Social Innovators (2020), over half of young people reported feeling anxious, worried or depressed, but over a third were feeling calm, motivated or enthusiastic. Feelings of anxiety or depression were more commonly reported by females than males. An online survey by Foróige (2020) found that young people reported feelings of anxiety and worry, with lack of face-to-face contact having a negative impact. The effects of being out of school for a protracted period of time were a worry for young people. Volunteer surveys of parents indicated that children missed their family, friends, their school or childcare and were upset about the restrictions on sports participation (Barron and Emmett, 2020a; Egan, 2020). In an online survey conducted by Barnardos (Fleming and O'Hora, 2020), many parents reported difficulties around their children's bedtime routines, tantrums or outbursts from their children and more fighting with siblings.

Using a convenience sample in England, Asbury et al. (2020) found a reported increase in anxiety and fear among families with children with a SEN (the majority of whom were on the ASD spectrum), with many parents feeling overwhelmed by the challenges they faced. Parents highlighted as the key challenges the loss of school- and community-based supports alongside the effect of the disruption to routine for the child (see also Chapter 3 ). A study of parents of children with ADHD in China indicated increasingly challenging behaviours among children, especially in relation to expressing anger (Zhang et al., 2020). Three online Irish surveys of convenience samples of parents of children with SEN reported similar challenges. The disruption to routine was seen as having very negative effects on children with SEN; many parents pointed to a regression in their child's behaviour and social skills (Barron and Emmett, 2020c; Inclusion Ireland, 2020; O'Connor et al., 2020). As with other health services (see Section 4.2), access to mental health and psychological support services has been interrupted by the pandemic restrictions. The study by O'Connor et al. (2020) found that almost all parents of children with SEN indicated that support for emotional-behavioural difficulties had been affected by the pandemic, being stopped/postponed (61\%), moved to online support $(21 \%)$ or reduced $(13 \%)$, with similar patterns reported for access to social services and educational support. 
There are good reasons, therefore, for expecting the levels of difficulties found in the adult population to be mirrored, if not amplified, among children and young people. Difficulties arising from the disruption to face-to-face social interaction (with peers and broader family) as well as in day-to-day routines will have strongly affected children and young people. Given that social support is an important protective factor against the effects of job loss or parental stress, the absence of face-to-face contact with non-household members is likely to exacerbate the effects of changed circumstances on psychological wellbeing. Furthermore, the economic shock resulting from parental unemployment loss is likely to contribute to socio-emotional difficulties, as was the case in the previous recession (Watson et al., 2014). Parental stress and depression have been linked to children's socioemotional difficulties (Nixon et al., 2019); the patterns found in the Irish adult population are of such a scale that they are very likely to affect children's wellbeing.

Studies on the impact of the pandemic have naturally taken place during the (height of) the restrictions. It is difficult to anticipate how long-lasting the experiences of depression and anxiety will be. However, unemployment is expected to remain at a high level into 2021, with significant consequences for adult and child wellbeing. Furthermore, research on children's experience of traumatic events, such as natural disasters, indicates long-lasting effects on psychological wellbeing (Abramson et al., 2010; Banks and Weems, 2014; Hoven et al., 2005; Fujiwara et al., 2016), with such effects evident even for very young children (see Klein et al., 2009, on the effects of 9-11 on children under 5). Effects have generally been found to be greater for families with lower socio-economic status (Pfefferbaum et al., 2015). For many families in low-income and/or precarious jobs, this will have been the second economic shock in just over a decade, with persistent or recurring financial strain likely to have a particularly acute impact on child outcomes (see, for example, Watson et al., 2014).

\subsection{SUMMARY}

This chapter has documented inequalities in child and adolescent physical and mental health in the pre-COVID-19 period. The nature of gender differences has been age-dependent, with a greater incidence of socio-emotional difficulties among males than females in early and middle childhood but more depressive symptoms among females during the period approaching the end of second-level education. To date, there has been little systematic research on the health impacts of the pandemic and related restrictions for children and young people in Ireland. However, international evidence along with Irish research on the adult population yields some important insights into the patterns that might be expected and the associated challenges for policy.

First, the employment and income loss resulting from the pandemic is likely to have significant negative effects on the physical and mental health of children and young 
people, at least in part because of the impact on their parents' own stress levels. This is likely to have a particular impact on those with initially lower levels of income. Whether this impact persists in the medium or long term is likely to depend, at least in part, on the duration of the recession. The suspension of much elective and routine medical services during the pandemic is also likely to lead to delays in accessing services, especially for those without private health insurance. These trends will create significant challenges for service providers, particularly in relation to therapeutic services such as speech and language therapy that already had long waiting lists.

Secondly, the growing levels of anxiety, stress and depression documented among the adult population are likely to be mirrored, if not amplified, among children and young people, given the patterns found of greater difficulties among young adults. Evidence from the aftermath of traumatic events such as natural disasters suggests that, for many, these effects can be long-lasting. The scale of difficulties is likely to be such that addressing them through existing child and adolescent mental health services may not be feasible, especially given high pre-COVID-19 levels of unmet demand for community mental health services (Brick et al., 2020b). It is crucial therefore to develop flexible and innovative approaches to promoting socioemotional wellbeing through schools (for example, the School Completion Programme) and youth services.

Thirdly, school closures have affected not only formal learning (see Chapter 3) but participation in sports and other structured activities, and socio-emotional support. In reopening schools, attention should be given to the broad spectrum of activities and supports offered in schools. Social, Personal and Health Education as well as the wellbeing programme at junior cycle are likely to be a very important resource in young people's adjustment to a post-COVID-19 world. Professional development and other resources for teachers are therefore crucial in this respect. The extent to which the pandemic restrictions have longer-term effects on child outcomes is likely to depend on the supports put in place to promote the socioemotional wellbeing of children, young people and their families, as well as measures to counter the financial strain and associated stress experienced by many disadvantaged families. 

The Transition to Further/Higher Education, Training and the Labour Market

\subsection{INTRODUCTION}

The transition from education to work is a complex process. Young people must navigate a range of decisions and pathways that have potentially long-reaching implications. The smoothness of this transition is strongly linked to the economic, educational and social capital that young people possess, as well as the institutional arrangements in place such as educational structures and active labour-market policies (Gangl et al., 2003; O'Reilly et al., 2019; Smyth et al., 2001; Russell and O'Connell, 2001). Prevailing economic conditions also play a significant role and there is a growing body of evidence on the long-term scarring effects of entering the labour market in a period of recession (see Section 5.3).

As labour-market entrants, young people are highly exposed to the COVID-19 crisis and recession. In this chapter we first examine the position of young people prior to the crisis, identifying groups of young people that are particularly vulnerable. In Section 5.3 we examine the emerging evidence of the impact of the crisis and in Section 5.4 draw lessons from research on previous recessions.

\subsection{THE LABOUR-MARKET POSITION OF YOUNG PEOPLE PRE-COVID-19}

Unemployment and NEET status ${ }^{39}$ among young people indicate problems in the education to work transition. Pre-COVID-19, young people's transitions from education to the labour market were highly stratified by social class. In 2019, the rate of youth unemployment ranged from 7.1 per cent of those in the two highest social classes (professional and managerial backgrounds) to 20.7 per cent among those from the two lowest social class backgrounds. ${ }^{40}$ Household structure and parental employment also influence the education-to-work transition. Living in a jobless household significantly increases the risk of being NEET (Zucotti and O’Reilly, 2018).

The critical role of education in making a successful transition into employment is highlighted in both Irish and international research (Gangl et al., 2003; Smyth, 2008; Kelly and McGuinness, 2014). Early school-leavers are particularly vulnerable

\footnotetext{
${ }^{39}$ Not in Employment, Education or Training as a proportion of all young people. The unemployment rate is expressed as a proportion of those active in the labour market (employed and unemployed) and therefore does not capture withdrawal from the labour market that may also occur in a time of economic crisis.

${ }^{40}$ Authors' analysis of the Labour Force Survey Q4 2019. Social class is based on ISCO occupational codes and household class is taken from the highest social class of the household members. Youth are defined as those aged under 25 years.
} 
to labour-market difficulties. Young people who leave school before the Leaving Certificate are four times more likely to be unemployed than school completers (Smyth et al., 2019). Moreover, the gap between early school-leavers and those with third-level education widened during the recession, increasing from 12 percentage points in 2007 to 33 percentage points in 2012 (Smyth et al., 2019). The school-to-work transition is also influenced by ethnicity and nationality. In the UK, most second-generation ethnic minority groups have a higher rate of participation in university than their white British counterparts, but a number of ethnic groups have a greater likelihood of being NEET (Zucotti and O'Reilly, 2018). In Ireland, research on the school-to-work transition of ethnic minority groups and migrant groups is relatively sparse. Young first-generation migrants in Ireland (aged 20-24) are just as likely as Irish nationals to have completed upper secondary education, with fewer than 5 per cent of the age cohort leaving school early (McGinnity et al., 2018). Nor is there a difference in the unemployment, employment and inactivity rates of this age cohort. Migrants aged 25 to 34 years are somewhat more likely to have third-level education than Irish nationals (ibid.) but this education may have been attained in their country of origin so does not necessarily imply equal transitions to third level in Ireland. Figures for all migrants are also likely to disguise inequalities among country and ethnic minority groups (McGinnity et al., forthcoming). Young people from a Traveller background have a substantially higher risk of dropping out of education early and face severe difficulty in labourmarket entry (Watson et al., 2017).

In addition to the greater risk of unemployment, young people are more exposed to low pay and insecure working conditions. In 2018, 20 per cent of employees earned less than two-thirds of median hourly pay, but this figure jumped to 61 per cent among young adults aged 18 to 24 years (McGinnity et al., forthcoming). Similarly, half of minimum-wage earners are aged under 25 years, even though this group account for approximately 10 per cent of all employees in Ireland (Redmond, 2020).

Young people are also over-represented in insecure employment, including the gig economy (ILO, 2020). Labour Force Survey figures for the first half of 2019 show that 31 per cent of young employees (aged 18-24) were on temporary contracts compared to 5-6 per cent of older age groups (McGinnity et al., forthcoming). This lack of security means that young people are at greater risk of job loss.

\subsection{IMPACT OF THE COVID-19 SHOCK}

The immediate impact of the COVID-19 crisis on youth employment is extremely stark. Employment among young people in Ireland and elsewhere in Europe is highly concentrated in the sectors worst affected by the crisis, such as the hospitality and retail sectors (Grotti et al., 2019; O'Reilly et al., 2019). Young people were also less likely to occupy jobs in which working from home was already an option (Redmond and McGuinness, 2020b). 
Consequently, job losses among young people far exceed those of older age groups. Using data on Pandemic Unemployment Payment (PUP) recipients, McQuinn et al. (2020) show that close to 60 per cent of young people aged 18-19 and 47 per cent of those aged 20-24 lost their jobs as result of the COVID-19 crisis compared to 26 per cent of all workers (Figure 5.1; see also Coates et al., 2020). These figures do not include seasonal workers, including students who take up summer employment to fund third-level education.

The International Labour Organization (ILO) suggests that cuts in working hours have also been extensive for young people who have remained in employment. Their preliminary survey results suggest that 23 per cent of young people in employment had their hours cut (ILO, 2020). ${ }^{41}$

In more normal times, emigration is an important option for young people who face employment difficulties in Ireland. The global nature of the pandemic means that this safety valve is not available to the current cohort of young people.

\section{FIGURE 5.1 PANDEMIC UNEMPLOYMENT PAYMENT CLAIMS AS \% OF EMPLOYMENT LEVEL IN 2019 Q4}

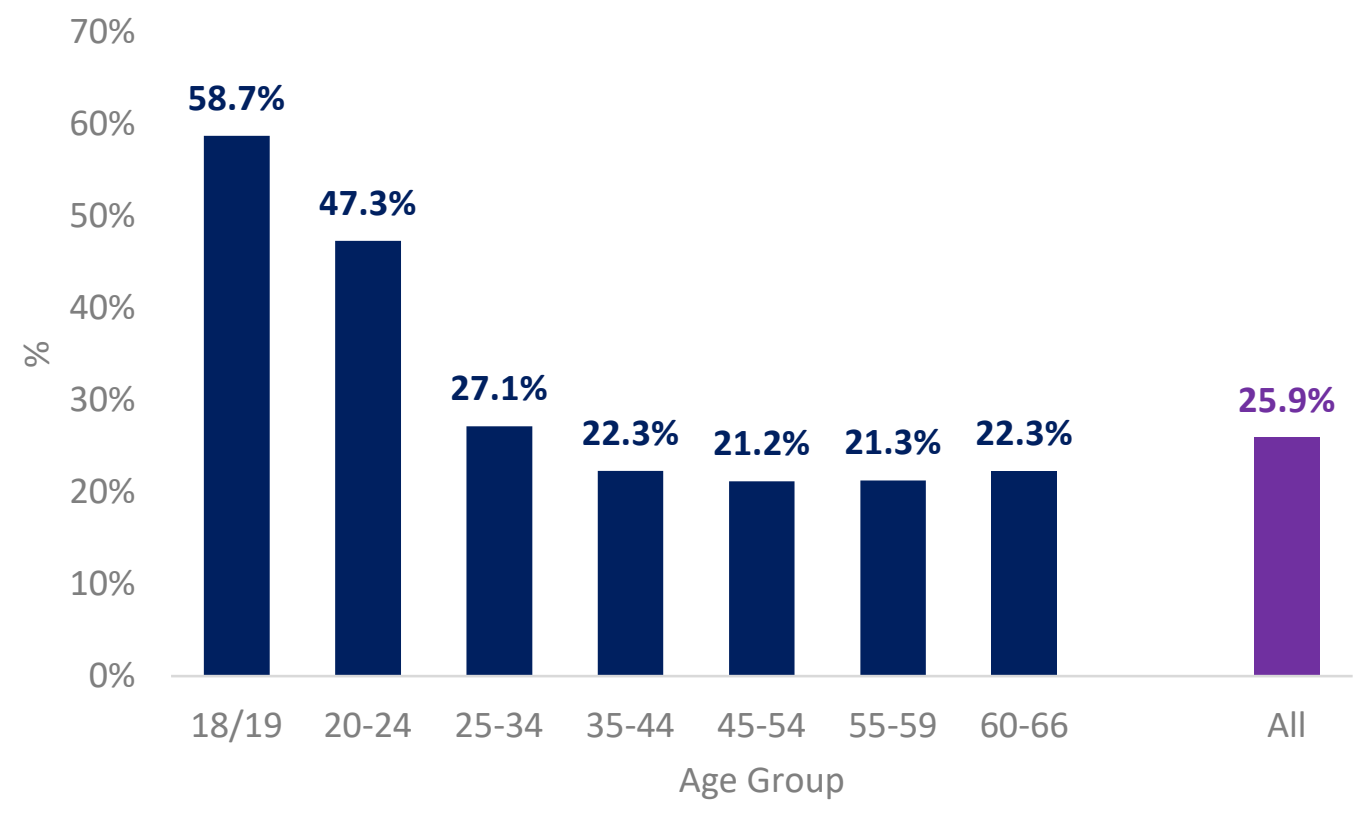

Source: ESRI summer QEC (McQuinn et al., 2020).

Research by the Sutton Trust in the UK has also charted the disruption caused by COVID-19 to apprenticeships and job training for young people (Doherty and Cullinane, 2020). Their survey ${ }^{42}$ in the first half of April of 156 HR leaders in companies employing apprentices found that just 39 per cent of apprenticeships

\footnotetext{
${ }^{41}$ No comparable figure is provided for other workers. CSO figures suggest that young workers in Ireland were less likely than older groups to have had their hours cut; however, this is not expressed as a percentage of those remaining in employment, so may reflect the greater experience of job loss for young people.

${ }^{42}$ Surveyed through the YouGov HR decision-makers Omnibus online survey.
} 
were continuing as normal, 36 per cent had been furloughed and 8 per cent made redundant. Almost 1 in 5 apprentices had their on-the-job learning suspended. Employers were also pessimistic about future apprenticeship options. Around a third said they would hire fewer or no apprentices in the coming year.

While the labour-market landscape for young people has become much more volatile, their access to supports from career guidance counsellors and formal networking events is likely to have diminished. Polling of young people in Year 13 in the UK found that they felt careers advice had particularly suffered during the lockdown (Montacute and Holt-White 2020). Young people from disadvantaged backgrounds are particularly dependent on formal careers advice (Smyth and Banks, 2012) and are therefore likely to be harder hit by its loss.

\subsection{TRANSITION TO FURTHER/HIGHER EDUCATION AND TRAINING}

Section 5.2 has discussed changes in the Irish youth labour market on foot of the pandemic and the implications for policy regarding young people. This section looks at the other transitions made by young people - into further and higher education and training.

FIGURE 5.2 PROPORTION OF 20 YEAR OLDS WHO HAD EVER TAKEN PART IN POST-SCHOOL EDUCATION/TRAINING (GUI COHORT '98, WAVE 4)

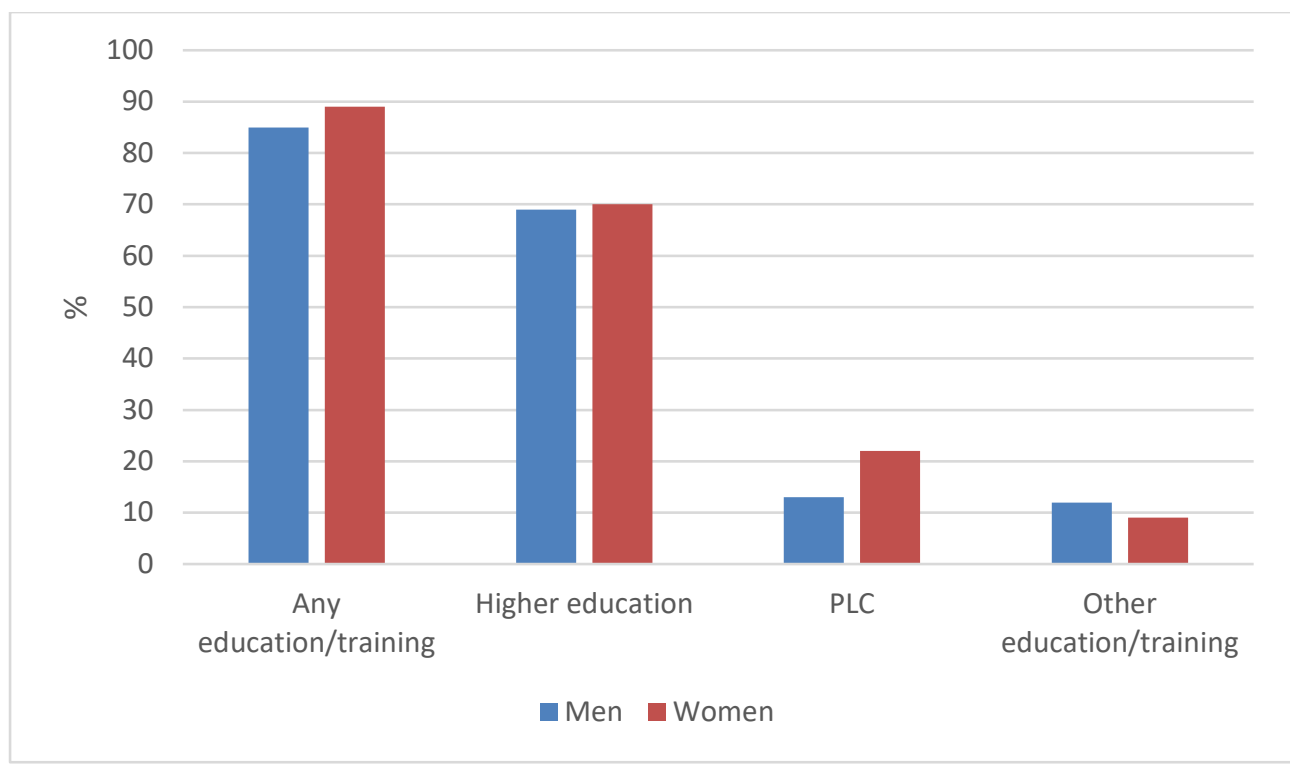

Source: Growing Up in Ireland Study Team (2019).

The dominant pattern among school-leavers in Ireland involves a transition to some form of education or training, most commonly higher education. Among 20 year olds, GUI data indicate that the vast majority (87\%) had taken part in at least one education or training course, with participation rates somewhat higher among women than men (Figure 5.2). The largest group (70\%) were taking or had taken a higher education course. 
The COVID-19 restrictions meant that further and higher education institutions (HEls) moved to online provision and, at the time of writing, many institutions are suggesting that the coming academic year will involve some form of blended learning, combining online lectures with some face-to-face tutorials or small-group work. For those young people leaving school this year, the transition to further or higher education will be quite a different experience from that of their predecessors, with different approaches to learning and most likely fewer opportunities to engage in college-based social activities. Research indicates that a majority of leavers report significant differences in teaching and learning between their second-level education and their post-school course, with particular difficulties emerging in relation to the standard expected of them, the difficulty of the course and managing their workload (McCoy et al., 2014). Many also report social difficulties in making new friends and adjusting to a new context. The level of support available in the institution emerges as a key factor in reducing the incidence of such academic and social difficulties among students (McCoy et al., 2014) but such support may be more difficult to access where students are spending a greater amount of time off campus. Supports for students with SEN may also be more difficult to access where young people are learning offline. A survey of school-leavers who went on to PLCs or higher education indicated that a significant group (15\%) accessed learning supports during their course while 3-4 per cent accessed disability support services; the group of young people potentially affected by the loss of or reduction in face-to-face supports is therefore substantial. In sum, COVID-19-related restrictions into the next academic year are likely to compound pre-existing challenges in making the transition from secondlevel to further/higher education.

The transition is likely to be especially affected for those who combine work-based and class-based learning. Since the pandemic, apprentice employment placements have been affected by broader sectoral restrictions, and training centres/colleges have been closed. Countries have been trying to maintain provision for apprentices but distance learning is described as piecemeal (CEDEFOP, 2020). Ireland is mentioned as one of the countries that has adopted distance learning, and usage is described as greater in the more recently developed apprenticeships such as finance or IT. Prior to the pandemic, there had been reports of lower take-up of apprentices by employers than desired. In the changed context, those currently on or hoping to start apprenticeships will be significantly affected by the broader youth labour-market challenges discussed in Section 5.2.

In some forms of education and training catering for the most marginalised groups, face-to-face contact between staff and participants is even more important in order to establish relationships of trust. For example, an evaluation of the Youthreach programme has shown the importance of positive relationships with, and support from, staff in re-engaging young people with learning (Smyth et al., 2019). Websites indicate that contact has been maintained with Youthreach learners via phone/text and social media. Given the challenges experienced by 
learners on the Youthreach programme (with many reporting mental health difficulties), it is crucial that face-to-face provision be resumed as soon as possible and that supports be put in place to address youth mental health issues among this group (see Chapter 4).

Among 20 year olds in the GUI study, most drew on multiple forms of funding for their studies/training (GUI Study Team, 2019). Almost two-thirds (64\%) received money from their family while 20 per cent reported indirect family support (in the form of food or accommodation). Just over four in ten (44\%) were using earnings from their own part-time employment. Loss of employment among their parents, coupled with probable restricted opportunities for part-time work and ineligibility for emergency income supports (PUP and TWSS) for seasonal workers, are likely to affect young people's ability to fund their education in the period to come. The Union of Students in Ireland (USI) has raised concerns about students committing to accommodation leases in the context of uncertainty about campuses being open. No research has been conducted to date in Ireland on the potential impact of this issue. However, a volunteer study in the UK (Montecute and Holt-White, 2020) indicates that around a fifth of higher education applicants are now unsure about their choice of course or decision to go to college. A third of existing students reported that they had lost their job or had reduced hours while over a fifth reported difficulties in their parents supporting them financially.

\subsection{LESSONS FROM PREVIOUS RECESSIONS}

The Great Recession provides extensive evidence on the impact of a severe economic shock on young people's labour-market transitions. Young people in Ireland and elsewhere in Europe bore the brunt of the employment crisis. While the general unemployment rate grew from 5 to 12 per cent from 2009 and 2012, the youth unemployment rate rose from 10 to 33 per cent. Over the same period, the proportion of NEETs increased from 10 per cent in 2006 to 19 per cent in 2012 (Kelly and McGuinness, 2014). While young men had a lower risk of unemployment and NEET status in 2006, this had reversed at the height of the recession, with the rise and fall of the construction industry playing a significant part in this pattern (ibid; Kelly et al., 2015).

Transitions into employment among NEET and unemployed youth dropped sharply during the recession, and the role of education in facilitating exits from unemployment and inactivity for young people increased in importance (Kelly and McGuinness, 2014). The role of nationality in finding a job also increased in the recession, with a worsening in the relative position of non-Irish nationals. The authors also found a decline in the negative impact of unemployment duration on getting a job. Across Europe, the Great Recession led to a hiring freeze of young workers and in particular a decline in the number of full-time permanent jobs available to this age cohort (O'Reilly et al., 2019b). 
Previous recessions also provide an insight into the possible longer-term impacts on young people. Entering the labour market at a time of recession is found to have a scarring effect on young people's subsequent earnings and labour-market prospects. Early unemployment spells can also have a lasting effect on health, wellbeing and job satisfaction, in some cases up to 20 years later (Bell and Blanchflower, 2011; Strandh et al., 2014). Even among those who find a job, recessions increase the likelihood of a mismatch between skills/education and job requirements. Being mismatched in their first employment confines a substantial proportion of graduates to low-level occupations on a more permanent basis (Dolton and Siles, 2003; McGuinness and Sloane, 2011).

Recent research on workers in 13 European countries who finished their education between 1987 and 2014 suggests that the earnings effect of entering the job market in a period of higher unemployment is greatest for graduates and persists for eight years (Regan, 2020). During the Great Recession, new graduates in the hardest-hit countries, including Ireland, Greece and Spain, incurred wage losses of over 20 per cent one year after graduation and a loss of between 12 and 23 per cent for the next ten years.

\subsection{SUMMARY}

The class of 2020 face unprecedented challenges in their post-education transitions. Those entering the labour market face a situation in which the most 'youth friendly' sectors, such as retail, accommodation and food, were hardest hit by the COVID-19 closures. While these sectors are now reopening, it is unlikely that there will be significant recruitment as employers deal with the additional costs associated with new social distancing measures and try to recoup some of their losses due to three months of closure. Experience shows that youth employment takes longer to recover following recession (O'Reilly et al., 2015) and current forecasts suggest that unemployment will remain high into 2021 (McQuinn et al., 2020). Previous recessions also suggest that inequalities between groups of young people are likely to widen, and those with fewest qualifications will be the most disadvantaged. However, even graduates are likely to face the longer-term consequences of entering the labour market in such poor economic conditions.

Young people entering further/higher education and training also face uncertainty and disruption. Much is still unknown about the delivery of college courses and training programmes; therefore school-leavers are making important decisions with insufficient information. Young people with SEN and those who are economically and socially disadvantaged will need additional supports in making these transitions so that existing inequalities are not further amplified. 



\section{CHAPTER 6}

\section{Conclusions}

\subsection{INTRODUCTION}

COVID-19 has resulted in a global public health crisis, with measures to reduce transmission leading to the closure of schools and workplaces and a reduction in social interaction. Although rates of serious illness from COVID-19 have been very low among children and young people, the direct impact on their lives of school closures and lack of peer interaction and the indirect impact through increased family financial stress and changed family dynamics are likely to be substantial, possibly long-term. This study draws on pre-COVID-19 evidence as well as emerging studies in Ireland and internationally on the impact of the pandemic on families, children and young people. These research findings are then used to identify the main issues for policy development in four main domains: family and peer relationships; education; health and wellbeing; and the youth labour market. As restrictions ease, it is timely to look at policies to address the impact of the pandemic and what, if any, compensatory measures are required in the short to medium term to ameliorate any such effects.

\subsection{MAIN FINDINGS}

The world-wide pandemic prompted many international studies looking at the effect of restrictions on society in general, including children and young people. Much of this research is ongoing and, at the time of writing, findings from many studies have yet to be published. A good deal of this research has been based on online non-probability ('volunteer') samples, making it impossible to generalise to the larger population. There have also been a number of rapid-response reviews reflecting on the impact of previous pandemics. This review places greater weight on studies based on representative samples of the relevant population, though studies based on convenience samples are mentioned where their findings are suggestive of emerging issues.

Evidence from the Growing Up in Ireland study and other Irish research highlights significant inequalities in children's experiences and outcomes depending on the family circumstances into which they are born (for an overview, see Williams et al., 2016). Some experiences, especially positive relationships between parents and children and high parental expectations for their children's future, are common across all social groups. However, children from more socio-economically disadvantaged backgrounds are found to have poorer health, lower levels of physical activity, higher rates of overweight/obesity, more socio-emotional difficulties, less involvement in (largely paid-for) structured sports and cultural activities outside school, lower levels of school engagement and lower academic 
performance. Other groups of children and young people, including those with special educational needs, Travellers, migrants and asylum-seekers, also face additional challenges.

Emerging evidence in Ireland and internationally suggests that these inequalities have grown as a result of the effects of the pandemic. The reasons for this are twofold. First, the negative effects on wellbeing and mental health have been disproportionately borne by more vulnerable groups (in terms of socio-economic disadvantage and overcrowded housing, among other factors) as well as by younger adults (CSO 2020d, e). There is a strong gender dimension, with women more likely to report feelings of depression, anxiety or sadness during the period of restrictions (CSO, 2020b). There has been less systematic evidence on the effects on children, though findings are suggestive of increased inequality for them too. Emotional difficulties have increased more for younger age groups (adults 18-34) ${ }^{43}$ so are likely to have increased for children and young people under 18. Children's socio-emotional and other outcomes are highly influenced by parental stress and depression (Nixon et al., 2019). They are therefore likely to experience difficulties as a result of their parents' reduced wellbeing and, given that pre-COVID-19 patterns of depression and parental stress were highly unequal, this impact will be greater for more disadvantaged groups.

The second reason for expecting growing inequality relates to the sharp shock to the economy of pandemic-related restrictions. Job losses have been concentrated among younger and lower-income groups (McQuinn et al., 2020). While the introduction of the Pandemic Unemployment Payment (PUP) and the Temporary Wage Subsidy Scheme (TWSS) have temporarily cushioned the decline in income for those in the lowest two income quintiles (Beirne et al., 2020), ${ }^{44}$ the phasing-out of these supports in the coming months alongside predicted continuing high rates of unemployment will lead to lower living standards among many families. Research on the Great Recession consistently points to the negative effects of persistent socio-economic vulnerability on the developmental outcomes of children and young people (Watson et al., 2016; Nixon et al., 2019). While the scale of the current recession is as yet unknown, a protracted drop in living standards and associated stresses for families will undoubtedly have a negative impact on children's wellbeing. Furthermore, young people making the transition to the labour market are likely to struggle to obtain employment. Previous research points to the long-term scarring effect of such precarity on their longer-term careers (see, for example, Helbling et al., 2019). The global nature of the pandemic and resulting recession means that, for the first time, emigration is restricted as an

\footnotetext{
${ }^{43}$ Further research on the extent to which this pattern is driven by greater levels of job loss among this group would be useful.

${ }^{44}$ Income loss is only one aspect of job loss or temporary lay-off with an impact on identity, routine and socioemotional wellbeing; the implications for health and wellbeing are discussed in Section 6.3.3.
} 
option for young people who face difficulties in accessing jobs in Ireland.

\subsection{IMPLICATIONS FOR POLICY}

This section looks at the implications of the report findings for policy development in relation to the four domains of family and peer relationships, education, health and wellbeing, and youth transitions. As will be outlined, some of the effects of the pandemic restrictions will likely be short-term, at least in the absence of a second wave of infections and new restrictions. For example, peer relationships might be expected to be re-established as face-to-face interaction resumes and educational institutions reopen, though there may be longer-term difficulties for some children with special educational needs.

The duration of other effects depends on two sets of factors. First, the impact of the substantial disruption to learning, especially for more disadvantaged groups, will depend on the timing of the resumption of school for all students and the measures put in place to address the gap. Evidence in the wake of other disruptions (because of teacher strikes or natural disasters) suggests that, in the absence of substantial supports, the effects on learning will be long-term. Secondly, the effects on many outcomes, including socio-emotional and physical wellbeing as well as educational performance, will depend on the severity and duration of the recession resulting from the economic shock associated with pandemic restrictions. Even a relatively short recession will, nonetheless, have a strong impact on the employment integration of young people and their subsequent career pathways.

\subsubsection{Family and peer relationships}

Studies point to two main drivers of family stress during the pandemic: the necessity to combine remote working with home-schooling and childcare, especially in the absence of other sources of support (such as extended family), and the income loss resulting from permanent or temporary lay-offs. The experience of remote working and home-schooling has brought the digital divide into sharp relief, with families differing in their access to an adequate number of devices and to high-speed broadband. This digital divide is closely related to socioeconomic advantage or disadvantage but also has a regional dimension, and thus highlights the importance of implementing the National Broadband Plan (see Mohan et al., 2020). The persistence of such family stress is likely to depend on the speed of the return to work and to childcare or education for all.

Given the economic shock and its consequences for family stress, a central concern for policy will centre on the protection of living standards among the population. Evidence indicates that Ireland has high levels of inequality in market income but that the effects of the social welfare and tax systems are highly redistributive by international standards (Roantree, 2020). Nonetheless, pre-COVID-19 patterns 
show higher levels of income poverty and deprivation among families with children and lone-parent families (CSO, 2020e). The phasing-out of PUP and TWSS in the coming months is likely to create challenges in maintaining living standards for families, especially where the period of mortgage breaks and restrictions on rent increases and evictions has elapsed. The drop in income is likely to be greatest for young people who move from the higher-rate PUP to the reduced level of Jobseeker's Allowance available to those under 25 years of age (who are not living independently). Without an economic recovery, it is estimated that child income poverty rates could increase up to 23 per cent (Regan and Maitre, 2020). Overcrowding has emerged as a driver of stress and anxiety during the pandemic and is therefore likely to particularly affect the most vulnerable groups, including Travellers, those in emergency accommodation and those in direct provision, highlighting long-standing issues in housing policy. McQuinn et al. (2020) highlight the need for the Government to increase investment in areas such as infrastructure and affordable or social housing, which could meet the twin goals of stimulating the domestic economy and improving housing conditions for vulnerable groups.

\subsubsection{Education}

One of the most dramatic aspects of the pandemic restrictions has been the closure of all educational institutions from early-years to tertiary levels over a long period. For very young children, the closure of centre-based provision and the impact of social distancing measures on access to relative (especially grandparent) care has meant that parents, especially mothers, have assumed an additional care burden. For older age groups, parents have been expected to home-school their children. Available evidence indicates that school closures have resulted in growing inequalities as children vary in their access to books and digital resources, and parents themselves have differential educational, cultural and time resources to support their children's learning. There are differences too across primary and second-level schools in how schools and teachers could support remote learning, with schools making a smoother transition to distance education where they had the infrastructure in place and/or greater prior experience of digital teaching and learning (Burke and Dempsey, 2020a; Mohan et al., 2020).

Support for children's learning at home has also been constrained by parents' combining home-schooling with remote working and the requirement for essential workers, disproportionately female and lower-paid (Redmond and McGuinness, $2020 \mathrm{~b})$, to continue to go to work. Approaches to assessment have changed, with a period of uncertainty around state exams ${ }^{45}$ followed by the cancellation of the Junior Certificate exams and the use of calculated grades for the Leaving Certificate. As well as experiencing a disruption to their learning, there is powerful testimony from parents on the impact of closures on children with disabilities and

${ }^{45}$ This uncertainty was seen by school principals as a particular source of stress for young people (see Mohan et al., 2020). 
SEN, highlighting the need for immediate supports (Barron and Emmett, 2020c; Inclusion Ireland, 2020).

Much of the discussion of schools re-opening has centred on logistical issues such as how to manage social distancing and its implications for class size and building capacity. While these issues are of course important, the more crucial question of how to address growing inequalities has received much less public attention. Children and young people from more disadvantaged backgrounds are more likely to have suffered from 'learning loss' over the period of school closures. Workingclass young people, especially boys, and Traveller students had lower levels of school engagement pre-COVID-19. While rates of school completion have improved markedly in recent years, there is a risk that, without support, some young people may not re-engage in education when schools resume. Those making the transition to second-level education will have missed the period of preparation for, and contact with, the new school, making the adjustment more challenging. Young people with SEN may struggle to re-adjust to the routines of school. The broader developmental context of the school may also be altered, at least in the short term, with curtailment of Transition Year (TY) trips and activities, likely challenges in obtaining work placements for those on the Leaving Certificate Applied programme and, in TY, the potential restriction of extracurricular activities.

Commentators in the UK have suggested that growing educational inequalities can only be tackled through additional hours of teaching and additional supports after schools resume, both of which would be expensive (Eyles et al., 2020). Research points to individual and small-group tuition as the most effective forms of intervention to address inequalities in learning (CEPEO, 2020; EEF, 2020). The English and Dutch governments have introduced tutoring programmes designed to provide resources for small-group tuition and other tailored supports. ${ }^{46}$ In Ireland, the Department of Education and Skills has announced an extension of the regular July summer programme ${ }^{47}$ which has offered extra learning opportunities (schoolor home-based) for a two- to four-week period for children with severe and profound intellectual disabilities and those with autism spectrum disorders. It is now being expanded to include children with Down syndrome and other conditions as well as any child in a special school or special class. All DEIS schools have been invited to express interest in offering a one-week programme for their students in August. At primary level, the programme is to focus on literacy and numeracy along with wellbeing. At second level, the programme is intended to reconnect with those students who disengaged from learning during the closure and focuses on wellbeing as well as skill development. Schools are expected to target those most in need of support but, at second level, a maximum of 10 per cent of students can be supported. While these programmes are welcome, a one-week programme will be insufficient to bridge the gap for these students and additional support will be

\footnotetext{
${ }^{46}$ www.gov.uk/government/news/billion-pound-covid-catch-up-plan-to-tackle-impact-of-lost-teaching-time
}

${ }^{47}$ www.education.ie/en/Parents/Services/summerprovision/ 
needed throughout the school year. There may be challenges too in re-engaging those most at risk in the programme if the offering is not seen as attractive. It is important that any such provision focuses on broader re-engagement to make schools a more attractive place for young people and facilitate retention; thought might be given to incorporating sports or other physical activities and other handson activities to make the programme (and any follow-up provision) more enticing for young people. The School Completion Programme offers considerable potential for the delivery of activities during the holiday period ${ }^{48}$ (and after school during term-time) for children and young people attending DEIS schools.

Additional learning supports in the form of one-to-one and small-group tuition will be crucial in addressing learning loss when schools resume. For younger children, play-based learning will be an important component of re-engaging them in education and addressing the learning gap (see CEPEO, 2020). The provision of such supports, especially one-to-one and small-group tuition, will require the allocation of substantial resources in the coming academic year, but this increased expenditure should be set against the considerable societal costs of early schoolleaving and academic underperformance. If schools do not resume on a full-cohort or full-time basis in the coming school year, the learning loss is likely to continue to grow, especially for socio-economically disadvantaged students and those with special educational needs.

In planning additional supports, it is important to note that a very significant proportion - over half - of children and young people from disadvantaged backgrounds attend non-DEIS schools, creating challenges for teachers in addressing the needs of students who had very different learning experiences during lockdown. Pre-COVID-19 research highlighted pressures for students and teachers to 'cover' the course in the available timeframe, especially at senior cycle (Smyth et al., 2019). This pressure will be exacerbated by the period of school closures. It is important, therefore, that agreement be reached on what is feasible for senior-cycle students to cover and be assessed on, as well as the number of class-based assessments expected for junior-cycle students. More broadly, the disruption to the system caused by the pandemic as well as a different model for Leaving Certificate assessment for the first time could usefully prompt further reflection on the need to reform senior cycle.

The pandemic crisis has revealed the fault-lines in the early-years sector in terms of its reliance on private providers as well as low pay and retention issues among staff (Russell et al., 2020). Serious concerns have been raised about the continued viability of providers, especially in the context of requirements to have specific measures and smaller groups in the post-COVID-19 period. In response, the DCYA has announced a financial package of $€ 75$ million to allow for early reopening of

\footnotetext{
${ }^{48}$ Holiday provision had been a key feature of SCP but expenditure cuts in the last recession meant that such provision was scaled back (Smyth et al., 2018).
} 
creches. At the time of writing, it is as yet unclear how many providers have resumed operations and how many will reopen in the coming months. The ongoing requirement for physical distancing will reduce the potential for grandparent care, leading to greater reliance on centre-based provision and higher costs for parents, many of whom were not paying for care by relatives or were doing so at a level significantly below the market rate before the pandemic.

At the other end of the age spectrum, it appears probable that third-level provision will rely on some form of blended learning, with lectures delivered remotely and some campus-based tutorials or practical work. This will result in a very different academic and social transition experience for those young people going to college for the first time this year. Reduced access to part-time or summertime work and uncertainty about accommodation when much learning is online are likely to increase the financial pressures for students. Given the importance of academic and social supports for retention (McCoy et al., 2014), it is crucial that higher education institutions develop innovative ways of supporting students' academic development and wellbeing in a context of reduced face-to-face interaction. Similar challenges face much further education provision. Indeed, face-to-face contact and support appear even more important in Post Leaving Certificate provision where group sizes are typically smaller and students report positive relationships with staff (McGuinness et al., 2018). Trusting relationships between staff and learners are especially important for programmes (such as Youthreach) catering for more vulnerable groups (Smyth et al., 2019), thus making the immediate resumption of face-to-face provision crucial. As in the last recession, apprenticeship programmes are likely to be particularly vulnerable in the coming months as young people may struggle to obtain or retain their job placements - an issue discussed in Section 6.3.4.

\subsubsection{Health and wellbeing}

Irish evidence points to a decline in the psychological wellbeing of adults, especially younger adults, during the pandemic restrictions (CSO, 2020b, d, e). The impacts on physical health for those not infected with the virus are less clearcut, with mixed patterns of increased consumption of junk food and alcohol, less physical exercise and weight gain among a significant minority, and increased levels of physical exercise among others (CSO, 2020b, e). A growth in expenditure on groceries during the pandemic may have led to healthier home-cooked meals but no research has been conducted on this issue to date. There has as yet been no systematic evidence on the patterns for children and young people in Ireland, though insights can be gleaned from the research on adults along with pre-COVID19 studies on the lives of children and young people.

As with the last recession (Watson et al., 2014; Nixon et al., 2019), the employment and income loss resulting from the pandemic are likely to have significant negative effects on the physical and mental health of children and young people. Such 
effects will be greater for those on initially lower levels of income, with the impact operating through parents' levels of stress and depression as well as the direct loss of resources for day-to-day life (Reinhold et al., 2018). The scale of the effects will depend on the scale and duration of economic vulnerability (see Watson et al., 2014), with child poverty expected to increase significantly in the absence of an economic recovery (Regan and Maitre, 2020). The suspension of much elective and routine medical services during the pandemic is also likely to lead to delays in accessing services, especially for those without private health insurance. It is probable that lack of contact with health services will have caused difficulties in the management of long-standing conditions. This is of concern given the greater prevalence of long-standing illness and conditions among children and young people from more socio-economically disadvantaged families. The impact of restricted access to services on health will only be evident in the longer term. There will be significant challenges for service providers, particularly in relation to therapeutic services such as speech and language therapy, which already had long waiting lists. Pre-COVID-19, there were substantial disparities by family income in children's use of dental services, an important issue to be considered in resuming preventative dental services for children. Access to three dental school-based assessments during the primary school years will also have been disrupted by the pandemic. These likely growing inequalities in child health provide further impetus for the rollout of Sláintecare and the National Oral Health Policy (Department of Health, 2018a; 2018b).

The growing levels of anxiety, stress and depression documented among the adult population are likely to be mirrored, if not amplified, among children and young people, given the patterns found of greater difficulties among young adults. Some children and young people will experience greater psychological difficulties than others. Evidence from the aftermath of traumatic events such as natural disasters suggests that, for many, these effects can be long-lasting. The scale of difficulties is likely to be such that addressing them through existing child and adolescent mental health services may not be feasible. This is especially likely in a context where evidence suggests significant levels of unmet demand for adult and child/adolescent community mental health services (Brick et al., 2020b), with '[d]edicated adolescent mental health services ... virtually non-existent on a national basis' (HSE, 2020b, p. 84). It is crucial therefore to develop flexible and innovative approaches to promoting socio-emotional wellbeing through schools (for example, the School Completion Programme) and youth services, an approach in keeping with Sharing the Vision (Government of Ireland, 2020) which emphasises the importance of preventative, often school-based, services. There is a case, therefore, for enhancing access to specialist psychological and therapeutic supports through schools, building on existing provision such as the National Educational Psychological Service (NEPS) and the School Completion Programme.

School closures have impacted on participation in sports and other structured activities, and socio-emotional support, all of which affect children's physical and 
socio-emotional wellbeing. In reopening schools, attention should be given to the broad spectrum of activities and supports offered in schools. Social, Personal and Health Education (SPHE) as well as the wellbeing programme at junior cycle are likely to be a very important resource in young people's adjustment to a postCOVID-19 world, though additional supports in the form of SPHE and life skills could also usefully be incorporated into senior cycle (HSE, 2020b; Smyth et al., 2019). Ongoing professional development (through Education Centres and other organisations such as Jigsaw) and other resources for teachers are therefore crucial in this respect. Children's sports participation is largely reliant on taking part in structured, including team-based, activities (school- or community-based) which have been discontinued during the period of restrictions. The pandemic restrictions may lead to fewer young people re-engaging with organised sports after a prolonged period of absence. At the time of writing, some summer camps, including GAA Cúl Camps, have resumed. Summer camps or programmes provide an important opportunity for young people to re-engage in sports activities. However, the paid-for nature of much organised sport (Watson et al., forthcoming) will be a constraint for families who have experienced employment or income loss as a result of the pandemic (or were on low incomes pre-COVID-19). Furthermore, participation patterns are likely to reflect the social gradient (and gender gap) found prior to the pandemic, making it crucial to offer activities through a range of outlets, such as the School Completion Programme and local youth clubs, to cater for more socio-economically disadvantaged communities.

\subsubsection{The youth labour market}

Given the particular exposure of young people to the current labour-market shock and the likely long-term consequences, there is an onus on policymakers to prioritise protective measures for this group.

The strong association between education and successful entry into the labour market means that supports to prevent disengagement and drop-out of young people are of critical importance. The School Completion Programme has played an important role in providing a flexible response to the needs of at-risk children and young people (Smyth et al., 2018). For those who have left school early, the Youthreach programme has proved effective in re-engaging young people facing complex challenges with learning (Smyth et al., 2019). Such supports are likely to become even more vital in the current climate, as early leavers face increasing challenges in accessing employment.

Comparative research has shown that education systems that have a stronger vocational training element and higher rates of educational attainment promote smoother education-to-work transitions (Gangl et al., 2003). Similarly, countries with strong training systems weathered the Great Recession with lower youth unemployment and inactivity rates (O'Reilly et al., 2019). For historical reasons, vocational education and training have been relatively underdeveloped in Ireland 
compared to other European countries (McGuinness et al., 2014). Nonetheless, the most effective active labour-market policies in Ireland, as elsewhere, are those where training is job-specific and linked to employers' skills needs (McGuinness et al., 2014). Engagement with employers therefore remains essential through, for example, the Regional Skills Fora. The digital economy offers new opportunities for young people. However, the ability to avail of these options depends on the responsiveness of training and education systems to new demands. Employers that provide apprenticeships may need particular supports to maintain training; for example, off-the-job training for apprentices on furlough. Further incentives may also be needed for employers to take on apprentices in the coming year. The ILO has recommended youth-targeted wage subsidy programmes to reduce the cost of retaining and hiring young workers, alongside greater investment in other active labour-market policies (ILO, 2020). The UK recently announced a f2bn 'kickstart scheme' to support the employment of young people. Employers can apply for a $£ 1,000$ wage subsidy for six-month work placements for young people at risk of long-term unemployment. Participants are paid at the national minimum wage level. New payments have also been introduced for employers who take on new apprentices (HM Treasury, 2020).

Research also tells us that more generous income supports can mitigate the scarring effects of unemployment on workers' subsequent earnings by preventing downward occupational mobility (Gangl, 2004). Since early career mismatches can have long-term consequences for some, welfare payments that allow young people to search for a better fit between job and skills may prevent entry to a trajectory that results in lower earnings and occupational attainment.

Finally, career and education advice supports from schools, colleges, employers and other service providers need to be protected, especially for young people from disadvantaged backgrounds who rely more on advice and support from their teachers and schools (Smyth et al., 2011; McCoy et al., 2014). Early access to guidance and advice may help young people avoid course choices that they may later regret (McCoy et al., 2014). Well-designed and targeted online supports could reach those not previously able to attend open days.

Successful transitions into stable employment are not only important for young people's economic wellbeing but also for their mental and physical health, both in the short and long term. Ruptures to this transition can block other aspects of transition to adulthood such as household and family formation. Policy actions to mitigate these multiple impacts are needed to prevent the cohort of 2020 suffering long-term scars. 


\subsection{ASSESSING THE MEDIUM- AND LONGER-TERM IMPACT OF THE PANDEMIC ON CHILDREN AND YOUNG PEOPLE}

This section looks at gaps in the evidence base on the effects of the pandemic on children and young people in Ireland, highlighting a potential research agenda for the future. The report has shown that a good deal of the research conducted to date has been based on convenience (non-probability) samples, usually with online surveys, making it impossible to generalise to the general population regarding the scale of any difficulties and the identification of those at greatest risk. Surveys based on representative samples of the relevant population provide a much stronger evidence base, with cross-sectional studies providing useful insights into the experiences of the pandemic and associated restrictions at a single point of time. However, the extent to which experiences and outcomes will change as restrictions are removed is unclear, leading some researchers to posit the need for longitudinal data collection and highlighting the value of existing longitudinal studies (such as the UK Understanding Society and the German Socioeconomic Panel study) in this regard (Kühne et al., 2020). The British cohort studies have conducted specific COVID-19 surveys with their samples; though the findings have not been published yet (at the time of writing), these data should provide rich insights on the impact of the pandemic on the experiences of people across a range of age groups, as a basis for policy development. In Ireland, the CSO has conducted a survey of the adult population on the social impact of the pandemic and captured its employment effects through the Labour Force Survey (CSO, 2020a, b, c, d, e). To date, there has been no systematic evidence from the perspective of children and young people (under 18 years of age), though some ongoing studies use convenience samples of this group. Future waves of the UCD Children's School Lives should provide valuable insights into the effects of school closure on the learning of primary school children. However, in filling the evidence gap, the Growing Up in Ireland study is best placed to capture the effects of the pandemic across all of the domains of children's and young people's lives. What are the implications for potential timing and content of any GUI-based COVID-19 study?

Studies on the impact of the pandemic have naturally taken place during the restrictions. It is difficult to anticipate how long-lasting the effects of some experiences such as disruption to education and a decline in wellbeing will be and therefore difficult to decide the optimal timing of research on the impact. Research on children's experience of traumatic events, such as disasters, has highlighted long-lasting effects on psychological wellbeing (Abramson et al., 2010; Banks and Weems, 2014; Hoven et al., 2005 Fujiwara et al., 2016) while disrupted learning (for example, because of school strikes) has had longer-term effects on cognitive development (Jaume and Willen, 2018; Johnson, 2011; Wills, 2014). Furthermore, unemployment is expected to remain at a high level into 2021, with significant consequences for adult and child wellbeing. For these reasons, it is crucial to conduct research on experiences after restrictions have eased and school and working life has resumed (even if in a somewhat different form). The desire to 
capture longer-term effects should, however, be balanced against potential difficulties in accurately recalling the period of pandemic restrictions if a long time has elapsed. For this reason, a COVID-19-related survey of the two GUI cohorts in autumn/winter 2020 would appear optimal.

The timing in the lives of cohort members is opportune. Cohort '08 members are making, or have just made, the transition to second-level education, a time of change and adjustment in their lives as well as a period of increasing engagement with friends as a source of their identity. Looking at their experiences will allow us to examine both the 'normal' change of adjusting to a new school setting as well as any additional challenges resulting from the effect of the pandemic. Cohort ' 98 members, the majority of whom went on to higher education, are in the process of integrating into the labour market. Their experiences are therefore likely to reflect the new precarity in the youth labour market and provide insights into the implications of unemployment or irregular employment for other aspects of their transition experiences (such as feeling like an adult or setting up their own home). Furthermore, the experience of the pandemic may have changed their envisaged future pathways or their behaviour more generally in terms of avoiding or taking risks - issues that could be usefully explored with this age group.

Information on the impact of the pandemic could be collected in two complementary ways: direct questions on the perceived effects on direct aspects of their lives (such as how they feel their relationship with their parents has changed), and looking at changes in responses to measures collected before and after the pandemic (e.g. parent-child relationship scales). It is crucial to capture variation among children and young people in their direct experience of the pandemic (for example, the illness or death of a family member) and in their experiences of the restrictions (for example, the level of contact from their school, whether their parents continued to work outside the home, whether they assumed greater responsibilities in caring for siblings). Questions could also be asked about positive aspects (such as experiences of remote working and learning, the development of particular coping strategies and the use of social media) that could usefully carry forward into lives in the post-pandemic period. Given that social distancing is expected to be in place at least until the end of 2020, a web survey is likely to be the best approach to data collection but would constrain the length of time respondents would be expected to spend completing the questionnaire. Coverage of the main domains of the children's and young people's lives would have to be balanced against an overburden of respondents resulting in lower response rates. Data from the British cohort studies could provide useful insights into the early effects of the pandemic, albeit in a different institutional context, and some questions could be replicated in Ireland to allow for comparative analyses of experiences. The content of the questionnaire should, of course, be age-appropriate, with school experiences, out-of-school activities and peer relationships more a focus for Cohort '08, and labour-market experiences more a concern for Cohort '98. Future waves of data collection for GUI, most likely with 
Cohort ' 08 at 13 years of age and Cohort ' 98 at 25 years, could build upon this COVID-19 survey to capture longer-term effects of the pandemic on the developmental trajectories of adolescents and young adults. Such data would yield a crucial evidence base for policy regarding children, young people and their families in a time of unprecedented crisis. 



\title{
APPENDIX
}

\author{
TABLE A1 \\ LIST OF COVID-19 RESEARCH (EMPIRICAL EVIDENCE, RELATED REVIEWS AND DATA) \\ INCLUDED IN THE STUDY
}
Irish research
Amárach (2020a). Coronavirus COVID-19: Public Opinion Tracking Research. Dublin: Department of Health.
Amárach (2020b). Emotional Wellbeing in a Pandemic. Dublin: Amárach.
Barron, C. and Emmett, M.J. (2020a). Impact of Coronavirus Restrictions on Children and Young People's Ability to Maintain their Play Worlds and Friendship Groups: What Do Children and Parents Say? Dublin: DCU.
Barron, C. and Emmett, M.J. (2020b). Report on the Impact of COVID-19 on Children's Play and Friendships in the Dublin City Council Area. Dublin: DCU.
Barron, C. and Emmett, M.J. (2020c). How has Social Distancing Impacted Children with Special Needs and their Parents? Dublin: DCU.
Beirne, K., Doorley, K., Regan, M., Roantree, B., Tuda, D. (2020). The Potential Costs and Distributional Effect of COVID-19 Related Unemployment in Ireland. Budget Perspectives Paper 1. Dublin: ESRI.
Bray, A., Banks, J., Ni Chorcora, E., Devitt, A. (2020). Teaching and learning during school closures. Lessons learned. Dublin: TCD.
Brick, A., Walsh, B., Keegan, C. and Lyons, S. (2020a). COVID-19 and Emergency Department Attendances in Irish Public Hospitals. ESRI Special Article. Dublin: ESRI.
Burke, J. and Dempsey, M. (2020). COVID-19 Practice in Primary Schools in Ireland Report. Maynooth:
Maynooth University.
Central Statistics Office (2020a). Monthly Unemployment June 2020.
Central Statistics Office (2020b). Social Impact of COVID-19 Survey on Women and Men April 2020.
Central Statistics Office (2020c). Employment and Life Effects of COVID-19.
Central Statistics Office (2020d). Social Impact of COVID-19 on Women and Men.
Central Statistics Office (2020e). Social Impact of COVID-19 by Age Group.
Central Statistics Office (2020f). Social Impact of COVID-19 Survey June 2020.
Central Statistics Office (2020g). Survey of Income and Living Conditions, Main Results.
Coates, D., Corcoran, D, Cronin, H. and Brioscu, A. (2020). The Initial Impacts of the COVID-19 Pandemic on Ireland's Labour Market. Dublin: Central Bank.
Dempsey, M. and Burke, J. (2020). COVID-19 Practice in Primary Schools in Ireland Report: A Two-Month
Follow-up. Maynooth: Maynooth University.
Doyle, O. (2020). COVID-19: Exacerbating Educational Inequalities? Dublin: UCD Geary Institute.
Egan, S. (2020). Play and Learning in the Early Years Survey: Impact of the COVID-19 Crisis on Children.
Limerick: Mary Immaculate College.
Fleming, P. and O'Hora, J. (2020). Impact on Family Life during COVID-19 Pandemic. Dublin: Barnardos.
Foróige (2020). Young People and COVID-19. Dublin: Foróige.
Hyland, P., Shevlin, M., McBride, O., Murphy, J. et al. (2020). Anxiety and Depression in Ireland during the COVID-19 Pandemic. PsyArXiv Preprint.
Inclusion Ireland (2020). The Implications of COVID-19 on the Education of Children with Intellectual
Disabilities and Autism. Retrieved from: www.inclusionireland.ie/publications/list
Lades, L., Laffan, K., Daly, M. \& Delaney, L. (2020). Daily Emotional Well-being during the COVID-19
Pandemic. Dublin: UCD.

Lunn, P. D., Timmons, S., Barjaková, M., Belton, C. A., Julienne, H. \& Lavin, C. (2020). Motivating Social

Distancing during the COVID-19 Pandemic: An Online Experiment. Dublin: ESRI.

McQuinn, K., O'Toole, C., Allen-Coughlan, M. and Coffey, C. (2020). Quarterly Economic Commentary Summer 2020. Dublin: ESRI.

Mohan, G., McCoy, S., Carroll, E., Mihut, G., Lyons, S., MacDomhnaill, C. (2020). Learning for All? Second Level Education during COVID-19 in Ireland. Dublin: ESRI. 
NPCPP (2020). Your view: COVID-19 and home schooling. National Parents Council Post Primary. Dublin: NPCPP.

O'Connor, C., Gallagher, E., Walsh, E. and McMahon, J. (2020). COVID-19 Worries, Parent/Carer Stress and Support Needs, by Child Special Educational Needs and Parent/Carer Work Status. Limerick: University of Limerick.

Office of the Ombudsman (2020). The Ombudsman and Direct Provision: Update for 2019. Dublin: Office of the Ombudsman.

Redmond, P. and McGuinness, S. (2020a). Essential Employees during the COVID-19 Crisis. ESRI Survey and Statistical Report Series. Dublin: ESRI.

Regan, M., and Maitre, B. (2020). Child Poverty in Ireland and the Pandemic Recession. Dublin: ESRI. Sport Ireland (2020). Impact of COVID-19 Restrictions on Sport and Recreational Walking. Dublin: Sport Ireland.

Young Social Innovators (2020). COVID-19 Youth Check In Survey. Dublin: YSI.

Ahmed, M. Z., Ahmed, O., Aibao, Z., Hanbin, S., Siyu, L., \& Ahmad, A. (2020). Epidemic of COVID-19 in China and associated psychological problems. Asian Journal of Psychiatry, 102092.

Alon, T.M., Doepke, M., Olstead-Rumsey, J., Tertilt, M. (2020). The Impact of COVID-19 on Gender Equality. Cambridge, MA: NBER Working Paper.

Ammerman, B. A., Burke, T. A., Jacobucci, R., \& McClure, K. (2020). Preliminary Investigation of the Association Between COVID-19 and Suicidal Thoughts and Behaviors in the US. Preprint.

Andrew, A., Cattan, S., Costa-Dias, M., Farquharson, C., Kraftman, L., Krutikova, S., Phimister, A., Sevilla, A. (2020). Learning during the Lockdown: Real-Time Data on Children's Experiences during Home Learning. London: The Institute for Fiscal Studies.

Asbury, K., Fox, L., Deniz, E., Code, A., \& Toseeb, U. (2020). How is COVID-19 affecting the mental health of children with Special Educational Needs and Disabilities and their families?. White Rose Research Online.

Bayrakdar, S. and Guveli, A. (2020). Inequalities in home learning and schools' provision of distance teaching during school closure of COVID-19 lockdown in the UK. Essex: Institute for Social and Economic Research. Benzeval, M., Borkowska, M., Burton, J., Crossley, T.F., Fumagalli, L., Jäckle, A.., Rabe, B. and Read, B. (2020). Understanding Society COVID-19 Survey April Briefing Note: Home Schooling. Essex: Understanding Society Working Paper No 12/2020, ISER, University of Essex.

Bones, U., Bates, J., Finlay, J., Roulston, S., Taggart, S. (2020), Ulster University Northern Ireland Parent Surveys: Experiences of Supporting Child(ren)'s Home Learning during COVID-19. UNESCO Centre, School of Education, Ulster University.

Brodeur, A., Clark, A., Fleche, S., \& Powdthavee, N. (2020). COVID-19, lockdowns and well-being: Evidence from Google Trends. SSRN preprint.

Brooks, S. K., Webster, R. K., Smith, L. E., Woodland, L., Wessely, S., Greenberg, N., \& Rubin, G. J. (2020). The psychological impact of quarantine and how to reduce it: rapid review of the evidence. The Lancet.

Bu, F., Steptoe, A., \& Fancourt, D. (2020). Who is lonely in lockdown? Cross-cohort analyses of predictors of loneliness before and during the COVID-19 pandemic. medRxiv preprint.

Burgess, S. and Sievertsen, H. (2020). Schools, Skills, and Learning: The Impact of COVID-19 on Education. VoxEu.org.

Cai, R. and Wang, Q. (2020). A Six-Step Online Teaching Method Based on Protocol-Guided Learning during the COVID-19 Epidemic: A Case Study of the First Middle School Teaching Practice in Changyuan City, Henan Province, China. Best Evidence in Chinese Education, 4(2): 529-534.

Cao, W., Fang, Z., Hou, G., Han, M., Xu, X., Dong, J., Zheng, J. (2020). The psychological impact of the COVID19 epidemic on college students in China, Psychiatry Research.

CEDEFOP (2020). Note on lifelong guidance and the COVID-19 pandemic: Responses from Cedefop's CareersNet. Thessaloniki: CEDEFOP.

Centre for Educational Policy \& Equalising Opportunities (CEPEO) (2020). Briefing Note: Academic and Social and Emotional Interventions in Response to COVID-19 School Closures. London: UCL. 
Conti, G. (2020). Supporting Parents and Children in the Early Years During (and After) the COVID-19 Crisis. Crawford, J., Butler-Henderson, K., Rudolph, J., Malkawi, B., Glowatz, M., Burton, R., Magni, P., Lam, S. (2020). COVID-19: 20 countries' higher education intra-period digital pedagogy responses. Journal of Applied Learning and Teaching. 3.1.

Cullinane, C., \& Montacute, R. (2020). COVID-19 and Social Mobility Impact Brief \#1: School Shutdown. London.

Dockery, M. and Bawa, S. (2020). Working from Home in the COVID-19 Lockdown. Bankwest Curtin Economics Centre Research Brief COVID-19 \#5.

Doherty, K., and Cullinane, D. (2020). COVID-19 and Social Mobility Impact Brief \#3: Apprenticeships. London: Sutton Trust.

Dreesen, T., Akseer, S., Brossard, M., Dewan P., Giraldo, J.-P., Kame, A., Mizunoya, S. and Ortizi, J. S. (2020). Promising practices for equitable remote learning. Emerging lessons from COVID-19 education responses in 127 countries. Innocenti Research Brief, UNICEF.

Drummond, M., Elliott, S., Drummond, C., Prichard, I. (2020). Youth sport and COVID-19: a potential generation lost. Emerald Open Research.

Education Endowment Foundation (2020). Impact of School Closures on the Attainment Gap: Rapid Evidence Assessment, London: Education Endowment Foundation.

Elmer, T., Mepham, K., \& Stadtfeld, C. (2020). Students under Lockdown: Assessing Change in Students' Social Networks and Mental Health during the COVID-19 Crisis. PsyArXiv Preprint.

Etheridge, B., \& Spantig, L. (2020). The Gender Gap in Mental Well-being during the COVID-19 Outbreak: Evidence from the UK. Essex: Institute for Social and Economic Research.

Eurydice (2020). School Closures: How is COVID-19 Affecting Schools in Europe? EACEA.

Eyles, A., Gibbons, S., Montebruno, P. (2020). COVID-19 School Shutdowns: what will they do to our children's education? A CEP COVID-19 analysis. Paper 001. London School of Economics.

Fancourt, D., Bu, F., Mak, H.W., Steptoe, A. (2020). COVID-19 Social Study: Results Release 9. London: UCL. Guan, H., Okely, A.D., Aguilar-Farias, N. et al. (2020). Promoting healthy movement behaviours among children during the COVID-19 pandemic. The Lancet Child and Adolescent Health, 4(6), 416-418.

HM Treasury (2020). A Plan for Jobs 2020: Policy Paper.

Hodges, C., Moore, S., Lockee, B., Trust, T., \& Bond, A. (2020). The difference between emergency remote teaching and online learning. Educause Review, 27.

Hossain, M. M., Sultana, A., \& Purohit, N. (2020). Mental health outcomes of quarantine and isolation for infection prevention: A systematic umbrella review of the global evidence. SSRN 3561265.

Humphreys K.L., Myint M.T., Zeanah C.H. (2020). Increased risk for family violence during the COVID-19 pandemic. Pediatrics.

Hupaku, C. and Petrongolo, C. (2020). Work, care and gender during the COVID-19 crisis. A CEP COVID-19 analysis. Paper 002. London School of Economics.

ILO (2020). Preventing exclusion from the labour market: Tackling the COVID-19 youth employment crisis, Policy Brief. Geneva: International Labour Organization.

Jessen, J. and Waights, S. (2020). Effects of COVID-19 Day Care Centre Closures on Parental Time Use: Evidence from Germany. VOX CEPR Policy Portal.

Jiao, W. Y., Wang, L. N., Liu, J., Fang, S. F., Jiao, F. Y., Pettoello-Mantovani, M., \& Somekh, E. (2020). Behavioral and emotional disorders in children during the COVID-19 epidemic. The Journal of Paediatrics, 221, 264.

Kuhfeld, M. and Tarasawa, B. (2020). The COVID-19 slide: What summer learning loss can tell us about the potential impact of school closures on student academic achievement, NWEA Research Brief.

Lancker, W. (2020). COVID-19, school closures, and child poverty: A social crisis in the making. The Lancet. Larkins, C., Stoecklin, D., Milkova, R., Del Moral Espin, L., Crowley, A., Mort, M., Easthope, L., Schuurman, M., Crook, D. and Fernandes, N. (2020). Building on Rainbows, Supporting Children's Participation in Shaping Responses to COVID-19. Lancashire: University of Central Lancashire.

Levita, L. (2020). Initial Research Findings on the Impact of COVID-19 on the Well-being of Young People Aged 13 to 24 in the UK. Sheffield: University of Sheffield. 
Liang, L., Ren, H., Cao, R., Hu, Y., Qin, Z., Li, C., \& Mei, S. (2020). The effect of COVID-19 on youth mental health. Psychiatric Quarterly, 1-12.

Limcaoco, R. S. G., Mateos, E. M., Fernandez, J. M., \& Roncero, C. (2020). Anxiety, worry and perceived stress in the world due to the COVID-19 pandemic. Preliminary results. medRxiv.

Liu, X., Liu, J., \& Zhong, X. (2020). Psychological State of College Students During COVID-19 Epidemic. SSRN 3552814.

Loades, M. E., Chatburn, E., Higson-Sweeney, N., Reynolds, S., Shafran, R., Brigden, A., et al. (2020). Rapid Systematic Review: The Impact of Social Isolation and Loneliness on the Mental Health of Children and Adolescents in the Context of COVID-19. Journal of the American Academy of Child \& Adolescent Psychiatry. Long, N. (2020). From social distancing to social containment: reimagining sociality for the coronavirus pandemic. Medicine Anthropology Theory. ISSN 2405-691X.

Markowska-Manista, U. and Zakrezewska-Oledzka, D. (2020). Family with children in times of pandemic what, where, how? Dilemmas of adult-imposed prohibitions and orders. Society Register 2020, 4(3): 89-110. Moghanibashi-Mansourieh, A. (2020). Assessing the anxiety level of Iranian general population during COVID-19 outbreak. Asian Journal of Psychiatry, 102076.

Montacute, C and Holt-White, E. (2020). COVID-19 and Social Mobility Impact Brief \#2: University Access and Student Finance. London: Sutton Trust.

Moroni, G., Nicoletti, C., Tominey, E. (2020). Children's Socio-emotional Skills and the Home Environment during the COVID-19 Crisis. VOX CEPR Policy Portal.

Niedzwiedz, C. L., Green, M., Benzeval, M., Campbell, D., Craig, P., Demou, E. ... \& Katikireddi, S. V. (2020). Mental Health and Health Behaviours Before and During the COVID-19 Lockdown: Longitudinal Analyses of the UK Household Longitudinal Study. medRxiv Preprint.

Office for National Statistics [ONS] (2020). Coronavirus and the Social Impacts on Great Britain. London: ONS.

Okruszek, L., Aniszewska-Stańczuk, A., Piejka, A., Wiśniewska, M., \& Żurek, K. (2020). Safe but Lonely? Loneliness, Mental Health Symptoms and COVID-19. OSF Preprint.

Oosterhoff, B., Palmer, C. A., Wilson, J., \& Shook, N. (2020). Adolescents' motivations to engage in social distancing during the COVID-19 pandemic: Associations with mental and social health. Journal of Adolescent Health.

Orgilés, M., Morales, A., Delvecchio, E., Mazzeschi, C., \& Espada, J. P. (2020). Immediate psychological effects of the COVID-19 quarantine in youth from Italy and Spain. PsyArXiv Preprint.

Pisano, L., Galimi, D., \& Cerniglia, L. (2020). A Qualitative report on Exploratory Data on the Possible Emotional/Behavioural Correlates of COVID-19 Lockdown in 4-10 Years Children in Italy. PsyArXiv Preprint.

Rajkumar, R. P. (2020). COVID-19 and mental health: A review of the existing literature. Asian Journal of Psychiatry, 102066.

Reimers, F. and Sleicher, A. (2020). A framework to guide an education response to the COVID-19 Pandemic of 2020. OECD: Paris.

Reimers, F., Schleicher, A., Saavedra, J., Tuominen, S. (2020). Supporting the continuation of teaching and learning during the COVID-19 Pandemic Annotated resources for online learning. OECD: Paris.

Rzymski P, Nowicki M (2020). Preventing COVID-19 prejudice in academia. Science 367 (6484):1313.

Sahu, P. (2020). Closure of Universities Due to Coronavirus Disease 2019 (COVID-19): Impact on Education and Mental Health of Students and Academic Staff. Cureus 12(4): e7541.

Save the Children (2020). COVID-19: Operational Guidance for Migrant \& Displaced Children.

Sevilla, A. and Smith, S. (2020). Baby Steps: The Gender Division of Childcare during the COVID-19 Pandemic. IZA DP No. 13302.

Shafer, K., Milkie, M., Scheibling, C. (2020). The Division of Domestic Labour Before \& During the COVID-19 Pandemic in Canada. OSF Preprint.

Shevlin, M., McBride, O., Murphy, J., Miller, J. G., Hartman, T. K., Levita, L., et al. (2020). Anxiety, Depression, Traumatic Stress, and COVID-19 Related Anxiety in the UK General Population During the COVID-19 Pandemic. PsyArXiv Preprint.

Spinelli, M., Lionetti, F., Pastore, M., \& Fasolo, M. (2020). Parents and Children Facing the COVID-19 Outbreak in Italy. SSRN 3582790. 
UNESCO (2020). Global Monitoring of School Closures Caused by COVID-19. Luxembourg: UNESCO. Urbina-Garcia, A. (2020). Young Children's Mental Health: Impact of Social Isolation During the COVID-19 Lockdown and Effective Strategies. Preprint.

Usher, K., Bhullar, N., Durkin, J., Gyamfi, N., Jackson, D. (2020). Family Violence and COVID-19: Increased Vulnerability and Reduced Options for Support. International Journal of Mental Health Nursing.

Viner, R., Russell, S., Croker, H., Packer, J., Ward, J., Stansfield, C., Mytton, O., Bonell, C., Booy, R. (2020). School closure and management practices during coronavirus outbreaks including COVID-19: a rapid systematic review, Lancet Child and Adolescent Health 2020; 4: 397-404.

Waite, P., Patalay, P., Moltrecht, B., McElroy, E. and Creswell, C. (2020). Report 02: COVID-19 Worries, Parent/Carer Stress and Support Needs, by Child Special Educational Needs and Parent/Carer Work Status. Co-SPACE study. Leicester: University of Leicester.

Walsh, G., Purdy, N., Dunn, J., Jones, S., Harris, J., \& Ballentine, M. (2020). Home-schooling in Northern Ireland During the COVID-19 Crisis: the experiences of parents and carers. Belfast.

Wang, C., Pan, R., Wan, X., Tan, Y., Xu, L., Ho, C. S., \& Ho, R. C. (2020). Immediate psychological responses and associated factors during the initial stage of the 2019 coronavirus disease (COVID-19) epidemic among the general population in China. International Journal of Environmental Research and Public Health, 17(5), 1729.

Xia, J. (2020). Practical exploration of school-family cooperative education during the COVID-19 epidemic: A case study of Zhenjiang Experimental School in Jiangsu province, China. China (March 15, 2020).

Xiao, H., Zhang, Y., Kong, D., Li, S., \& Yang, N. (2020). Social capital and sleep quality in individuals who selfisolated for 14 days during the coronavirus disease 2019 (COVID-19) outbreak in January 2020 in China. Medical Science Monitor: International Medical Journal of Experimental and Clinical Research, 26, e923921-1.

You, D., Lindt, N., Allen, R., Hansen, C., Beise, J., Blume, S. (2020). Migrant and displaced children in the age of COVID-19: How the pandemic is impacting them and what can we do to help. Migration Policy Practice, 10.

YouGov (2020). YouGov Survey Results.

YoungMinds (2020). Coronavirus: Impact on Young People with Mental Health Needs.

Zhang, J., Shuai, L., Yu, H., Wang, Z., Qiu, M., Lu, L., et al. (2020). Acute stress, behavioural symptoms and mood states among school-age children with attention-deficit/hyperactive disorder during the COVID-19 outbreak. Asian Journal of Psychiatry, 51, 102077.

Zhou, L., Wu, S., Zhou, M., Li, F. (20002020). 'School's Out, But Class's On', The Largest Online Education in the World Today: Taking China's Practical Exploration During the COVID-19 Epidemic Prevention and Control as an Example. Best Evidence in Chinese Education, 4(2): 501-519. Doi: 10.15354/bece.20.ar023. 



\section{REFERENCES}

Abdalla, S., Cronin, F., Daly, L., Drummond, A., Fitzpatrick, P., et al. (2010). All Ireland Traveller Health Study: Summary of Findings. Dublin: UCD.

Abramson, D. M., Park, Y. S., Stehling-Ariza, T., \& Redlener, I. (2010). Children as bellwethers of recovery: dysfunctional systems and the effects of parents, households, and neighborhoods on serious emotional disturbance in children after Hurricane Katrina. Disaster Medicine and Public Health Preparedness, 4(S1), S17S27.

Ackerman, R., Kashy, D., Donnellan, M., Neppl, T., Lorenz, F., Conger. R. (2013). The Interpersonal Legacy of a Positive Family Climate in Adolescence. Psychological Science, 24, 3, 243-250. DOI: 10.1177/0956797612447818.

Ahmed, M. Z., Ahmed, O., Aibao, Z., Hanbin, S., Siyu, L., \& Ahmad, A. (2020). Epidemic of COVID-19 in China and associated psychological problems. Asian Journal of Psychiatry, 102092.

Alon, T.M., Doepke, M., Olstead-Rumsey, J., Tertilt, M. (2020). The Impact of COVID-19 on Gender Equality. Cambridge, MA: NBER Working Paper.

Altintas, E., \& Sullivan, O. (2016). Fifty years of change updated: Cross-national gender convergence in housework. Demographic Research, 35, 455-470.

Amárach (2020a). Coronavirus COVID-19: Public Opinion Tracking Research. Dublin: Department of Health.

Amárach (2020b). Emotional Wellbeing in a Pandemic. Dublin: Amárach.

Ammerman, B. A., Burke, T. A., Jacobucci, R., \& McClure, K. (2020). Preliminary Investigation of the Association Between COVID-19 and Suicidal Thoughts and Behaviors in the US. Preprint.

Andrew, A., Cattan, S., Costa-Dias, M., Farquharson, C., Kraftman, L., Krutikova, S., Phimister, A., Sevilla, A. (2020). Learning during the Lockdown: Real-Time Data on Children's Experiences during Home Learning. London: The Institute for Fiscal Studies.

Armstrong, D., Kane, G., O'Sullivan, G., Kelly, M. (2010). National Survey of Parental Attitudes to and Experiences of Local and National Special Education Services. Dublin: NCSE.

Asbury, K., Fox, L., Deniz, E., Code, A., \& Toseeb, U. (2020). How is COVID-19 affecting the mental health of children with Special Educational Needs and Disabilities and their families? White Rose Research Online.

Atteberry, A. and McEachin, A. (2020). School's Out: The Role of Summers in Understanding Achievement Disparities. (EdWorkingPaper: 19-82). Retrieved from Annenberg Institute at Brown University: https://doi.org/10.26300/2mam-bp02.

Baker, M. (2013). Industrial actions in schools: strikes and student achievement. Canadian Journal of Economics/Revue canadienne d'économique, 46(3), 1014-1036.

Banks, J., Frawley, D., \& McCoy, S. (2015). Achieving inclusion? Effective resourcing of students with special educational needs. International Journal of Inclusive Education, 19(9), 926-943. doi:10.1080/13603116 2015.1018344 
Banks, D. M. \& Weems, C. F. (2014). Family and peer social support and their links to psychological distress among hurricane-exposed minority youth. American Journal of Orthopsychiatry, 84(4), 341-352.

Barron, C. and Emmett, M.J. (2020a). Impact of Coronavirus Restrictions on Children and Young People's Ability to Maintain their Play Worlds and Friendship Groups: What Do Children and Parents Say? Dublin: DCU.

Barron, C. and Emmett, M.J. (2020b). Report on the Impact of COVID-19 on Children's Play and Friendships in the Dublin City Council Area. Dublin: DCU.

Barron, C. and Emmett, M.J. (2020c). How has Social Distancing Impacted Children with Special Needs and their Parents? Dublin: DCU.

Bayrakdar, S. and Guveli, A. (2020). Inequalities in home learning and schools' provision of distance teaching during school closure of COVID-19 lockdown in the UK. Essex: Institute for Social and Economic Research.

Beirne, K., Doorley, K., Regan, M., Roantree, B., Tuda, D. (2020), The Potential Costs and Distributional Effect of COVID-19 Related Unemployment in Ireland. Budget Perspectives Paper 1. Dublin: ESRI.

Belfield, C. R. \& Levin, H. M. (Eds.). (2007). The Price We Pay: Economic and Social Consequences of Inadequate Education. Washington, DC: Brookings Institution Press.

Bell, D. N. F. \& Blanchflower, D. G. (2011). Young people and the Great Recession. Oxford Review of Economic Policy, 27, 241-267.

Benzeval, M., Borkowska, M., Burton, J., Crossley, T.F., Fumagalli, L., Jäckle, A.., Rabe, B. and Read, B. (2020). Understanding Society COVID-19 Survey April Briefing Note: Home Schooling. Essex: Understanding Society Working Paper No 12/2020, ISER, University of Essex.

Blank, G., Dutton, W. H., and Lefkowitz, J. (2020). Oxis 2019: Digital Divides in Britain Are Narrowing but Deepening. SSRN. https://doi.org/10.2139/ssrn.3522083.

Blossfeld, H. P., Buchholz, S., Skopek, J., \& Triventi, M. (eds.). (2016). Models of Secondary Education and Social Inequality: An International Comparison. Cheltenham: Edward Elgar Publishing.

Blossfeld, H., Kulic, N., Skopek, J., Triventi, M. (eds.) (2017). Childcare, early education and social inequality. Cheltenham: Edward Elgar Publishing.

Bray, A., Banks, J., Ni Chorcora, E., Devitt, A. (2020). Teaching and learning during school closures. Lessons learned. Dublin: TCD.

Brazendale, K., Beets, M. W., Turner-McGrievy, G. M., Kaczynski, A. T., Pate, R. R., \& Weaver, R. G. (2018). Children's obesogenic behaviors during summer versus school: a within-person comparison. Journal of School Health, 88(12), 886-892.

Brick, A., Walsh, B., Keegan, C. and Lyons, S. (2020a). COVID-19 and Emergency Department Attendances in Irish Public Hospitals. ESRI Special Article. Dublin: ESRI.

Brick, A., Keegan, C., Wren, M.A. (2020b). Baseline Utilisation and Demand for Specialist Mental Health Services in Ireland 2018. Dublin: ESRI. 
Briody, J. (2020). Parental Unemployment During the Great Recession and Childhood Adiposity. Dublin: UCD Geary Institute.

Brodeur, A., Clark, A., Fleche, S., \& Powdthavee, N. (2020). COVID-19, lockdowns and wellbeing: Evidence from Google Trends. SSRN preprint.

Brooks, S. K., Webster, R. K., Smith, L. E., Woodland, L., Wessely, S., Greenberg, N., \& Rubin, G. J. (2020). The psychological impact of quarantine and how to reduce it: rapid review of the evidence. The Lancet.

Bu, F., Steptoe, A. \& Fancourt, D. (2020). Who is lonely in lockdown? Cross-cohort analyses of predictors of loneliness before and during the COVID-19 pandemic. medRxiv preprint.

Bukodi, E. \& Goldthorpe, J. H. (2013). Decomposing 'social origins': The effects of parents' class, status, and education on the educational attainment of their children. European Sociological Review, 29(5), 1024-1039.

Burgess, S. and Sievertsen, H. (2020). Schools, Skills, and Learning: The Impact of COVID-19 on Education. VoxEu.org, Retrieved from: https://voxeu.org/article/impact-covid19-education.

Burke, J. and Dempsey, M. (2020). COVID-19 Practice in Primary Schools in Ireland Report. Maynooth: Maynooth University. Retrieved from:

www.into.ie/app/uploads/2020/04/COVID-19-Practice-in-Primary-SchoolsReport-1.pdf

Cai, R. and Wang, Q. (2020). A Six-Step Online Teaching Method Based on Protocol-Guided Learning during the COVID19 Epidemic: A Case Study of the First Middle School Teaching Practice in Changyuan City, Henan Province, China. Best Evidence in Chinese Education, 4(2): 529-534. Doi: 10.15354/bece.20.rp010. Retrieved from: http://scinedu.bonoi.org/sites/default/files/files/Report2_BECE-V4N215Mar2020_QZW.pdf.

Calati, R., Ferrari, C., Brittner, M., Oasi, O., Olié, E., Carvalho, A. F. \& Courtet, P. (2019). Suicidal thoughts and behaviors and social isolation: A narrative review of the literature. Journal of Affective Disorders, 245, 653-667.

Cantillon, B., Chzhen, Y., Handa, S., Nolan, B. (20170. Children of austerity. Impact of the great recession on child poverty in rich countries. New York: UNICEF, Oxford University Press, 2017. www.unicef-irc.org/publications/ pdf/Children_of_austerity.pdf (accessed April 3, 2020).

Cao, W., Fang, Z., Hou, G., Han, M., Xu, X., Dong, J., Zheng, J. (2020). The psychological impact of the COVID-19 epidemic on college students in China, Psychiatry Research, https://doi.org/10.1016/j.psychres.2020.112934

CEDEFOP (2020). Note on lifelong guidance and the COVID-19 pandemic: Responses from Cedefop's CareersNet. Thessaloniki: CEDEFOP.

Central Statistics Office (2020a). Monthly Unemployment June 2020. Retrieved from: www.cso.ie/en/releasesandpublications/er/mue/monthlyunemploymentjune202 $0 /$.

Central Statistics Office (2020b). Social Impact of COVID-19 Survey April 2020. Retrieved from: www.cso.ie/en/releasesandpublications/ep/p-sic19/socialimpactofcovid19surveyapril2020/. 
Central Statistics Office (2020c). Employment and Life Effects of COVID-19. Retrieved from: www.cso.ie/en/releasesandpublications/er/elec19/employmentandlifeeffectsofc ovid-19/.

Central Statistics Office (2020d). Social Impact of COVID-19 on Women and Men.

Retrieved from:

www.cso.ie/en/csolatestnews/pressreleases/2020pressreleases/pressstatements ocialimpactofcovid-19onwomenandmenapril2020/.

Central Statistics Office (2020e). Social Impact of COVID-19 by Age Group. Retrieved from: www.cso.ie/en/releasesandpublications/br/b-csi/socialimpactofcovid19byagegroupapril2020/.

Central Statistics Office (2020f). Social Impact of COVID-19 Survey June 2020. Retrieved from: www.cso.ie/en/releasesandpublications/ep/psic19eep/socialimpactofcovid-

19surveyjune2020asnapshotofexperiencesandexpectationsinapandemic/resultsa ndanalysis/

Central Statistics Office (2020g). Survey of Income and Living Conditions Main Results.

Retrieved from:

https://statbank.cso.ie/multiquicktables/quickTables.aspx?id=sia12_sia22

Centre for Educational Policy \& Equalising Opportunities (CEPEO) (2020). Briefing Note: Academic and Social and Emotional Interventions in Response to COVID-19 School Closures. London: UCL.

Cheung, Y. T., Chau, P. H., \& Yip, P. S. (2008). A revisit on older adults suicides and Severe Acute Respiratory Syndrome (SARS) epidemic in Hong Kong. International Journal of Geriatric Psychiatry, 23(12), 1231-1238.

Coates, D., Corcoran, D, Cronin, H. and Brioscu, A. (2020). The Initial Impacts of the COVID19 Pandemic on Ireland's Labour Market. Dublin: Central Bank.

Conti, G. (2020). Supporting Parents and Children in the Early Years During (and After) the COVID-19 Crisis. Retrieved from https://voxeu.org/article/supporting-parentsand-children-early-years-during-and-after-covid-19-crisis.

Crawford, J., Butler-Henderson, K., Rudolph, J., Malkawi, B., Glowatz, M., Burton, R., Magni, P., Lam, S. (2020). COVID-19: 20 countries' higher education intra-period digital pedagogy responses. Journal of Applied Learning and Teaching. 3.1. Retrieved from: https://journals.sfu.ca/jalt/index.php/jalt/article/view/191

Cullinane, C., \& Montacute, R. (2020). COVID-19 and Social Mobility Impact Brief \#1: School Shutdown. London. Retrieved from www.suttontrust.com/wpcontent/uploads/2020/04/COVID-19-Impact-Brief-School-Shutdown.pdf

Darmody, M. and Enright, S. (forthcoming 2020). Education of immigrant students. Integration Monitor 2020. Dublin: ESRI.

Darmody, M. and Smyth, E. (2018). Immigrant student achievement and educational policy in Ireland. In Volante et al. (eds.), Immigrant Student Achievement and Education Policy. Cross-Cultural Approaches. Springer.

Dempsey and Burke (2020). COVID-19 Practice in Primary Schools in Ireland Report: A TwoMonth Follow-up. Maynooth: Maynooth University. 
Department of Education and Skills (2019). Retention Rates of Pupils in Second-Level Schools: Entry Cohort 2012. Dublin: DES.

Department of Health (2018a). Sláintecare Implementation Strategy. Dublin: Department of Health.

Department of Health (2018b). Smile agus Sláinte: National Oral Health Policy. Dublin: Department of Health.

de Quervain, D., Aerni, A., Amini, E., Bentz, D., Coynel, D., Gerhards, C. et al. (2020). The Swiss Corona Stress Study. OSF preprint.

Dockery, A. M. and Bawa, S. (2014a). Is working from home good work or bad work? Evidence from Australian employees. Australian Journal of Labour Economics, 17(2), 163-190.

Dockery, A.M. and Bawa, S. (2014b). Is Working from Home Good Work or Bad Work? Evidence from Australian Employees. Working Paper 14/2, Bankwest Curtin Economics Centre, Curtin University.

Dockery, M. and Bawa, S. (2020). Working from Home in the COVID-19 Lockdown. Bankwest Curtin Economics Centre Research Brief COVID-19 \#5.

Doherty, K., and Cullinane, D. (2020). COVID-19 and Social Mobility Impact Brief \#3: Apprenticeships. London: Sutton Trust.

Doherty, E., Walsh, B., \& O'Neill, C. (2014). Decomposing socioeconomic inequality in child vaccination: results from Ireland. Vaccine, 32(27), 3438-3444.

Dolton, P., \& Siles, M. (2003). The determinants and consequences of overeducation. In F. Buchel, A. de Grip, \& A. Mertens (eds.), Overeducation in Europe (pp. 189-217). Cheltenham, UK: Edward Elgar.

Dooley, B., O'Connor, C., Fitzgerald, A., \& O’Reilly, A. (2020). My World Survey 2: National Study of Youth Mental Health in Ireland. Dublin: UCD.

Doyle, O. (2020). COVID-19: Exacerbating Educational Inequalities? Dublin: UCD Geary Institute.

Dreesen, T., Akseer, S., Brossard, M., Dewan P., Giraldo, J.-P., Kame, A., Mizunoya, S. and Ortizi, J. S. (2020). Promising practices for equitable remote learning. Emerging lessons from COVID-19 education responses in 127 countries. Innocenti Research Brief, UNICEF. Retrieved from: www.unicef-irc.org/publications/pdf/IRB\%20202010.pdf.

Drummond, M., Elliott, S., Drummond, C., Prichard, I. (2020). Youth sport and COVID-19: a potential generation lost. Emerald Open Research, online.

Education Endowment Foundation (2020). Impact of School Closures on the Attainment Gap: Rapid Evidence Assessment, London: Education Endowment Foundation.

Eisenberg ME, Olson RE, Neumark-Sztainer D, Story M, Bearinger LH. Correlations between family meals and psychosocial well-being among adolescents. Archives of Paediatric and Adolescent Medicine. 2004; 158:792-796. doi: 10.1001/archpedi.158.8.792.

Egan, S. (2020). Play and Learning in the Early Years Survey: Impact of the COVID-19 Crisis on Children. Limerick: Mary Immaculate College. 
Eivers, E., Clerkin, A., Millar, D. and Close, S. (2010). The 2009 National Assessments: Technical Report. Dublin: Educational Research Centre.

Elmer, T., Mepham, K., \& Stadtfeld, C. (2020). Students under Lockdown: Assessing Change in Students' Social Networks and Mental Health during the COVID-19 Crisis. PsyArXiv Preprint.

Etheridge, B., \& Spantig, L. (2020). The Gender Gap in Mental Well-being during the COVID19 Outbreak: Evidence from the UK. Essex: Institute for Social and Economic Research.

European Institute for Gender Equality (2020). Gender Equality Index 2019. Vilnius: European Institute for Gender Equality.

Eurydice (2020). School Closures: How is COVID-19 Affecting Schools in Europe? https://eacea.ec.europa.eu/national-policies/eurydice/content/how-covid-19affecting-schools-europe_en

Eyles, A., Gibbons, S., Montebruno, P. (2020). COVID-19 School Shutdowns: what will they do to our children's education? A CEP COVID-19 analysis. Paper 001. London School of Economics.

Fahey, T., Keilthy, P., Polek, E. (2012). Family Relationships and Family Well-Being: A Study of the Families of Nine-Year-Olds in Ireland. Dublin: UCD. Retrieved from: www.ucd.ie/t4cms/Family\%20Relationships\%20and\%20Family\%20WellBeing\%20Dec\%202012.pdf

Fancourt, D., Bu, F., Mak, H.W., Steptoe, A. (2020). COVID-19 Social Study: Results Release 9. London: UCL.

Fleming, P., and O'Hora, J. (2020). Impact on Family Life during COVID-19 Pandemic. Dublin: Barnardos.

Foróige (2020). Young People and COVID-19. Dublin: Foróige.

Fujiwara, T., Yagi, J., Homma, H., Mashiko, H., Nagao, K., \& Okuyama, M. (2017). Symptoms of post-traumatic stress disorder among young children 2 years after the Great East Japan Earthquake. Disaster Medicine and Public Health Preparedness, 11(2), 207215.

Fundamental Rights Agency (2014). Violence against Women. Vienna: Fundamental Rights Agency.

Gangl, M. (2004). Welfare states and the scar effects of unemployment: A comparative analysis of the United States and West Germany. American Journal of Sociology, 109(6), 1319-1364.

Gangl, M., Müller, W., and Raffe, D. (2003). Conclusions: Explaining Cross-National Differences in School-to-Work Transitions. In Transitions from Education to Work in Europe: The Integration of Youth into EU Labour Markets, edited by M. Gangl and W. Müller, 277-305. Oxford: Oxford University Press.

Government of Ireland (2020). Sharing the Vision: A Mental Health Policy for Everyone. Dublin: Stationery Office. 
Grotti, R., Maître, B., Watson, D. (2018). Technical Paper on Social Inclusion and Access to Care Services in Ireland. Dublin: Department of Employment Affairs and Social Protection.

Grotti, R., Russell, H. \& O'Reilly (2019) Where do young people work? in O'Reilly, J., Leschke, J., Ortlieb, R., Seeleib-Kaiser, M., \& Villa, P. (eds.). Youth Labor in Transition: Inequalities, Mobility, and Policies in Europe. Oxford: Oxford University Press.

Growing Up in Ireland Study Team (2018a). Key Findings: Cohort '08 at 9 Years Old, Health and Physical Development (No. 3). Dublin: ESRI/TCD/DCYA.

Growing Up in Ireland Study Team (2018b). Key Findings: Cohort '08 at 9 Years Old, Relationships \& Socio-emotional Well-being (No. 4). Dublin: ESRI/TCD/DCYA.

Growing Up in Ireland Study Team (2019). Key Findings: Cohort '98 at 20 Years Old in 2018/19, Education, Training and Employment (No. 4). Dublin: ESRI/TCD/DCYA.

Guan, H., Okely, A.D., Aguilar-Farias, N. et al. (2020). Promoting healthy movement behaviours among children during the COVID-19 pandemic. The Lancet Child and Adolescent Health, 4(6), 416-418.

Helbling, L.A., Sacchi, S. and Imdorf, C. (2019) Comparing long-term scarring effects of unemployment across countries: the impact of graduating during an economic downturn. In Hvinden, B. O'Reilly, J. Schoyen, M. \& Hygge, C. (eds.) Negotiating Early Job Insecurity Well-being, Scarring and Resilience of European Youth. Cheltenham: Edward Elgar. DOI: https://doi.org/10.4337/9781788118798

HM Treasury (2020). A Plan for Jobs 2020: Policy Paper. https://www.gov.uk/government/publications/a-plan-for-jobs-documents/aplan-for-jobs-2020

Hodges, C., Moore, S., Lockee, B., Trust, T., \& Bond, A. (2020). The difference between emergency remote teaching and online learning. Educause Review, 27.

Hossain, M. M., Sultana, A., \& Purohit, N. (2020). Mental health outcomes of quarantine and isolation for infection prevention: A systematic umbrella review of the global evidence. SSRN 3561265.

Hoven, C. W., Duarte, C. S., Lucas, C. P., Wu, P., Mandell, D. J., Goodwin, R. D. ... \& Musa, G. J. (2005). Psychopathology among New York City public school children 6 months after September 11. Archives of General Psychiatry, 62(5), 545-551.

HSE (2020). A Vision for Change: Report of the Expert Group on Mental Health Policy. Dublin: HSE.

Humphreys K.L., Myint M.T., Zeanah C.H. (2020). Increased risk for family violence during the COVID-19 pandemic. Pediatrics; doi: 10.1542/peds.2020-0982

Hyland, P., Shevlin, M., McBride, O., Murphy, J. et al. (2020). Anxiety and Depression in Ireland during the COVID-19 Pandemic. PsyArXiv Preprint.

Iannotti, R. J., Chen, R., Kololo, H., Petronyte, G., Haug, E., \& Roberts, C. (2012). Motivations for adolescent participation in leisure-time physical activity: international differences. Journal of Physical Activity and Health, 10(1), 106-114. 
ILO (2020) Preventing exclusion from the labour market: Tackling the COVID-19 youth employment crisis, Policy Brief. Geneva: International Labour Organisation

Inclusion Ireland (2020). The Implications of COVID-19 on the Education of Children with Intellectual disabilities and Autism. Retrieved from:

www.inclusionireland.ie/publications/list

Jaume, D., \& Willén, A. (2019). The long-run effects of teacher strikes: evidence from Argentina. Journal of Labor Economics, 37(4), 1097-1139.

Jessen, J. and Waights, S. (2020). Effects of COVID-19 Day Care Centre Closures on Parental Time Use: Evidence from Germany. VOX CEPR Policy Portal. Retrieved from: https://voxeu.org/article/covid-19-day-care-centre-closures-and-parental-timeuse.

Jiao, W. Y., Wang, L. N., Liu, J., Fang, S. F., Jiao, F. Y., Pettoello-Mantovani, M., \& Somekh, E. (2020). Behavioral and emotional disorders in children during the COVID-19 epidemic. The Journal of Pediatrics, 221, 264.

Johnson, D. R. (2011). Do strikes and work-to-rule campaigns change elementary school assessment results? Canadian Public Policy, 37(4), 479-494.

Kelly, E., Kingston, G., Russell, H., \& McGinnity, F. (2015). The equality impact of the unemployment crisis, Journal of the Statistical and Social Inquiry Society of Ireland, Vol. XLIV.

Kelly, E \& McGuinness, S. (2014). Impact of the Great Recession on unemployed and NEET individuals' labour market transitions in Ireland, Economic Systems (2014), http://dx.doi.org/10.1016/j.ecosys.2014.06.004.

Klein, T. P., Devoe, E. R., Miranda-Julian, C., \& Linas, K. (2009). Young children's responses to September 11th: The New York City experience. Infant Mental Health Journal, 30(1), 1-22.

Költo, A., Gavin, A., Molcho, M., Kelly, C., Walker, L. and Nic Gabhainn, S. (2020). The Irish Health Behaviour in School-aged Children (HBSC) Study 2018. Galway: NUI Galway.

Kuhfeld, M. and Tarasawa, B. (2020). The COVID-19 slide: What summer learning loss can tell us about the potential impact of school closures on student academic achievement, NWEA Research Brief. Retrieved from:

www.nwea.org/content/uploads/2020/05/Collaborative-Brief_COVID19-SlideAPR20.pdf

Kühne, S., Kroh, M., Liebig, S., Zinn, S. (2020). The need for household panel surveys in times of crisis: the case of SOEP-CoV. Survey Research Methods, 14(2), 195-203.

Lades, L., Laffan, K., Daly, M., \& Delaney, L. (2020). Daily Emotional Well-being during the COVID-19 Pandemic. Dublin: UCD.

Lancker, W. (2020). COVID-19, school closures, and child poverty: A social crisis in the making. The Lancet. https://doi.org/10.1016/ S2468-2667(20)30084-0.

Larkins, C., Stoecklin, D., Milkova, R., Del Moral Espin, L., Crowley, A., Mort, M., Easthope, L., Schuurman, M., Crook, D. and Fernandes, N. (2020). Building on Rainbows, Supporting Children's Participation in Shaping Responses to COVID-19. Lancashire: University of Central Lancashire. 
Levita, L. (2020). Initial Research Findings on the Impact of COVID-19 on the Well-being of Young People Aged 13 to 24 in the UK. Sheffield: University of Sheffield.

Liang, L., Ren, H., Cao, R., Hu, Y., Qin, Z., Li, C., \& Mei, S. (2020). The effect of COVID-19 on youth mental health. Psychiatric Quarterly, 1-12.

Limcaoco, R. S. G., Mateos, E. M., Fernandez, J. M., \& Roncero, C. (2020). Anxiety, worry and perceived stress in the world due to the COVID-19 pandemic. Preliminary results. medRxiv.

Liu, X., Liu, J., \& Zhong, X. (2020). Psychological State of College Students During COVID-19 Epidemic. SSRN 3552814.

Loades, M. E., Chatburn, E., Higson-Sweeney, N., Reynolds, S., Shafran, R., Brigden, A., et al. (2020). Rapid Systematic Review: The Impact of Social Isolation and Loneliness on the Mental Health of Children and Adolescents in the Context of COVID19. Journal of the American Academy of Child \& Adolescent Psychiatry.

Long, N. (2020). From social distancing to social containment: reimagining sociality for the coronavirus pandemic. Medicine Anthropology Theory. ISSN 2405-691X (Submitted).

Lunn, P. D. (2010). The sports and exercise life-course: A survival analysis of recall data from Ireland. Social Science \& Medicine, 70(5), 711-719.

Lunn, P., Kelly, E., \& Fitzpatrick, N. (2013). Keeping them in the game: Taking up and dropping out of sport and exercise in Ireland. Dublin: ESRI.

Lunn, P. D., Timmons, S., Barjaková, M., Belton, C. A., Julienne, H., \& Lavin, C. (2020). Motivating Social Distancing during the COVID-19 Pandemic: An Online Experiment. Dublin: ESRI.

Markowska-Manista, U. and Zakrezewska-Oledzka, D. (2020). Family with children in times of pandemic - what, where, how? Dilemmas of adult-imposed prohibitions and orders. Society Register 2020, 4(3): 89-110. ISSN 2544-5502 DOI: 10.14746/sr.2020.4.3.05.

McCoy, S., Lyons, S., Coyne, B., Darmody, M. (2016). Teaching and Learning in SecondLevel Schools at the Advent of High-Speed Broadband. Dublin: ESRI. Retrieved from: www.esri.ie/system/files/media/file-uploads/2016-04/RS51.pdf.

McCoy, S., Smyth, E., Watson, D., Darmody, M. (2014). Leaving School in Ireland: A Longitudinal Study of Post-School Transitions. ESRI Research Series 36. Dublin: ESRI.

McGinnity, F., Fahey, É., Arnold, S., Maitre, B. \& O’Connell, P. J. (2018). Monitoring Report on Integration 2018. Dublin: ESRI.

McGinnity, F., McMullin, P., Murray, A., Russell, H. (2017). Social inequality and cognitive outcomes in Ireland: what is the role of the home learning environment and childcare? In Blossfeld et al. (eds.), Childcare, Early Education and Social Inequality: An International Perspective. Elgar Publishing.

McGinnity, F., Murray, A. \& Russell H. (2015). Non-parental Childcare and Child Cognitive Outcomes at Age 5: Results from the Growing Up in Ireland Infant Cohort. Dublin: Department of Children and Youth Affairs. 
McGinnity, F. and Russell, H. (2008). Gender Inequalities in Time Use. The Distribution of Caring, Housework and Employment Among Women and Men in Ireland. Dublin: The Equality Authority/ESRI.

McGinnity, F., Russell, H, Enright, S. \& Privalko, I. (forthcoming) Socio-Economic Rights Monitoring Framework: Monitoring Decent Work. Dublin: IHREC/ESRI.

McGuinness, S., Bergin, A., Kelly, E., McCoy, S., Smyth, E., Whelan, A., \& Banks, J. (2014). Further Education and Training in Ireland: Past, Present and Future. Dublin: ESRI.

McGuinness, S., Bergin, A., Kelly, E., McCoy, S., Smyth, E., Watson, D., \& Whelan, A. (2018). Evaluation of PLC Programme Provision. Dublin: ESRI.

McGuinness, S., \& Sloane, P. J. (2011). Labour market mismatch among UK graduates: An analysis using reflex data. Economics of Education Review, 30, 130-145.

McLeod, S., Harrison, L. J., Whiteford, C., \& Walker, S. (2016). Multilingualism and speechlanguage competence in early childhood: Impact on academic and socialemotional outcomes at school. Early Childhood Research Quarterly, 34, 53-66.

McMunn, A., Bird, L., Webb, E., \& Sacker, A. (2020). Gender divisions of paid and unpaid work in contemporary UK couples. Work, Employment and Society, 34(2), 155-173.

McNamara, E., Murphy, D., Murray, A., Smyth, E. and Watson, D. (forthcoming). Growing Up in Ireland: The Lives of 17/18 Year Olds of Cohort'98. Dublin: DCYA.

McQuinn, K., O'Toole, C., Allen-Coughlan, M. and Coffey, C. (2020). Quarterly Economic Commentary Summer 2020. Dublin: ESRI.

Melhuish, E., and Gardiner, J. (2018). Study of Early Education and Development (SEED): Impact Study on Early Education Use and Child Outcomes up to age four years. Department for Education Research Report. Retrieved from: https://assets.publishing.service.gov.uk/government/uploads/system/uploads/at tachment_data/file/738725/SEED_Impact_Age_4_Report_September_2018.pdf

Moghanibashi-Mansourieh, A. (2020). Assessing the anxiety level of Iranian general population during COVID-19 outbreak. Asian Journal of Psychiatry, 102076.

Mohan, G., McCoy, S., Carroll, E., Mihut, G., Lyons, S., MacDomhnaill, C. (2020). Learning for All? Second Level Education during COVID-19 in Ireland. Dublin: ESRI.

Montacute, C and Holt-White, E. (2020). COVID-19 and Social Mobility Impact Brief \#2: University Access and Student Finance. London: Sutton Trust.

Moos, R. (1986). The Social Climate Scales. Palo Alto, CA: Consulting Psychologists Press.

Moroni, G., Nicoletti, C., Tominey, E. (2020). Children's Socio-emotional Skills and the Home Environment during the COVID-19 Crisis. VOX CEPR Policy Portal. Retrieved from: https://voxeu.org/article/children-s-socio-emotional-skills-and-homeenvironment-during-covid-19-crisis.

Murray, A., McNamara, E., Williams, J., Smyth, E. (2019). GUI - The Lives of 5-year-olds. Dublin: DCYA.

Niedzwiedz, C. L., Green, M., Benzeval, M., Campbell, D., Craig, P., Demou, E. ... \& Katikireddi, S. V. (2020). Mental Health and Health Behaviours Before and During the COVID-19 Lockdown: Longitudinal Analyses of the UK Household Longitudinal Study. medRxiv Preprint. 
Nixon, E. (2012). Growing Up in Ireland: How Families Matter for Social and Emotional Outcomes of 9-year-old Children. Dublin: Government Publications.

Nixon, E., Layte, R. \& Thornton, M. (2019). Growing Up in Ireland: The Effects of Economic Recession and Family Stress on the Adjustment of 3-year olds in Ireland. Dublin: DCYA.

Nolan, A., \& Layte, R. (2014). Socio-economic Inequalities in Child Health in Ireland. The Economic and Social Review, 45(1, Spring), 25-64.

Nolan, A., and Smyth, E. (2020). Clusters of Health Behaviours among Young Adults in Ireland. Dublin: HSE/ESRI.

NPCPP (2020). Your view: COVID-19 and home schooling. National Parents Council Post Primary.

NTACC (2013). National Traveller Accommodation Consultative Committee Annual Report. Dublin: NTACC.

O'Connor, C., Gallagher, E., Walsh, E. and McMahon, J. (2020). COVID-19 Worries, Parent/Carer Stress and Support Needs, by Child Special Educational Needs and Parent/Carer Work Status. Limerick: University of Limerick.

OECD (2020). Education at a Glance. Paris: OECD.

Office for National Statistics [ONS] (2020). Coronavirus and the Social Impacts on Great Britain. London: ONS.

Office of the Ombudsman (2020). The Ombudsman and Direct Provision: Update for 2019. Dublin: Office of the Ombudsman.

Okruszek, L., Aniszewska-Stańczuk, A., Piejka, A., Wiśniewska, M., \& Żurek, K. (2020). Safe but Lonely? Loneliness, Mental Health Symptoms and COVID-19. OSF Preprint.

Olds, T., Maher, C., \& Dumuid, D. (2019). Life on holidays: differences in activity composition between school and holiday periods in Australian children. $B M C$ Public Health, 19(2), 450.

Oosterhoff, B., Palmer, C. A., Wilson, J., \& Shook, N. (2020). Adolescents' motivations to engage in social distancing during the COVID-19 pandemic: Associations with mental and social health. Journal of Adolescent Health.

O’Reilly, J., Eichhorst, W., Gábos, A. Hadjivassiliou, K. Lain, D., Leschke, J, McGuinness, S. Mýtna Kureková, Nazio, T., Ortlieb, R., Russell, H. and Villa, P. (2015). Five Characteristics of Youth Unemployment in Europe: Flexibility, Education, Migration, Family Legacies, and EU Policy. Sage Open 5 (1): 1-19. doi: $10.1177 / 2158244015574962$.

O'Reilly J., Grotti, R., Russell H. (2019a). Are some sectors more 'youth friendly' than others? Employment regimes, sectors, and gender disparities in the Great Recession. Human Resources Management Journal, 1-19. https://doi.org/10.1111/1748-8583.12242.

O’Reilly, J., Leschke, J., Ortlieb, R., Seeleib-Kaiser, M., \& Villa, P. (2019b). Comparing Youth Transitions in Europe: Joblessness, Insecurity, institutions and inequality, in O’Reilly, J., Leschke, J., Ortlieb, R., Seeleib-Kaiser, M., \& Villa, P. (eds.). Youth Labor 
in Transition: Inequalities, Mobility, and Policies in Europe. Oxford: Oxford University Press.

Orgilés, M., Morales, A., Delvecchio, E., Mazzeschi, C., \& Espada, J. P. (2020). Immediate psychological effects of the COVID-19 quarantine in youth from Italy and Spain. PsyArXiv Preprint.

Pavee Point Traveller and Roma Centre and Department of Justice and Equality (2018). Roma in Ireland: A National Needs Assessment. Dublin: Pavee Point.

Pérez-Pereira, M., Tinajero, C., Rodríguez, M. S., Peralbo, M., \& Sabucedo, J. M. (2012). Academic effects of the Prestige oil spill disaster. The Spanish Journal of Psychology, 15(3), 1055-1068.

Pfefferbaum, B., Jacobs, A. K., Houston, J. B., \& Griffin, N. (2015). Children's disaster reactions: the influence of family and social factors. Current Psychiatry Reports, 17(7), 57.

Pisano, L., Galimi, D., \& Cerniglia, L. (2020). A Qualitative report on Exploratory Data on the Possible Emotional/Behavioral Correlates of COVID-19 Lockdown in 4-10 Years Children in Italy. PsyArXiv Preprint.

Rajkumar, R.P. (2020). COVID-19 and mental health: A review of the existing literature. Asian Journal of Psychiatry, 102066.

Rashid, H., Ridda, I., King, C., et al. (2015). Evidence compendium and advice on social distancing and other related measures for response to an influenza pandemic. Paediatric Respiratory Review, 16: 119-26.

Redmond, P. (2020). Minimum Wage Policy in Ireland. Dublin: ESRI.

Redmond, P. and McGuinness, S. (2020a). Essential Employees during the COVID-19 Crisis. ESRI Survey and Statistical Report Series. Dublin: ESRI.

Redmond, P. and McGuinness, S. (2020b). Who Can Work from Home in Ireland? ESRI Survey and Statistical Report Series. Dublin: ESRI.

Regan, M. (2020). Wage Scarring among Unlucky European Cohorts. Dublin: ESRI Working Paper.

Regan, M. and Maitre, B. (2020). Child Poverty in Ireland and the Pandemic Recession. Dublin: ESRI.

Reimers, F. and Sleicher, A. (2020). A framework to guide an education response to the COVID-19 Pandemic of 2020. OECD: Paris.

Reimers, F., Schleicher, A., Saavedra, J., Tuominen, S. (2020). Supporting the continuation of teaching and learning during the COVID-19 Pandemic. Annotated resources for online learning. OECD: Paris.

Reinhard, E., Layte, R., McCrory, C., Panico, L. \& Avendano, M. (2018). The great recession and the health of young children: a fixed-effects analysis in Ireland. American Journal of Epidemiology, 187(7), 1438-1448.

Roantree, B. (2020). Understanding income inequality in Ireland. Journal of the Statistical and Social Inquiry Society of Ireland, online. 
Russell, H., Grotti, R., McGinnity, F. \& Privalko, I. (2019). Caring and Unpaid Work in Ireland. Dublin: ESRI.

Russell, H., Kenny, O., McGinnity, F. (2016). Childcare, Early Education and Socio-Emotional Outcomes at Age 5: Evidence from the Growing Up in Ireland study. Dublin: Pobal/ESRI.

Russell, H., Leschke, J., \& Smith, M. (2019). Balancing flexibility and security in Europe? The impact of unemployment on young peoples' subjective well-being. European Journal of Industrial Relations, https://doi.org/10.1177/0959680119840570.

Russell, H., McGinnity, F., Fahey, E., Kenny, O. (2018). Maternal Employment and the Cost of Childcare in Ireland. Dublin: Pobal/ESRI.

Russell, H. \& O'Connell, P. (2001). Getting a job in Europe: The transition from unemployment to work among young people in nine European countries. Work, Employment and Society, 15, 1-24.

Russell, H., Watson, D., Smyth, E., and McGinnity, F. (2020). ESRI Submission on Childcare. Submission to the Oireachtas Committee on Child Care.

Rzymski P, Nowicki M (2020). Preventing COVID-19 prejudice in academia. Science 367 (6484):1313. https://doi.org/10.1126/science.abb4870. PubMed PMID: 32193314

Sacerdote, B. (2012). When the Saints Go Marching Out: Long-Term Outcomes for Student Evacuees from Hurricanes Katrina and Rita. American Economic Journal: Applied Economics, 4(1):109-35.

Sahu, P. (2020). Closure of Universities Due to Coronavirus Disease 2019 (COVID-19): Impact on Education and Mental Health of Students and Academic Staff. Cureus 12(4): e7541. DOI 10.7759/cureus.7541

Save the Children (2020). COVID-19: Operational Guidance for Migrant \& Displaced Children. Retrieved from: https://bettercarenetwork.org/sites/default/files/202004/OperationalGuidanceCOVID19andMigrationandDisplacement.pdf

Shafer, K., Milkie, M., Scheibling, C. (2020). The Division of Domestic Labour Before \& During the COVID-19 Pandemic in Canada. OSF Preprint.

Shevlin, M., McBride, O., Murphy, J., Miller, J. G., Hartman, T. K., Levita, L., et al. (2020). Anxiety, Depression, Traumatic Stress, and COVID-19 Related Anxiety in the UK General Population During the COVID-19 Pandemic. PsyArXiv Preprint.

Smyth, E. (2008). Just a phase? Youth unemployment in the Republic of Ireland. Journal of Youth Studies, 11(3): 313-329.

Smyth, E. (2016a). Arts and Cultural Participation among Children and Young People: Insights from the Growing Up in Ireland study. Dublin: Arts Council/ESRI.

Smyth, E. (2016b). Wellbeing and School Experiences among 9-and 13-year-olds: Insights from the Growing Up in Ireland study. Dublin: NCCA/ESRI.

Smyth, E. (2017). Growing Up in Ireland: Off to a Good Start? Primary School Experiences and the Transition to Second-Level Education. Dublin: The Stationery Office.

Smyth, E. (2018). The Transition to Primary Education: Insights from the Growing Up in Ireland Study. Dublin: ESRI. 
Smyth, E. (forthcoming). Arts and Cultural Participation among 17 Year Olds. Dublin: Arts Council/ESRI.

Smyth, S. \& Banks, J. (2012) 'There was never really any question of anything else': Young People's Agency, Institutional Habitus and the Transition to Higher Education, British Journal of Sociology of Education, 33, 263-281.

Smyth, E., Banks, J., \& Calvert, E. (2011). From Leaving Certificate to Leaving School: A Longitudinal Study of Sixth Year Students. Dublin: ESRI.

Smyth, E., Banks, J., O'Sullivan, J., McCoy, S., Redmond, P., McGuinness, S. (2019). Evaluation of the National YouthReach Programme. Dublin: Solas/ESRI.

Smyth, E., Gangl, M., Raffe, D. et al. (2001). A Comparative Analysis of Transitions from Education to Work in Europe (CATEWE): Final Report. Dublin: Report to the European Commission.

Smyth, E., McCoy, S., Banks, J. (2019). Student, Teacher and Parent Perspectives on Senior Cycle Education. Dublin: ESRI.

Smyth, E., McCoy, S., \& Kingston, G. (2015). Learning from the Evaluation of DEIS. Dublin: ESRI.

Spinelli, M., Lionetti, F., Pastore, M., \& Fasolo, M. (2020). Parents and Children Facing the COVID-19 Outbreak in Italy. Available at SSRN 3582790.

Sport Ireland (2020). Impact of COVID-19 Restrictions on Sport and Recreational Walking. Dublin: Sport Ireland.

Sprang, G., \& Silman, M. (2013). Posttraumatic stress disorder in parents and youth after health-related disasters. Disaster Medicine and Public Health Preparedness, 7(1), 105-110.

Steinmetz, S., Bianchi, A., Tidjens, K. and Biffignandi, S. (2014). Improving web survey quality. In M. Callegaro, R. Baker, J. Bethelem, A.S. Göritz, J.A. Krosnick and P.J. Lavrakas (eds.), Online Panel Research: A Data Quality Perspective, New Jersey: John Wiley \& Sons.

Strandh, M. Winefield, A., Nilsson, K. \& Hammarstrom, A. (2014). Unemployment and mental health scarring during the life course, European Journal of Public Health, $24,3,440-445$.

Tatsuta, N., Nakai, K., Satoh, H., \& Murata, K. (2015). Impact of the great east Japan earthquake on child's IQ. The Journal of Pediatrics, 167(3), 745-751.

UNESCO (2020). Global Monitoring of School Closures Caused by COVID-19. Luxembourg: UNESCO.

Urbina-Garcia, A. (2020). Young Children's Mental Health: Impact of Social Isolation During the COVID-19 Lockdown and Effective Strategies. Preprint.

Usher, K., Bhullar, N., Durkin, J., Gyamfi, N., Jackson, D. (2020). Family Violence and COVID19: Increased Vulnerability and Reduced Options for Support. International Journal of Mental Health Nursing. doi: 10.1111/inm.12735.

Viner, R., Russell, S., Croker, H., Packer, J., Ward, J., Stansfield, C., Mytton, O., Bonell, C., Booy, R. (2020). School closure and management practices during coronavirus outbreaks including COVID-19: a rapid systematic review, Lancet Child and 
Adolescent Health 2020; 4: 397-404, https://doi.org/10.1016/ S23524642(20)30095-X.

Waite, P., Patalay, P., Moltrecht, B., McElroy, E. and Creswell, C. (2020). Report 02: COVID19 Worries, Parent/Carer Stress and Support Needs, by Child Special Educational Needs and Parent/Carer Work Status. Co-SPACE study. Leicester: University of Leicester.

Walsh, G., Purdy, N., Dunn, J., Jones, S., Harris, J., \& Ballentine, M. (2020). Homeschooling in Northern Ireland During the COVID-19 Crisis: the experiences of parents and carers. Belfast. Retrieved from www.stran.ac.uk/wpcontent/uploads/2020/05/Research-Report-Homeschooling-in-Northern-Irelandduring-the-COVID-19-Crisis.pdf

Wang, C., Pan, R., Wan, X., Tan, Y., Xu, L., Ho, C. S., \& Ho, R. C. (2020). Immediate psychological responses and associated factors during the initial stage of the 2019 coronavirus disease (COVID-19) epidemic among the general population in China. International Journal of Environmental Research and Public Health, 17(5), 1729.

Watson, D., Kenny, O., McGinnity, F. (2017). A Social Portrait of Travellers in Ireland. Dublin: ESRI.

Watson, D., Maitre, B., Whelan, C. T., \& Williams, J. (2014). Dynamics of Child Economic Vulnerability and Socio-emotional Development: An Analysis of the First Two Waves of the Growing Up in Ireland Study. Dublin: Office of the Minister for Children.

Watson, D., Smyth, E., McNamara, E., O'Mahony, D., Murray, A. and O'Reilly, C. (forthcoming). Growing Up in Ireland: The Lives of 9-Year-Olds of Cohort '08. Dublin: DCYA.

Williams, J., Greene, S., Doyle, E., Harris, E., Layte, R., McCoy, S., McCrory, C., Murray, A., Nixon, E., O'Dowd, T., O'Moore, M., Quail, A., Smyth, E., Swords, L., Thornton, M. (2009). GUI - The Lives of 9-year-olds. Dublin: ESRI.

Williams, J., Nixon, E., \& Smyth, E. (eds.) (2016). Cherishing All the Children Equally?: Children in Ireland 100 Years on from the Easter Rising. Dublin: Oak Tree Press.

Williams, J., Thornton, M., Morgan, M., Quail, A., Smyth, E., Murphy, D., O'Mahony, D. (2018). GUI - The Lives of 13-year-olds. Dublin: ESRI.

Wills, G. (2014). The effects of teacher strike activity on student learning in South African primary schools. Economic Research Southern Africa Working paper.

Xia, J. (2020). Practical exploration of school-family cooperative education during the COVID-19 epidemic: A case study of Zhenjiang Experimental School in Jiangsu province, China. China (March 15, 2020).

Xiao, H., Zhang, Y., Kong, D., Li, S., \& Yang, N. (2020). Social capital and sleep quality in individuals who self-isolated for 14 days during the coronavirus disease 2019 (COVID-19) outbreak in January 2020 in China. Medical Science Monitor: International Medical Journal of Experimental and Clinical Research, 26, e9239211.

You, D., Lindt, N., Allen, R., Hansen, C., Beise, J., Blume, S. (2020). Migrant and displaced children in the age of COVID-19: How the pandemic is impacting them and what 
can we do to help. Migration Policy Practice, 10. Retrieved from: https://data.unicef.org/resources/migrant-and-displaced-children-in-the-age-ofcovid-19/

YouGov (2020). YouGov Survey Results. Retrieved from www.yougov.co.uk.

YoungMinds (2020). Coronavirus: Impact on Young People with Mental Health Needs. Retrieved from: https://youngminds.org.uk/media/3708/coronavirusreport_march2020.pdf

Young Social Innovators (2020). COVID-19 Youth Check In Survey. Dublin: YSI.

Zhang, J., Shuai, L., Yu, H., Wang, Z., Qiu, M., Lu, L., et al. (2020). Acute stress, behavioural symptoms and mood states among school-age children with attentiondeficit/hyperactive disorder during the COVID-19 outbreak. Asian Journal of Psychiatry, 51, 102077.

Zheteyeva, Y., Rainey, J.J., Gao, H., Jacobson, E.U., Adhikari, B.B., Shi, J., et al. (2017). Unintended costs and consequences of school closures implemented in preparation for Hurricane Isaac in Harrison County School District, Mississippi, August-September 2012. PLoS ONE 12(11): e0184326. https://doi.org/10.1371/journal. pone.0184326

Zhou, L., Wu, S., Zhou, M., Li, F. (2020). 'School's Out, But Class's On', The Largest Online Education in the World Today: Taking China's Practical Exploration During The COVID-19 Epidemic Prevention and Control as An Example. Best Evidence in Chinese Education, 4(2): 501-519. Doi: 10.15354/bece.20.ar023

Zucotti, C. \& O'Reilly, J. (2019) Do Scarring Effects Vary by Ethnicity and Gender?, in O'Reilly, J. et al. (eds.), Youth Labor in Transition, Oxford: Oxford University Press. 
Whitaker Square,

Sir John Rogerson's Quay,

Dublin 2

Telephone +35318632000

Email admin@esri.ie

Web www.esri.ie

Twitter @ESRIDublin

ISBN 978-0-7070-0532-4 